\title{
Imaging in clinical lung cancer staging
}

Citation for published version (APA):

Hochstenbag, M. (2003). Imaging in clinical lung cancer staging. [Doctoral Thesis, Maastricht University]. Datawyse / Universitaire Pers Maastricht. https://doi.org/10.26481/dis.20031205mh

Document status and date:

Published: 01/01/2003

DOI:

10.26481/dis.20031205mh

Document Version:

Publisher's PDF, also known as Version of record

\section{Please check the document version of this publication:}

- A submitted manuscript is the version of the article upon submission and before peer-review. There can be important differences between the submitted version and the official published version of record.

People interested in the research are advised to contact the author for the final version of the publication, or visit the DOI to the publisher's website.

- The final author version and the galley proof are versions of the publication after peer review.

- The final published version features the final layout of the paper including the volume, issue and page numbers.

Link to publication

\footnotetext{
General rights rights.

- You may freely distribute the URL identifying the publication in the public portal. please follow below link for the End User Agreement:

www.umlib.nl/taverne-license

Take down policy

If you believe that this document breaches copyright please contact us at:

repository@maastrichtuniversity.nl

providing details and we will investigate your claim.
}

Copyright and moral rights for the publications made accessible in the public portal are retained by the authors and/or other copyright owners and it is a condition of accessing publications that users recognise and abide by the legal requirements associated with these

- Users may download and print one copy of any publication from the public portal for the purpose of private study or research.

- You may not further distribute the material or use it for any profit-making activity or commercial gain

If the publication is distributed under the terms of Article $25 \mathrm{fa}$ of the Dutch Copyright Act, indicated by the "Taverne" license above, 


\section{Imaging in clinical lung cancer staging}





\title{
Imaging in clinical lung cancer staging
}

\author{
PROEFSCHRIFT
}

ter verkriiging van de graad van doctor aan de Universiteit Maastricht,

op gezag van Prof. dr. A.C. Nieuwenhuijzen Kruseman, Rector Magnificus, volgens het besluit van het College van Decanen, in het openbaar te verdedigen op vrijdag 5 december 2003 orn 10.00 uur

door

Monique Hochstenbag

Geboren op 12 februari 1964 te Maastricht

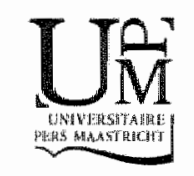


Promotor

Prof. dr. E.F.M. Wouters

\section{Co-promotor}

Dr. G.P.M. ven Velde

Dr. A. Twijnstra

Beoordelingscommissie

Prof. dr. B. Mochtar (voorzitter)

Prof. dr. H.J.M. Groen (Riiksuniversiteit Groningen)

Prof. dr. G. Heidendal

Prof. dr. C.C.E. Koning (Universiteit van Amsterdam)

Prof. dr. J. Manni 
Aan mijn ouders,

Voor Marcel, Iron en Ruben 



\section{Contents}

Chapter 1 General introduction.

Chapter 2 Asymptomatic brain metastases in small cell lung cancer: magnetic resonance imaging is useful at initial diagnosis. 33

Chapter 3 MRI of the brain of neurologic asymptomatic patients with large cell or adenocarcinoma of the lung. Does it influence prognosis and trearment?

Chapter 4 Detection of bone marrow metastases in small cell lung cancer.

Comparison of magnetic resonance imaging with standard methods.

Chapter 5 Imaging of lung lesions suspected of cancer and staging of non small cell lung cancer by Positron Emission Tomography.

Chapter 6 Mediastinal staging of lung cancer with 2-(fluorine-18)fluoro-2-deoxy-D-glucose positron emission tomography and a dualt-head coincidence gamma camera.

Chapter $7 \quad$ "'In-octreotide scintigraphy in staging of small cell lung cancer.

Chapter $8 \quad$ General discussion and surnmary.

Chapter 9 Samenvatting.

Dankwoord. 

General introduction 
10 Chapter 1 


\section{Incidence of lung cancer}

Lung cancer is one of the most prevalent and lethal cancers in the world. According to the World Health Organisation, 3 people die every minule worldwide from lung cancer. Lung cancer is the leading cause of cancer deaths in the United States among both men and women. More Americans die from lung cancer than from breast, prostate, colon and ovarian cancers combined. In 2001, an estimated 157.400 deaths in the United States were caused by lung cancer, accounting for $28 \%$ of all cancer deaths.' Lung cancer is also the most common cause of cancer death among men in Europe, although there is a trend of decreasing lung cancer rates. The mortality associated with lung cancer among women in Europe continues to increase, which is undoubtedly caused by the continued increase of cigarette smoking in women. ${ }^{2}$ Cigarette smoking is by far the most important risk factor in the development of lung cancer. Even lifetime non-smoking women and men run a risk of developing lung cancer following exposure to environmental tobacco smoke (also called passive smoking). ${ }^{3,4}$ The mortality patterns throughout Europe are very heterogeneous and largely reflect different smoking habits in the various demographic groups. 5.6

The lung cancer mortality data do not differ much between the countries in north-western Europe, although lung cancer mortality for Dutch adults and especially females is still among the highest. ${ }^{2}$

The Netherlands Cancer Registry reported that lung cancer was the second most common type of cancer in The Netherlands in 1998 after breast cancer. In men the prevalence of prostate cancer exceeded that of lung cancer. In women breast cancer and colorectal cancer were followed by lung cancer. After a marked increase in the 1960s and 1970s the incidence of lung cancer in males has decreased considerably since the beginning of $1980 \mathrm{~s}$. In females, however, lung cancer incidence continued to increase in 1989-1998.

\section{Histological classification of lung carcinoma}

Accurate histological identification in lung cancer is essential for determining the prognosis and treatment options. In general lung cancer is divided in non small cell lung cancer (NSCLC) and small cell lung cancer (SCLC). SCLC represents $15-25 \%$ of all lung cancers. Currently, about $40 \%$ of NSCLC cases are adenocarcinoma subtypes and about $40 \%$ squamous tumours. The remaining 
$20 \%$ of NSCLC cases have large cell anaplastic and other less common subtypes.

The World Health Organisation's histological classification of carcinoma of the lung was updated in $1999^{8}$ and is listed in lable 1.1 .

Table 1 Histological classification of carcinoma of the lung.

$$
\text { linosive malignent lung cancer }
$$

1. Squamous cell carcinomi

2. Small cell carcinoma

3 Adenocarcinoma

\section{Large cell carcinama}

\section{Adenosquamous carcinomo}

6. Cordmome with pleomophic sarcomatoid or screanatous: elements

\section{Carcinoid tumours}

8. Careiname of salivary gland type

9. Undassified carcinoma
Vorients

Papillory

Clear cell

Smallcell

Basolaid

Combined small cell

Acinar

Papillary

Bronchioloalveolar cell carcinomo

Nonmucinous

Mucinous

Mxed muchous non mucinous or intermediate cell type

Solid adenocarcinoma with mucin formation

Adenocarcinono with mixed subtypes:

Wellodifferentiated foetal adenocarcinoma

Mucinous (colloid) adenocarcinoma

Muchous cystadenocorchoma

Signet-ring adenacarcinomo

Clear cell adenocarcinomo

Large cell neuroendocrine carcinoma (LCNEC)

Combined LCNEC

Basaloid careinoma

Lymphoepithelioma like carcmomo

Clear coll carcinoma

Large cell carcinoma whth rhabdoid phenotype

Careinoma wh spindle or giant cells

Pleomorphic carcinoma

spindle cell carcinoma

Giant cell carcinoma

Carinosarcoma

Pulnonary blastoma

Others

Typical carcinoid

Atypical carcinoid

Mucoepidemoid carchoma

Adenoid cystic carcinoma

Others 


\subsection{Therapeutic and prognostic consequences}

NSCLC subtypes are preferably treated with surgical intervention, depending on disease stage and localisation. This is in contrast to SCLC, since this fumour type grows rapidly with early and widespread dissemination of the tumour, a stage which has very often been reached at the time of initial diagnosis. Patients exhibiting this stage of the disease are mainly treated by chemotherapy.

Despite major advances in understanding and treating lung cancer, the overall 5 -year survival rate is $14 \%$ for NSCLC and $3 \%$ for SCLC. ${ }^{9,10}$ Even in patients with NSCLC who have undergone curative surgery, the 5 year survival remains less than 50\%." The main reasons for the poor prognosis even after curative operation are the development of metastases when the primary tumours are still small coupled with the lack of effective methods for early diagnosis and of systemic therapies with sufficient efficacy to deal with micrometastatic disease.

\section{Staging}

Accurate staging is important in the evaluation of patients with lung cancer in order to determine therapy and prognosis. It is now generally recognised that besides histological classification of lung cancer the prognosis mainly depends on the anatomical extent of the tumour (TNM classification) and the possible therapeutic options.

\subsection{TNM staging of lung cancer}

The American Joint Committee introduced the first staging system for lung cancer in 1974 (AJCC). ${ }^{12}$ This system was derived from the elinical characteristics and survival data of 2155 patients who were retrospectively analysed for their dinical, anatomical, radialogical and pathological characteristics. The recommendation for classifying malignant fumours according to the TNM description was proposed as follows: the primary tumour characteristics ( $T$ descriptor) and its complications, regional lymph node metastasis ( $N$ descriptor) and for distant metastases ( $M$ descriptor). The subsets of $T, N$ and $M$ were grouped into a small number of stages (stage I through $\mid V$ ) that clearly correspond with survival. In 1986 the Union Internationale Contre le Cancer (UICC) introduced its own staging system for lung cancer, which was more or less the same as the staging system of the AJCC. In 1997 both groups together presented the third revision of the International Staging System for lung cancer (table 1.2). ${ }^{13}$

These revisions were based on an update of the clinical, surgical, pathological and follow-up information of 5319 patients. They provide greater specificity for 
identifying patients with the same treatment options and similar prognosis. The TNM system has gained wide acceptance and is now applied to all lung tumours although the SCLC is an exception (see later).

Table 1.2 Revised (1997) TNM classification for lung cancer.

\begin{tabular}{|c|c|}
\hline Srage & TNM Subset \\
\hline Occull & TXNoMO \\
\hline 0 & TISNOMO \\
\hline $1 \mathrm{~A}$ & $\mathrm{TINOMO}$ \\
\hline $1 B$ & T2NOMO \\
\hline $11 \mathrm{~A}$ & TINTMO \\
\hline IIB & $\mathrm{T} 2 \mathrm{~N} 1 \mathrm{MO}$ \\
\hline & T3MOMO \\
\hline IIA & T3M MMO, TIN2MO, T2N2MO, T3N2MO \\
\hline $11 \mathrm{~B}$ & TA (any stage NI MO, (any stage T) N3MO \\
\hline N & (any staige T) (any stage NI) MT \\
\hline
\end{tabular}

In the TNM classification a distinction is made between a pre-thoracotomy (clinical) staging (CTNM) and a pathological evaluation of the surgical (postsurgical) specimen (pTNM). The clinical staging is necessary to optimise selection of surgical or other therapy and depends upon the thoroughness of the diagnostic investigation and the staging facilities available. After extensive clinical staging in some patients a pathological staging can complete the staging process and thus lead to a better understanding of therapy options and survival prospects. Exhaustive clinical staging is not always possible or clinically necessary so in these cases the pathological stage is the same as the clinical stage.

\subsubsection{T descriptor}

Characterisation of the primary tumour $(T)$ is part of the staging process. In $T_{x}$ the primary fumour cannot be assessed. In T0 there is no evidence of primary tumour. Tis means carcinoma in situ. A TI tumour is defined as a lesion $3 \mathrm{~cm}$ or smaller in greatest dimension, surrounded by lung or visceral pleura, without bronchoscopic evidence of invasion more proximal than the lobar bronchus. A T2 tumour is larger than $3 \mathrm{~cm}$ in greatest dimension or involves either the visceral pleura or main bronchus. The proximal extent of such a main bronchus lesion should be more than $2 \mathrm{~cm}$ away from the carina. In addition a fumour associated with atelectasis or obstructive pneumonitis eventually extending to the hilar region but not affecting the entire lung, is classified as T2. A T3 tumour directly invades any of the following: diaphragm, mediastinal pleura, and 
parietal pericardium or chest wall. A tumour in the main bronchus $<2 \mathrm{~cm}$ distal to the carina but without involvement of the carina, or associated atelectasis or obstructive pneumonitis of the entire lung is also classified as T3. A T4 tumour shows invasion of any of the following: mediastinum, heart, great vessels, trachea, aesophagus, carina or vertebral body. A tumour with malignant pleural or pericard effusion or with a satellite tumour nodule(s) in the primary-tumour lobe is classified as T4.

\subsubsection{N descriptor}

Regional lymph modes are classified as $N x$ if regional lymph nodes cannot be assessed, as NO if there are no regional lymph node metastases, as N1 if there are metastases to the ipsilateral peribronchial and/or ipsilateral hilar lymph nodes and intrapulmonary nodes involved by direct extension of the primary tumour, as $\mathrm{N}_{2}$ if there are metastases to ipsilateral mediastinal and/or subcarinal lymph node (s), as N3 if there are metastases to contralateral mediastinal, contralateral hilar, ipsilateral or contralateral scalene, or supraclavicular lymph node (s).

Accurate evaluation of the $N$ status is performed according to the classification of regional lymph node stations standardised in $1997 .^{14}$

Anatomic landmarks for 14 mediastinal, hilar and intrapulmonary lymph nodes stations are designated. Stations $1-9$ are within the mediastinal pleural reflection and are classified as N2. Stations 10-14 are located distal to the mediastinal pleura and within the visceral pleura. They are classified as NT. Metastatic supraclavicular nodes do not receive a station designation. In case of intraoperative staging this elassification is used (figure 1,1$).^{15,16}$

\subsubsection{M descriptor}

Accurate evaluation of the $M$ status is mainly based on imaging methods. Mx means that the presence of distant metastasis have not been assessed. In case of no distant metastases, $M O$ is used and distant metastases are designated $M I$. Separate metastatic nodules in the ipsilateral non-primary tumour lobe of the lung also are classified $M 1$.

\section{Staging of small cell lung cancer}

The staging classification of SCLC in limited and extensive disease was first introduced by the Velerans Administration Lung Cancer Study Group (NALSG). " Limited disease (LD) was defined as fumour involvement of only 1 hemithorax 
including the mediastinum, ipsilateral hilar and supraclavicular lymph nodes. In all other cases patients were considered to have extensive disease (ED). Approximately $60 \%$ of patients present with metastatic disease, particularly to the liver, adrenal glands, bone, bone marrow and brain.

Although the TNM system ${ }^{13}$ assesses the extent and burden of disease more accurately than the VALSG system it was found to be of limited value in SCLC because there was an overlap in prognosis and therapy between TNM stages. Currently the TNM system is utilised in rare presentation of potentially resectable disease, which occurs in far less than $10 \%$ of SCLC cases. ${ }^{18}$

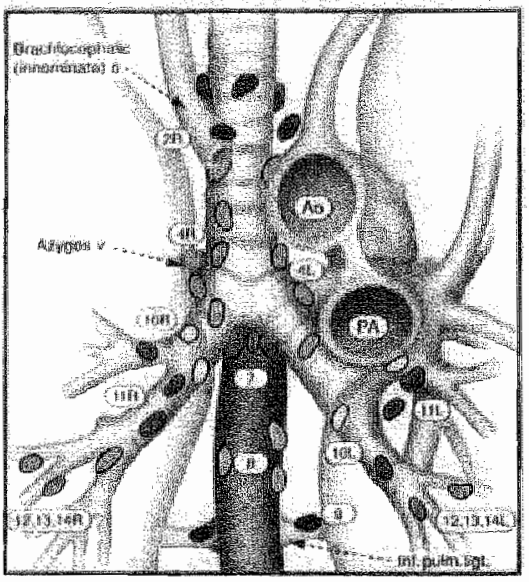

\section{Superior Mediastinal Nodes}

- Highost Mediastinal

2 Upper Paratrachical

(9) Pre-vascular and Retroth theal

(5) Lower Paratracheal (including Azygos Nodes)

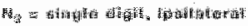

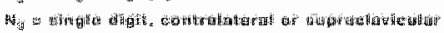

\section{Aortic Nodes}

- 5 Subaontic (A-P window)

- Para-aortic (ascending aorta or phrenic)

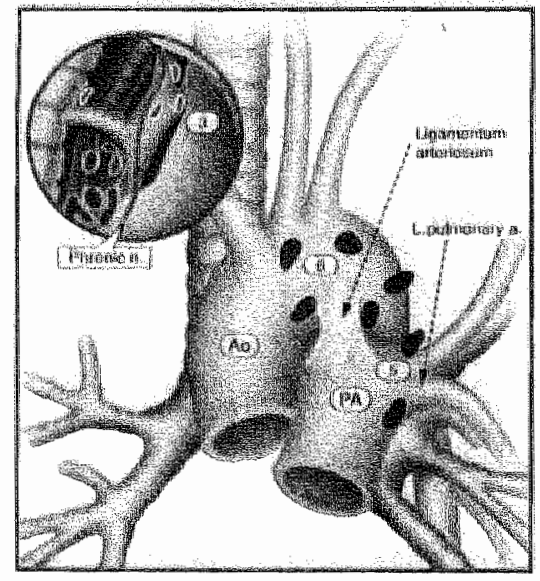

\section{Infertior Mediastinal Nodes}

-7 Subcarinal

(6) Parabsophageal (below carma)

- 9. Puimonary Ligament

\section{$\mathbb{N}_{\text {i }}$ Nodes:}

O 10 Hilar

- 11 interlobar

6. 12 Lobar

(3) Segmental

14 Subsegmental

Figure 1.1 Regional lymph node stations for lung cancer staging adapled from Naruke ${ }^{15}$ and the ATS/North American LCSG.6. 


\section{Imaging of lung carcinoma}

Imaging plays an important rale in all aspects of the staging process of lung cancer: determination of local fumour involvement (T), hilar and mediastinal lymph node involvement (N) and distant metastatic disease (M). Imaging is also important in screening studies for lung cancer.

\subsection{Chest radiography}

This imaging modality is available in every hospital, is cheap and the radiation dose is low however the diagnosis of early lung cancer on the chest radiograph can be very difficult. Small lesions can be missed through poor technical quality, poor viewing conditions and errors in perception and misinterpretation by the viewer. ${ }^{19,20}$ Quekel et al found a "failure to detect rate" of $19 \%$, which was much lower than previous studies. ${ }^{21-23}$

$\mathrm{T} 1$ and $\mathrm{T} 2$ lesions are readily identified on chest radiographs. Although the diagnostic sensitivity is high, plain chest radiograph is poor in detailing the tumour invasion of the chest wall or mediastinum, furthermore evaluation of the mediastinum for mediastinal nodes and evaluation of distant metastases are not possible. ${ }^{24}$

\subsection{Computed Tomography of the chest}

The advantage of computed tomography (CT) for lung cancer screening is its ability to demonstrate smaller tumours, presumably at an earlier stage, than those that can be detected with conventional chest radiography. The introduction of the low-dose spiral CT renewed interest in screening programs for the early detection of lung cancer. This techrique could possibly decrease lung cancer mortality but the extent of this effect is as yet unknown and whether lung cancer screening will be cost-effective is yet to be determined. ${ }^{25,26}$

CT of the thorax is the standard imaging modality in all patients with lung cancer and provides information about localisation and size of the primary tumour, chest wall invasion, mediastinall lymph nade metastases and distant metastases. ${ }^{24}$ The CT scan should include an area from above the apices of the lungs to below the adrenal glands.

\subsubsection{Evaluation of the primary tumour (T)}

Staging of $T 1$ and $T 2$ tumours is performed well with $C T$ although it is not possible to distinguish tumour from inflammation or fibrosis because of limited 
contrast resolution. The accuracy of CT to assessing the invasiveness of the tumour in the chest wall (T3) and mediastinum (T4) is not optimal. ${ }^{27,28}$ In case of contact between the tumour and mediastinal structures it is very difficult to distinguish between tumour adhesion to the mediastinum or invasion. ${ }^{29}$ The most reliable CT indicator for diagnosing chest wall invasion is bone destruction or a mass in the chest wall. These indicators, however, exhibit a poor sensitivily and specificity. ${ }^{27}, 30$

\subsubsection{Evaluation of lymph node metastases (N)}

Mediastinal lymph nodes are generally identified on axial CT images as nonenhancing, oval soft tissue densities surrounded by mediastinal fat. The mast common used critterion for malignant lymph nodes is a diameter $\geq 1 \mathrm{~cm}$. One pitfall in using o nodal size threshold to distinguish benign from malignant lymph nodes at CT is that small, normal-sized nodes $(<1 \mathrm{~cm})$ at CT can have microscopic tumour disease in up to $40 \%$ of cases and enlarged lymph nodes. are reactive nodes in $25 \%$ to $37 \% .^{31-35}$ Intravenous contrast administration adds little to the accuracy of staging. ${ }^{36,37}$ These problems lim the overall sensitivity of CT scanning for lymph node metastasis to a range of $55-75 \%$, whereas the overall specificity of CT scanning range from 65 to $86 \%$. The accuracy is between 60 and $80 \%$. Although the accuracy of CT evaluation of the mediastinum is moderate, this is still considered the golden imaging standard for imaging the mediastinum in a non-invasive way. ${ }^{31,33,46}$

\subsection{Magnetic resonance imaging of the chest}

The role of magnetic resonance imaging (MRI) in evaluating the size and extent of the primary tumour has not proven to be particularly useful except for a few situations. MRI is more accurate than CT in delineating mediastinal-, wascular-, chest wall-, diaphragm-and spine invasion. ${ }^{47,48}$ MRI is particularly useful in the evaluation of superior sulcus tumours as CT is limited by its axial format and streak artefacts from the shaulders. MRI can accurately assess the extent of local invasion, including brachial plexus and subclavian vessel involvement. 49.51

The role of MRI in the evaluation of the $N$ status is limiting. No significant advantages are demonstrated compared to CT in the evaluation of lymph nodes in the mediastinum. ${ }^{4,52}$

\subsection{Evaluation of distant metastases $(M)$}

Up to $40 \%$ of patients with newly diagnosed lung cancer have distant metastases at presentation. ${ }^{10,53,54}$ The most common metastases are brain, liver, adrenal glands, lungs, bone marraw and bone. The role of imaging in the detection of 
metastases of lung cancer is controversial. Several studies indicated that it is not cast-effective to search for distant metastases with imaging procedures unless the patient is symptomatic. ${ }^{55,50}$ The American Thoracic Society (ATS) and the European Respiratory Society (ERS) recommend that a search of metastatic disease should be restricted to patients with symptoms and signs suggesting metastases. $^{2.4}$

\subsubsection{Liver}

Approximately $12 \%$ of patients with NSCLC have silent liver metastases ${ }^{57}$, although isolated liver metastases are not common. ${ }^{54}$ For detection of liver metastases optimal contrast enhancement of the liver is needed to discriminate benign lesions, such as cysts and hemangiomas, from metastatic fumour. Standard contrast-enhanced CT requires extra scanning time and increased radiation dosage and is not recommended by ATS and ERS at initial staging ${ }^{24}$ however helical or spiral CT permits evaluation of both the thorax and the entire liver with a single bolus of contrast in a much reduced scan time.

\subsubsection{Adrenal glands}

Adrenal metastases are found in approximately $7 \%$ of patients with lung cancer at the time of presentation and are more common than adenomas. ${ }^{56}$ In a normal sized adrenal gland, metastases are found in up to $12 \%,{ }^{57,58}$ The majority of patients with adrenal metastases are asymptomatic and have no routine clinical indicators of adrenal gland disease. The inclusion of adrenal glands on routine chest $\mathrm{CT}$ requires a minimum of extra time, radiation dose and requires no administration of contrast. This imaging is therefore recommended by the ATS and ERS. Adrenal adenomas are less than $3 \mathrm{~cm}$, well circumscribed, homogeneous and show low attenuation due to fatty content on CT $\left(<-10\right.$ Hounsfield). ${ }^{56.59}$ In lesions not meeting these criteria further investigation with needle aspiration biopsy is necessary. MRI lespecially with new advances in chemical shift and dynamic gadolinium-enhanced techniques) may be helpful in differentiation of adrenal metastasis from adenoma. ${ }^{60}$

\subsubsection{Brain}

Brain metastases in NSCLC are generally associated with abnormal neurological examination. ${ }^{6 !}$. In a meta-analysis of patients with NSCLC, CT of the brain discovered asymptomatic brain metastases in anly $3 \%$ of patients ${ }^{55}$ and $11 \%$ false-positive results were seen with CT brain. ${ }^{62}$ Therefore the ATS/ERS guidelines recommend a cranial CT in patients with newly diagnosed NSCLC only if neurologic symptoms and signs (e.g. headaches, seizures) are present or in patients with non-specific findings that suggest widespread disease ${ }^{24}$ 
$20 \mid$ Chopter 1

In SCLC lung cancer patients, brain metastases are a mare common event than in NSCLC. At time of diagnosis SCLC 10\% of patients presented with BM. . $^{63}$ During the course of the disease the cumulative risk is around $50 \%$ at 2 years and rises to $80 \%$ at autopsy ${ }^{44.65}$ however in asymptomatic patients, the yield of $\mathrm{CT}$ is only $3 \%$ to $8 \% .60 .63$

\subsubsection{Bone and bone marrow}

In bones with haematopoietacally active marrow, approximately $40 \%$ of total blood flow to the bone is to the marrow. Therefore tumours that have a propensity to metastasise to bone often exhibit marrow involvement. It can be suggested that intramedullary metastases produce detectable lesions by replacement of marrow. This occurs before either intrinsic or reactive metabolic changes in cortical bone can be detected. The most frequent locations of bone metastases related to lung cancer are spine, pelvis, sternum, ribs and skull.

In NSCLC bone metastases are common and are often symptomatic. The ATS and ERS recommend a radionuclide bone scan only in the presence of bone pain, an elevated serum allkaline phosphatase and elevated calcium. ${ }^{24}$ The value of preoperative radionuclide bone scanning in NSCLC patients without symptoms or laboratory signs is marginal. In one study ${ }^{69}$ it was shown that all patients with NSCLC with skeletal metastases had suggestive findings but there was a high rate of false positive findings.

In SCLC patients bone marrow metastases are found in up to $30 \%$ with standard investigations like unilateral or bilateral bone marrow aspirates and biopsies. Bone marrow involvement is however seen in up to $50 \%$ in bone marrow aspirates immunostained with monoclonal antibodies ${ }^{71}$ and autopsy studies revealed bone marrow metastases up to $65 \% .^{72}$ Thus our conventional staging modalities of detection of skeletal metastases show a low sensitivity and may be invasive and painful.

\section{Invasive staging}

Although the imaging methods described here are at present the standard in many staging protocols and guidelines for the staging of lung cancer patients, there are several limitations as described above: the accuracy is not optimal and several imaging methods are necessary. Invasive tests with tissue sampling are often unavoidable and are time consuming and unpleasant for the patients. 


\subsection{Mediastinum}

Cervical mediastinoscopy is the most accurate way to stage superior mediastinal lymph nodes. It is a highly effective and safe procedure. ${ }^{32,73}$. The false-negative rate of mediastinoscopy is generally less than $10 \%$, and there should be no false positives. The lymph nodes most accessible to cervical mediastinoscopy are right and left upper paratracheal stations $(2 R, 2 L)$, station 3 , right and left paratracheal stations $(4 R, 4 L)$ and subcarinal nodes (7). Unapproachable by mediastinoscopy are par-oesophagal (8) nades, pulmonary ligament nodes (9) and in general hilar and all other intrapulmonary nodes. Also not accessible are the lymph nodes located in the cortapulmonary window (5) and supracartic nodes (6). The procedure of choice for these stations is an anterior mediastinotomy.

There is still no consensus for proceeding to a mediastinoscopy in patients without enlarged mediastinal nodes on CT scan. ${ }^{74}$ Some investigators advise direct tharacotomy in patients with normal mediastinal findings on $\mathrm{CT} .{ }^{75.77} \mathrm{On}$ the other hand De Leyn and others recommend that all patients with apparently operable NSCLC with conventional staging should undergo invasive staging by mediastinoscopy with sampling of lymph nodes as definitive diagnostic pathological staging procedure. ${ }^{32}$ Twenty percent of normal sized lymph nodes exhibited tumour cells. This had prognostic and therapeutic implications since pre-operative induction chemotherapy improves patient survival in case of a positive mediastinoscopy. ${ }^{78-81}$

\section{Functional imaging}

The limitations of conventional imaging in lung cancer are well recognised. These procedures have limitations in the determination of the biological properties of the detected nodules, lymph nodes and suspicious lesions found. Functional methods such as positron emission tomography (PET) using tracers of fumour metabolism or somatostatin scan using tracers binding to tumour receptors offer the possibility of more sensitive and specific imaging of tumours within one investigation.

\subsection{Positron emission tomography}

PET allows the imaging of structures by their ability to concentrate specific molecules that have been labelled with a positron-emitting isotope. Malignant cells have a high rate of glycolysis and an increased cellular uptake of glucose, due to an increased expression of glucose transport proteins. ${ }^{82.83}$ The most commonly used imaging agent for PET is deoxyglucose linked to 18-fluorine, a 
positron emitter (FDG). PET can be interpreted by standardised uptake value (SUV) or by wisual interpretation.

\subsubsection{Evaluation of the primary tumour (T) by FDG-PET}

FDG.PET is accurate in the differentiation between benign and malignant tissue. This can be very important in the diagnostic evaluation of lung cancer and especially in case of a solitary pulmonary nodule (SPN). A SPN is found in approximately 1 in 500 routine chest radiographs and more than $40 \%$ of SPNs are malignant. ${ }^{85}$ Reports have shown a high sensitivity $(82$ to $100 \%$ ) and specificity (75 to 100\%) of FDG-PET as diagnostic tool. ${ }^{85.90}$ There are however some limitations. Lesions smaller than $1 \mathrm{~cm}$ may not have the critical amount of metabolically active malignant cells required for PET scanning. ${ }^{91,92}$ Because of low metabolic tumour activity there is minimal or no FDG uptake in specific lesions such as bronchioloalveolar cell carcinoma and carcinoid tumours. ${ }^{93.95}$ False positive FDG uptake can be found in inflammatory conditions such as bacterial pneumonia ${ }^{\% 6}$, active sarcoidosis ${ }^{97}$, granulomatous disease or tuberculosis. This high uptake is due to the metabolic activity of macrophages and granulocytes.

\subsubsection{Evaluation of the mediastinum (N) by FDG-PET}

FDG.PET may allow detection of metastases to mediastinal lymph nodes. This has been examined in well designed studies with sensitivities and specificities of FDG-PET reported in the range of $76 \%-100 \%$ and $82 \%-100 \%$ respectively ${ }^{39}$ 41,44,98-103 however false positive results are possible. These are due to metabalically active inflammation. False negative results are less frequent and are due to low tumour deposit in the mediastinal nodes. Lymph nodes smaller than $0.7 \mathrm{~cm}$ may be a problem due to partial volume effect caused by limited scan resolution.

\subsubsection{Evaluation of distant metastases (M) by FDG.PET}

FDG.PET allows not only mediastinal staging but is also applicable in the detection of distant metastases in bone ${ }^{104,105}$, liver ${ }^{106}$, adrenal glands ${ }^{10 \%}$ and other organs. ${ }^{108}$ There are limitations in PET evaluation of brain metastases because of the high FGD uptake of normal brain fissue. ${ }^{109}$

\subsubsection{Complicating factors of FDG-PET}

An elevated serum glucose level results in a decreased uptake of FDG because of the competitive reaction with glucose. So patients with diabetes mellitus should be carefully interpreted or they should not undergo this procedure. 
Caution must be used in the interpretation of lesions near the mediastinum because PET scans lack anatomic detail. So it can be difficult to distinguish an N2 node from a N1 node or a central tumour process. Because of false positive mediastinal results and lack of anatomic detail mediastinoscopy is still advisable to prove N2-N3 disease in patients with a positive FDG-PET for mediastinal lymph nodes and central tumours.

\subsection{Hybrid positron emission tomography}

The limited availability, high costs and the need for a cyclotron to generate the radionuclide limits the utility of PET scans at the moment. Cheaper dual-headed gamma camera coincidence imaging, referred to as hybrid PET have been introduced. Hybrid PET is able to image FDG but without the expense of a PET scanner. It is an alternative to high-performance PET (so-called dedicated PET) for the staging of lung cancer however the first generation non-attenuation corrected hybrid PET showed a lower sensitivity than dedicated PET. ${ }^{10-112}$ The sensitivity for small lymph node metastases is limited by low contrast. It has been shown that attenuation carrection markedly improves image quality with better delineation of anatomical structures and it is therefore helpful in overcoming the limitations of dual-headed gamma camera. ${ }^{13}$

\subsection{Octreotide scan}

Certain tumour types (over-) express high affinity receptors for peptide hormones and may represent new molecular targets for cancer diagnosis. Somatostatin receptors have been found on the cell surface of neuroendocrine tumours, SCLC, medullary thyroid cancer, warious tumours of the nervous system and lymphoma. ${ }^{114,115}$ By now 5 human receptor subtypes have been characterised. ${ }^{116}$ These receptors may represent targets for tumour staging. Somatostatin analogs were the first class of receptor binding peptides to be developed. The radiolabeled analogue "IIn-octreotide is most used for imaging of somatostatin receptors and can be used as a single tool to stage patients with SCLC. ${ }^{11 \%-122}$ 


\section{Aims of the study}

1. MRI of the brain is more sensitive than CT for the early detection of brain metastases and detects significantly smaller brain metastases. It is the madality of choice to exclude brain metastases. ${ }^{123,124} \mathrm{MRI}$ of the brain has not been investigated extensively in the staging of SCLC and NSCLC. As brain melastases are of prognostic as well as therapeutic importance it is postulated that MRI of the brain is a valuable tool in the staging process of lung cancer to detect asymptomatic brain metastases. This assumption was investigated for both types of lung cancer (chapter 2 and 3 ).

2. MRI allows for non-invasive evaluation of large volumes of bone marrow and is a sensitive imaging modality for detecting SCLC bone marrow involvement. ${ }^{125}$ MRI has the advantage of being painless, being able to scan a wide part of the body and both intramedullary and cortical fumour invasion is detectable. The frequency of bone marrow metastases in SCLC with MRI and the influence on the stage of disease compared to bone scintigraphy and bone marrow biopsy and aspiration was investigated (chapter 4).

3. A so-called totai body FDG-PET allows for simultaneous intra- and extrathoracic staging. Several studies presented already promising data of whole body FDG-PET in comparison to conventional staging and up to $25 \%$ of patients considered to have resectable NSCLC were shown by FDG.PET to have unsuspected advanced disease. ${ }^{40,42,108,126.130}$ The accuracy and clinical impact of whole body FDG-PET on the detection of malignant disease in pulmonary lesions and on the staging of NSCLC compared to our conventional modalities was investigated (chapter 5).

4. If was postulated that the hybrid PET is equivalent to dedicated PET so a comparison was made of the diagnostic performance of hybrid PET, dedicated PET and CT for mediastinal staging of NSCLC in order to assess the impact of non-uniform attenuation correction (chapter 6).

5. 111 In-octreotide has been shown to bind to somatostatin receptors of SCLC fumours. "In-octreotide scan could therefore be an excellent staging modality in SCLC. The efficacy of "'In-octreotide in the detection and localisation of the primary tumour and metastases of SCLC and its contribution in the staging of this disease comparing with conventional staging procedures was studied (chapter 7). 


\section{References}

1. Jemal A, Chu KC, Tarone RE. Recent trends in lung cancer mortality in the United States. J Natt Cancer Inst 2001;93(4):277-83.

2. Brennan $\mathbf{P}$, Bray I. Recent trends and future directions for lung cancer martality in Europe. Br $J$ Concer $2002 ; 87(1): 43-8$.

3. Hackshaw AK, Law MR, Wald NJ. The accumulated evidence on lung cancer and environmental tobacco smoke. BM 1997;315(7114):980-8.

4. Zhong L, Goldberg MS, Parent ME, Hanley JA. Exposure to environmental tobacco smoke and the risk of lung cancer: a meta-analysis. Lung Cancer 2000;27(1):3-18.

5. Kubik AK, Parkin DM, Plesko 1, Zatonski W, Kramarowa $E$, Mohner M, Friedl HP, Juhasz L, Tzvetansky CG, Reissigova J. Patterns of cigarette sales and lung cancer mortality in some central and eastern Eurapean countries, 1960-1989. Cancer 1995;75(10):2452-60.

6. Bayle P. Cancer, cigarette smoking and premature death in Europe: a rewiew induding the Recommendations of European Cancer Experts Consensus Meeting, Helsinki, October 1996. Lung Cancer 1997;17(1): 1-60.

7. Visser O, C.J., Dijck JAAM wan, Siesling S. Incidence of cancer in the Netherlands 1998. 2002, Vereniging van Integrale Kankercentra: Utrecht.

8. Travis TV, C.T., Carrin B, Shimosato Y, Brambilla E., Histologic and graphical Hext stides for the histologic typing of lung and pleural tumars. In: World Health Organisation Pathology Panel: World Health Organisation. International Histalogy Classification of Tumors. 3rd ad. Springer verlag, Berlin. 1999:5.

9. Boring CC, Squires TS, Tong T. Cancer statistics, 1992. CA Cancer J Clin 1992;42(1):19-38.

10. Landis SH, Murray $T$, Bolden S, Wingo PA. Cancer statistics, 1999. CA Cancer I Clin $1999 ; 49(1): 8-31,1$.

11. Pearson FG. Lung cancer. The past twenty-five years. Chest 1986;89(4 S):200S-5S.

12. Mountain CF, Carr DT, Anderson WA. A systenz for the clinical staging of lung cancer. Am J Roentgenol Radium Ther Nucl Med 1974;120(1):130-8.

13. Mountain CF. Revisions in the International System for Staging Lung Cancer. Chest $1997 ; 111(6): 1710-7$.

4. Mountain CF, Dresler CM. Regional lymph node classification for lung cancer staging. Chest $1997 ; 11116): 1718-23$.

15. Naruke T, Suemasu K, Isthikawa S. Lymph node mapping and curability at various levels of metastasis in resected lung cancer. I Thorac Cardiovasc Surg 1978;76(6):832-9.

16. American Thoracic Sociely. Medical section of the American Lung Assaciation. Clinical staging of primary lung cancer. Am Rev Respir Dis 1 983;127[5]:659-64.

17. Abrams J, Doyle LA, Aisner J. Staging, prognastic factors, and special considarations in small cell lung cancer. Semin Oncol 1988;15(3):261-77

18. Inove $M$, Miyoshi S, Yasumitsu T, Mori T, luchi $K$, Maeda H, Matsuda H. Surgical results for small cell lung cancer based on the new TNM staging systerm. Thoracic Surgery Sudly Group of Osaka Universily, Osaka, Japian. Ann Thorac Surg 2000; 7015):1615.9.

19. Quekel LG, Kessels AG, Goei R, van Engelshoven JM. Detection of lung cancer on the chest radiogroph: a study an observer performance. Eur J Radiol 2001;39(2):111-6.

20. Austin $\mathrm{JH}_{x}$ Romney $B M$, Goldsmith LS. Missed bronchogenic carcinoma: radiographic findings in 27 patients with a potentially resectable lesion evident in retrospect. Radiology $1992 ; 182[1): 115-22$.

21. Quekel LG, Kessels $A G$, Goei $R$, wan Engelshoven JM. Miss rate of lung cancer on the chest radiograph in clinical practice. Chest 1999:115(3):720-4.

22. Heelan RT, Flehinger Bl, Melomed MR, Zaman MB, Perchick WB, Caravelli Jf, Martini N. Nonsmall-cell lung cancer: results of the New York sereening program. Radiology $1984 ; 151(2): 289-93$.

23. Muhm JR, Miller WE, Foniana RS, Sanderson DR, Uhlerhopp MA. Lung cancer detected during o screening program using four-month chest radiographs. Radiology $1983_{;} 148(3): 609$. 15 . 
24. Pretreatment evoluation of nom-small-cell lung cancer. The American Thoracic Society and The Europeen Respiratory Society. Am I Respir Crit Care Med 1997; 15611]:320-32.

25. Paik EF Jr, Black WC, Goadman PC. CT screening for lung concer: not ready for routme prectice. Radiology 2001,221(3):587-91; discussion 598-9.

26. van Klaveren R, Habbema JDF, Pedersen JH, de Koning HU, Oudkerk M, Hoogsteden HC. Lung cancer screening by low-dose spiral computed fomography. Eur Respir I $2001 ; 18(5): 857-66$.

27. Pearlberg. JL, Sondler MA, Beute GH, Lewis. JW Jr, Madrazo BL. Limitations of CT in evaluation of neoplasms involving chest wall. J Comput Assist Tomogr 1987;11(2):290-3.

28. Herman SJ, Winton TL, Weisbrod GL, Towers MA, Mentzer SJ. Mediastinal invasion by bronchogenic carcinoma: CT signs. Radiology 1994;190(3):841-6.

29. Glazer HS, Kaiser LR, Anderson DJ, Molina PL, Emami B, Roper CL, Sagel SS, Indeterminate mediastinal invasion in bronchogenic carcinoma: CT evaluotion. Radiology $1989 ; 173(1)$ : 37.42 .

30. Pennes DR, Glazer GM, Wimbish KJ, Gross BH, Long RW, Orringer MB. Ches: wall invasion by lung cancer: limitations of CT evaluation. AJR Am J Roentgenol 1985; 144(3):507.11.

31. McLoud TC, Eourgouin PM, Greenberg RW, Kosiuk JP, Templeton PA, Shepard IA, Moore EH, Wain JC, Mathisen DJ, Grillo HC. Bronchogenic carcinoma: analysis of staging in the mediastinum with CT by correlative lymph node mapping and sampling. Radiolagy $1992 ; 182(2): 319-23$

32. De Leyn P, Vansteenkiste J, Cuypers P, Deneffe G, Van Raemdanck D, Coosemans W, Verschakelen J, Lerut T. Role of cervical mediastinoscopy in staging of non-small cell lung cancer without enlarged mediastinal lymph nodes on CT scan. Eur J Cardiothorac Surg $1997 ; 12(5): 706-12$.

33. Gdeedo A, Schil P, Corthouts B, Van Mieghem F, Van Meerbeeck J, Van Marck E. Prospective evaluation of computed tomography and mediastinoscopy in mediastinal lymph nade staging. Eur Respir J 1997;10(7):1547.51.

34. Arita T, Matsumoto T, Kuramitsu T, Kawamura M. Matsunaga N, Sugi K, Esata KK Is it possible to differentiate malignant mediastinal nodes from benign nodes by size? Reewaluation by $\mathrm{CT}$, transesophageal echocardiography, and nadai specimen. Chest $1996 ; 110 / 4): 1004-8$.

35. Drent M, Gelissen JP, Ascoop CA, Wagenaar SS, van den Basch JM. Mediastinall lymph node enlargement as a result of mitral valve stenosis. Chest 1992;102(4):1269-71.

36. Polz EF Jr, Erasmus JJ, MCAdams HP, Connolly JE, Marom EM, Goodman PC, Leder RA, Keogan MT, Hendon JE. Lung cancer staging and management: comparison of contrastw enhanced and nonentranced lyelical CT of the thorax. Radiology $1999 ; 212(1): 56-60$.

37. Cascade PN, Gross BH, Kazerooni EA, Quint LE, Francis $1 R$, Strawderman M, Korobkin M Variability in the delection of enlarged mediastinal lymph nodes in slaging lung cancer: a comparison of contrast-enhanced and unenhanced CT. A.JR Am I Roentgenol $1998: 170(4): 927-31$.

38. Dalles RE Stark RMA, Raman S. Computed tomography to stege lung cancer. Approaching a controversy using meta analysis. Am Rev Respir Dis 1990,14115 Pi 1)11096-101.

39. Vonsteenkishe JF, Stroobonts $S G$, De Leyn PR, Dupont PJ. Bogaent J; Maes A, Deneffe G., Nackaerts KL, Verschakelen JA, Lerut TE, Mortelmans LA, Demedts MG. Lymph node staging in non-small-cell lung cancer with FDG.PET scan: a prospective study on 690 lymph node stations from 68 patients. J Clin Oncol 1998; 16 (6):2142-9.

40. Pieterman RM, van Putten JW, Meuzelaar J $\downarrow$, Mooyoart EL, Vaalburg W, Koeter GH, Fidler V, Pruin J, Groen HJ. Preopenative staging of non-small-cell lung cancer with positron-emission tomography. N Engl J Med 2000;343(4):254-61

41. Kernstine KH, Stanford W, Mullem BF, Rossi NP, Thompsan BH, Bushnell DL, MeLoughlin KA, Kerm JA. PET, CT, and MRI with Combidex for mediastinal staging in non-smail cell lung corcinoma. Ann Thorac Surg 1999;68(3):1022-8. 
Ceneral introduction

42. Valk PE, Pounds TR, Hopkins DM, Haseman MK, Hofer GA, Greiss HB, Myers RW, Lutrin CL. Staging non-small cell lung cancer by whole-body positron enission tomographic imaging. Ann Thorac Surg 1995;60(6):1573-81; discussion 1581-2.

43. Gupia NC, Graeber GM, Bishop HA. Comparative efficacy of positron emission tomography with fluorodeoxyglucose in evaluation of small $(<1 \mathrm{~cm})$, intermediate $(1$ to $3 \mathrm{~cm})$, and large $(>3 \mathrm{~cm})$ lymph node lesions. Chest 2000; $117(3): 773-8$.

44. Weng $E$, Tran $L$, Rege $S$, Safa $A$, Sadeghi $A$, Juillard $G$, Mark $R$, Santiago $S$, Brown $C$, Mandelkern $M$. Accuracy and dinical impact of mediastinal lymph node staging with FDG.PET imaging in potentially resectable lung cancer. Am J Clin Oncol 2000;23(1):47 -52.

45. Berlangieri SU, Scott AM, Knight SR, Fitt GI, Hennessy OF, Tochon-Danguy H.l, Clarke CP, Mckay WJ. F-18 fluorodeaxyglucose positron emission tomagraphy in the non-inwasive staging of non-small cell lung cancer. Eur J Cardiothorac Surg 1999;16(S1):S25-530.

46. Dillemans $B$, Deneffe $G$, Verschakelen J, Decramer $M$. Value of computed tomography and mediastinoscopy in preoperative evaluation of mediastinal nodes in non-small cell liung cancer. A study of 569 patients. Eur J Cardiothorac Surg 1994:8(1):37.42.

47. Webb WR, Gatsonis C, Zerhouni EA, Heelan RT, Glazer GM, Francis IR, McNeil BJ. CT and MR imaging in staging non-small cell bronchogenic carcinoma: report of the Radiologic Diagnostic Oncology Group. Radiology 1991;178(3):705-13.

48. Padowani B, Mouroux J, Seksik L, Chanalet S, Sedat J, Rotomondo C, Richelme H, Series II. Chest wall invasion by bronchogenic carcinoma: evaluation with MR imaging. Radiology 1993;187(1):33-8.

49. Fortier M, Mayo JR, Swensen SJ, Munk PL, Vellet DA, Muller NL. MR imoging of chest wall lesions. Radiographies 1994; 14:3):597.606.

50. Kuhlman JE, Bouchardy L, Fishman EK, Zerhouni EA. CT and MR imaging evaluation of chesit wall disorders. Radiographics 1994;14:(3):571-95.

51. Heelan RT, Demas BE, Carawelli JF, Martini N, Bains MS, McCormack PM, Burt M, Panicek DM. Mizner A. Superior sulcus tumors: CT and MR imaging. Radiology 1989;170[3 Pt 1): $637-41$.

52. Patterson GA, Ginsberg RI, Poon PY, Cooper JD, Goldberg M, Jones D, Pearson FG, Todd TR, Waters P, Bull S. A prospective evaluation of magnetic resonance imaging, computed tomography, and mediastinoscopy in the preoperative assessment of mediastinal node status in bronchogenic carcinoma. J Thorac Cardiovase Surg 1987;94(5):679-84.

53. Sider $L$, Horejs $D$. Frequency of extrathoracic metastases from bronchogenic cancinoma in patients with normal-sized hilar and mediastinal lymph nodes on CT. A.R Am J Roentgenof $1988 ; 151(5): 893-5$.

54. Quint LE, Tummala 5 , Brisson L, Francis IR, Krupnick AS, Kazerooni EA, lannetroni MD, Whyte $\mathrm{RI}$ Orringer $\mathrm{MB}$. Distribution of distant metastases from newly diagnosed non-small call lung cancer. Ann Thorac Surg 1996;62(1):246*50.

55. Hillers TK, Sauve MD, Guyatt GH. Analysis of published studies on the detection of extrathoracic metastases in patients presumed to have openablie non-small cell lung cancer. Thorax 1994;49(1):14-9.

56. Silvestri GA, Littenberg B, Colice GL. The clinical evaluation for detecting metastatic lung cancer. A meta-analysis. Am J Respir Crit Care Med 1995;152(1):225-30.

57. Salvatierra A, Baamonde $C_{*}$ Llamas JM, Cruz F, Lopez-Pujol J. Extrathoracic sitaging of bronchogenic carcinoma. Chest 1990;97(5):1052-8.

58. Pagani Jj. Nonm-small celli lung carcinoma adrenal metastases. Computed tomography and percutaneous needle biopsy in their diagnosis. Cancer 1984;53(5):1058-60.

59. Oliwer TW Jr, Bernardino ME, Miller JI, Mansour K, Greene D, Davis WA. Isolated adrenal masses in nonsmall-cell bronchogenic carcinoma. Radiology 1984;153(1):217.8.

60. Schwariz LH, Ginsberg MS, Burt ME, Brown KT, Getrajdman GI, Panicek DM. MRI as an alternative to CT-guided biopsy of adrenal masses in patients with lung cancer. Ann Thorac Surg 1998;65(1): 193-7. 
61. Hooper RG, Tentholder MF, Undenwood GH, Beechler CR, Sprathing L. Computed tomographic scanning of the brain in intilal stoging of bronchogenic corcinoma. Chest; $1984,85(6): 774-6$.

62. Patchell RA, Tibbs PA, Walsh JW, Dempsey RJ, Maruyamo Y, Kryscio Rl, Markesbery WR, Macdonald JS, Young $B$. A randomized trial of surgery in the treatment of single metastases to the brain. N Engl J Med 1990;322(8):494-500.

63. wan Oosterhou: AG, van de Pol M, ten Velde GP. Twilnstro A. Neurologic disorders in 203 consecutive patients with small cell lung cancer. Results of a longitudinal study. Cancer $1996,77(8): 143444]$.

64. Nugent JL. Bunn PA Jr, Matthews M, Ihde DC, Cohen MH, Gazdar A, Minna JD. CNS metastases in small cell bronchogenic carcinoma: increasing frequency ond changing pattern with lengthening survival. Cancer 1979;44:15):1885-93.

65. Komaki $R$, Cax JD. Whitson W. Risk of brain metostasis from small cell carcinoma of the lung related to length of surwiwal and prophylactic irradiation. Cancer Treat Rep 1981;65/9. 101:811-4.

66. Crane JM, Nelson MJ, thde DC, Makuch RW, Glatstein E, Zabell A, Johnston-Early A, Bates $H R$, Suini $N$, Cohen $M H$, al. A comparison of compuled tomography and radionuclide scanning for detection of brain metastases in small cell lung cancer. I Clin Oncol $1984 ; 2(9): 1017.24$.

67. Hardy J, Smith 1, Cherryman $G$, Vincent $M$, Judson 1, Perren $T$, Williams $M$. The value of computed tomagraphic (CT) scan surveillance in the detection and management of brain metastases in patients with small cell lung cancer. Br J Cancer 1990;62(4):684-6.

68. Johnson DH. Windham WW, Allen JH, Greco FA. Limited value of CT brain scans in the siaging of smail cell lung cancer. AJR Am J Roentgenal 1983;140(1);37 40.

69. Michel F, Soler M, Imhof E, Perruchoud AP. Iritial staging of non-small cell lung cancer: value of routine radioisotope bone scanning. Thorax 1991;46171:469-73.

70. Tritz DB, Doll DC. Ringenberg QS, Anderson $S_{y}$ Madsen R, Perry MC, Yairbro JW. Bone marrow involvement in small cell lung cancer. Clinical significance and correlation with routine laboratory variables. Cancer 1989:6344!:763-6.

71. Stahel RA, Mabry M, Skarin AT, Speak J, Bernal SD. Detection of bone marrow metastasis in small-cell hung cancer by monoclonal antibody. $J$ Clin Oncol 1985;3(4):455-61.

72. Kristiansen PE, Osterlind $K$. Hansen M. Detection of bone marrow relapse in patients with small cell carcinoma of the lung. Cancar 1986,58(1),2538-4\%.

73. Hammoud ZT, Anderson RC, Meyers BF, Guthre TJ, Roper CL, Cooper ID, Patterson GA. The current role of mediastinoscapy in the evaluation of thoracic disease. IThorac Cardiovase Surg 1999:118(5):894-9.

74. Britsh Thoracic Saciety; Society of Cardiohoracic Surgeons of Great Britain and Ireland Working Party. BTS guidelines: guidelines on the selection of patients with lung cancer for sutgery. Thorax 2001;56(2):89-108.

75. Investigation for mediastinal disease in patients with apparently operable lung cancer. Canadian Lung Oncology Group. Amn Thorde Sung 1995;60 (5):1382-9.

76. Daly BD, Mueller JD, Foling W, Diehl JT, Bankaff MS, Karp DO, Rand WM. N2 lung cancer; outcome in potients with false-negative computed tomographic scans of the chest. I Thorac Cardiovasc 5urg 1993; 105(5):904-10; discussion 910-1.

77. Cybulsky III, Lamza LA, Ryan MB, Putnam JB Jr. MCMurtrey MM, Rohh JA. Prognostic significance of computed tomography in resected N2 lung cancer. Ann Thorac Surg $1992,54(3) ; 533-7$.

78. Andre F, Grunemwald D, Pignon JP, Dujon A, Pujol JL, Brichon PY, Brouchet $L$, Quoix E, Westeel $V$, Le Chevalier T. Survival of patients with resected N2 mon-small-cell lung cancer: evidence for a subclassification and implications. J Clin Oncol 2000;18(16):2981-9.

79. Roth JA, Fossella F, Komaki R, Ryan MB, Putnam JB Ji, Lee IS, Dhingra $H$, De Caro L, Chasen $M$, MeGavran $M$, al. A randomized trial comparing perioperative chemotherapy and surgery with surgery alone in resectable stage IIIA nom-small-cell lung cancer. J Natl Cancer inst 1994,869):673.80. 
80. Rosell R, Gomez-Codina J, Camps C, Maestre J, Podille J, Canto A, Mate Ji, Li S, Roig J.

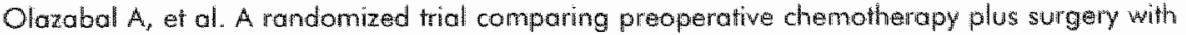
surgery alone in patients with non-snall-cell lung cancer. N Engl J Med 1994;330/3):153-8.

81. Vansteenkiste J, De Leyn P, Deneffe G, Menten J, Lerut T, Demedis M. Present status of induction treatment in stage $\|$ llA-N2 non-small cell lung cancer: a rewiow. The Leuven Lung Cancer Group. Eur I Cardiothorac Surg 1998:13(1):1-12.

82. Nolop KB, Rhodes CG, Brudin LH, Beaney RP, Krausz $T$, Jones $T$, Hughes IM. Glucose utilization in viwo by human pulmonary neoplasms. Cancer $1987 ; 60,11): 2682-9$.

83. Yamamoto $T$, Seino $Y$, Fukumoto $H$, Koh $G$, Yano $H$, Inagaki $N$, Yamada $Y$, lnoue $K$, Manabe T. Imura $H$. Over-expression of facilitative glucose transponter genes in human cancer. Biochem Biophys Res Commun 1990;170(1):223-30.

84. Lowe $V_{J}$, Hoifman JM, Dellong DM, Patz EF, Coleman RE. Semiquantitative and visual analysis of FDG.PET images in pulmonary abnormalities. J Nucl Med 1994,35111]:177/16.

85. Mack. MJ, Hazelrigg SR, Landreneau RJ. Acuff TE. Thoracascopy for the diagnosis of the indeterminate solitary pulmonary nodule. Ann Thorac Surg 1993;56141:825.30; discussion 830.2 .

86. Yansteenkiste JF, Stroobants SG. The role of positron emission tomography with 18F-fluoro.2. deoxy-D-glucose in respiratiory ancology. Eur Respir J 2001;17(4):802-20.

87. Lowe WJ, Fletcher JW, Gobar L, Lawson M, Kirchner P, Valk P, Karis J, Hubner K, Delbeke D, Heiberg EV, Paz EF, Coleman RE. Prospective investigation of positron emission tomagraphy in lung nodules. J Clin Oncol 1998; 16131:1075-84.

88. Patz. EF Jr, Lowe VJ, Hoffman JM, Paine SS, Burrowes P, Coleman RE, Goodman PC. Focal pulmonary abnormalities: evaluation with F-18 fluorodeoxyglucase PET scanning. Radiolagy $1993 ; 188(2): 487-90$.

89. Gupta N, Gill H, Grceber G, Bishop H, Hurst J, Stephens T. Dynamic positron emission tomagraphy with $F-18$ fluoradeaxyglucose imaging in differentiation of benigin from mallignant lung/mediastinal lesions. Chest 1998;114(4): 1105-11.

90. Dewan NA, Gupta NC. Redepenining LS, Phalen JJ, Frick MP. Diagnostic efficacy of PET FDG imaging in solitary pulmonary nodules. Palential rale in evaluation and management. Chest $1993 ; 104(4): 997-1002$

91. Duhaylongsod FG, Lawe VJ, Patz EF JF, Vaughn AL, Coleman RE, Wolfe WG. Delection of primary and recurrent lung cancer by means of $F-118$ flyorodeoxyglucose positron emission tomography (FDG PET). J Thorac Cardiovasc Surg 1995;1 10(1):130-9; discussion 139-40.

92. Scatt WJ. Schwabe JL, Gupto NC, Dewan NA, Reeb SD, Sugimolo JT. Positron emission tomography of lung tumors and mediastinall lymph nodes using 118 Flluorodeoxyglucose. The Members of the PET-Lung Tumor Study Group. Ann Thorac Surg 1994:58(3):698-703.

93. Kim BT, Kim Y, Lee KS, Yoon SB, Cheon EM, Kwon OJ, Rhee CH, Han J, Shin MH. Localized form of bronchioloalveolar aarcinoma: FDG PET findings. A.R. Am I Roenigenol $1998 ; 170(4): 935-9$

94. Higashi $K$, Ueda $Y$, Seki $H$, Yuasa $K$, Oguchi $M$, Noguchi $T$, Taniguchi $M$, Tonami $H$, Okimura T. Yamamato I. Fluarine-18-FDG PET imaging is negative in bronchialodivedar lung carcinoma. J Niud Med 1998;39(6):1016-20

95. Erasmus JJ, MeAdams HP, Patz EF Jr, Coleman RE, Ahuia V, Goodman PC. Evaluation of primary pulmanary carcinoid tumars using FDG PET. AJR Arn J Roentgenol 1998;170)(5): $1369-73$.

96. Kapucu 10, Meltzer CC, Townsend DW, Keenan RJ, Luketich JD. Fluorine-18. fluarodeoxyglucose uplake in prneumonia. J Nud Med $1998,39(7): 1267.9$.

97. Brudin LH, Walind SO, Rhodes CG, Pantin CF, Sweatman M, Jones T, Hughes M Fluorine-18 deoxylucose uptake in sarcoidosis meosured with positron emission tomagraphy. Eur INucl Med 1994;21(4):297-305.

98. Bury T, Paulus P, Dowlati A, Corhay JL, Weber T, Ghaye B, Schoffers $I$, Limet R, Albert A, Rigo $P$. Radermecker M. Staging of the mediastinum: value of positron emistion tomography imaging in non-small cell lung cancer. Eur Respir \1996;9(12):2560-4. 
99. Steinent HC, Hauser M, Allemann F, Engel H, Berthold T, von Schulthess GK, Weder W. Nonsmall cell lung cancer: nodal staging with $F D G$ PET versus $C T$ with correlative lymph node mapping and sampling. Radiology 1997;202(2):44]-6.

100. Pofz EF Jr, Lowe $V$, Goodman ${ }^{\circ} C$, Herndon J. Thoracic nadal staging with PET imaging with 1BFDG in palients with bronchagenic carcinoma. Chest 1995;108(6):1617-21.

101. Chin R Jr, Ward R, Keyes JW. Choplin RH, Reed JC, Wallenhaupt S, Hudspeth AS, Haponik EF. Mediastinal staging of non-small-cell lung cancer with positron emission tomography. Am I Respir Crit Care Med 1995:152!6 P| 1):2090-6.

102. Scott WJ, Gobar LS, Terry JD, Dewan NA, Sunderland JJ. Mediastinal lymph node staging of non-small-cell lung cencer: a prospective comparison of computed fomography and positron emission lomography. I Thorac Cardiowase Surg 1996;111/31:642-8.

103. Sasaki M. Ichiya $Y$, Kunwabara $Y$, Akashi $Y$, Yoshida T, Fukumura T, Murayama $S$, Ishida $T$, Sugio K. Mosuda $K$. The usefulness of FDG positron emission tomography for the detection of mediastinal hmph node metastases in patients with non-small cell lung cancer: a comparative study with $X$-ray computed tomagraphy. Eur I Nucl Med 1996;23(7):741-7.

104. Bury T, Burreto A, Daenen F, Barthelemy N, Ghaye B, Rigo P. Fivorine-18 deoxyglucose positron emission tomagraphy for the detection of bone melastases in patients with non-small cell lung concer. Eur J Nucl Med 1998:25(9):1244-7.

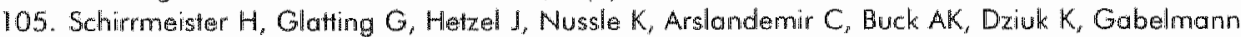
A, Reske SN, Hetzel M. Prospective evaluation of the clinical value of planar bone scons, SPECT, and (18]F-labeled NoF PET in newly diagnosed long cancer. I Nucl Med $2001 ; 42(12): 1800-4$.

106. Hustinx. R, Paulus $P$, Jacquet $N$, Jerusalem $G$, Bury $T$, Riga $P$. Clinical evaluation of whole-body $18 \mathrm{~F}$-fluoroderoxyglucosie positron emission tomography in the detection of liver metastases. Arin Oncol 1998:9(4):397-401.

107. Erasmus JJ, Patz EF Jr, MaAdams HP, Murray JG, Herndon J, Coleman RE, Goodman PC. Evaluation of adrenal masses in patients with bronchogenic carcinoma using $18 \mathrm{~F}$. Fhuorodeaxyglucose positron emission tomography. A.JR Am J Roentgenol 1997; 168(5): 1357.60 .

108. Woder W, Schmid RA, Bruchhaus H, Hillinger S, von Schulthess GK, Sieinert HC. Detection of extrathoracic metastases by positron emission tomography in lung cancer. Ann Thorac Surg $1998 ; 66(3): 886-92$; discussion 892-3.

109. Griffeth LK, Rich KM, Dehdashti F, Simpson JR, Fusselman MU, McGuire AH, Siegel BA. Brain metastases from non-central nerwous system tumors: exwaluation with PET. Radialogy $1993 ; 186(1): 37-44$.

110. Stokkel MP. Bakker PF, Heine R, Schlosser NJ, Lammers JW, Van Rijk PP. Siaging of lymph nodes with FDG dual-hecded PET in patients with non-small-cell lung cancer. Nucl Med Commun 1999:20(11):1001-7.

111. Weber WA, Newerwe J, Sklarek J, Ziegler SI, Bartenstein P, King B, Treumann T, Enterrottacher $M_{4}$ Krap $M$, Houssinger KE, Lichte $H$, Praver HW. Thetter $O$, Schwaiger $M$. Imaging of lung cancer with ftuorine-18 fluarodeoxyglucose: comparison of a dual-head gamma camera in coincidence mode with a full-ring positton emission tomography system. Eur J Nucl Med $1999 ; 26(4) ; 388-95$.

112. Tatsumi $M$, Yulani $K$, Watanabe $Y$, Miyoshi $\$$, Tomiyama $N$, Johkah $T$, Kusuoka H, Nakamura H. Nishimura T. Feasibility of fluorodeoxyglucose dual-head gamma camera coincidence imaging in the evaluation of lung cancer: comparison with FDG PET. I Nucl Med $1999: 40141: 506-73$.

113. Zimny $M$, Kaiser HJ, Cremerius U, Reinartz P, Schreckenberger $M$, Sabri O, Buell U. Dual-head gamma camera 2-fluorine-18-fluoro-2-deoxy-D-glucose pasitron emission tomography in oncolagical patients: effects af non-uniform atenuation correction on lesion detection. Eur $J$ Wud Med 1999;26(8):818-23. 
114. Reubi JC, Schaer JC, Markwalder R, Waser B, Horisberger U, Laissue J. Distribution of somatostatin receptors in normal and neoplastic human tissues: recent advances and potential relevance. Yale $\mathrm{J}$ Biol Med 1997;70(5-6):471-9.

115. Reubi JC, Waser B, Sheppard M, Macaulay V. Somatostatin receptors are present in small-cell but not in non-small-cell primary lung carcinomas: relationship to EGF-receptors. Int I Cancer $1990 ; 45(2): 269-74$.

116. Yamada $Y$, Kagimoto $S$, Kubota $A$, Yasuda K, Masuda K, Someya $Y$, Ihara $Y$, Li $Q$, Imura $H$, Seino $S_{\text {s }}$ et al. Cloning, functional expression and pharmacological characterization of a fourth (hSSTR4) and a fith (hSSTR5) human somatastatin receptor subtype. Biachem Biophys Res Commun 1993;195(2):844:52.

117. Reubi JC, Lamberts SJ, Krenning EP. Receptor imaging of human diseases using radiolabeled peptides. J Recept Signal Transduct Res 1995;15(1-4):379-92

118. Krenning EP, Kwekkeboom DJ, Bakker WH, Breeman WA, Kooil PP, Oei HY, van Hagen $M_{a}$ Postema PT, de Jong M, Reubi $1 C$, et al. Somalostatin receptor scinfigraphy with $[111 / \mathrm{n}-\mathrm{DTPA}$. D-Phe 1]- and [1231-Tyr3]-octreotide: the Ratterdam experience with more than 1000 patients. Eur Nud Med 1993;20(8):716-31.

119. Kirsch $\mathrm{CM}$, von Pawel J, Grau I, Tatsch K. Indium-111 pentetreotide in the diagnostic work-up of patients with bronchogenic carcinoma. Eur J Nucl Med 1994;21(12):1318-25.

120. O'Byrne KJ, Ennis JT, Freyne PJ, Clancy L, Prichard JS, Carney DN. Scintigraphic imaging of small-cell lung cancer with [11 $1 \mathrm{In}$ ]pentetreotide, a radiolabelled somatastatin analogue. Br J Cancer 1994:6914):762-6.

121. Maini CL, Tolani A, Venturo I, Pigorini F, Sciuto R, Semprebene A, Boni S, Giunta S, Lopez M. Somalostatin receptor imaging in small cell lung cancer using $1111 / n$-DTPA-octreotide: a preliminary study. Nucl Med Commun 1993;14(11):962-8.

122. Berenger N, Moretti JL, Boaziz C, Vigneron N, Morere JF, Breou JL. Somatostatin receplor imaging in small cell lung cancer. Eur J Cancer 1996;32A(B):1429-31.

123. Yokoi $K$, Kamiya N, Matsuguma H, Machilida S, Hirose T, Mori K, Tominaga K. Detection of brain metastasis in patentially aperable non-small cell lung cancer: a comparison of $\mathrm{CT}$ and MRI. Chest 1999;115131:714-9.

124. Earnest $F$ 4th, Ryu JH, Miller GM, Luetmer PH, Forstrom LA, Burnett OL, Rowland CM, Swensen SJ, Midthun DE. Suspected non-small cell lung cancer: incidence of occult brain and skeletal metastases and effectiveness of imaging for detection pilot study. Radiology $1999 ; 21111$ ): 137.45 .

125. Trillet $V$, Revel D. Combaret $V$, Fawrot $M$, Laire R, Tabib A, Pages J, Jacquemat P, Bomartin A, Mornex JF, el all. Bone marrow metastases in small cell lung cancer: detection with magnetic resonance imaging and monotonal antibodies. Br J Cancer 1989;6011:83-8.

126. Bury T, Dowlati A, Poulus: P, Corhay IL, Hustinx R, Ghaye B, Radermecker M, Rigo P. Whalebody 18FDG positron emission tomagraphy in the staging of non-small cell lung cancar. Eur Respir J 1997;10(11):2529-34.

127. Marom EM, McAdams HP, Erosmus JJ, Goodman PC, Culhane DK, Coleman RE, Herndon JE. Patz EF III. Staging non-small cell lung cancer with whole-body PET. Radiology $1999 ; 212(3): 803-9$.

128. Lewis P, Griffin S, Marsden P. Gee T, Nunan T, Malsey M, Dussek J. Whole-body 18F. fluorodeoxyglucose positron emission lomagraphy in preaperative evaluation of lung cancer. Lancet $1994 ; 34418932$ 1:1265-6.

129. Vansteenkiste JF, Stroobants SG, Do Leyn PR, Dupont PJ Verschakelen JA, Nackaerts KL. Mortelmans LA. Mediastinal lymph node staging with FDG.PET scan in patienis with potentially operable non-small cell lung cancer: a prospective analysis of 50 cases. Leuven Lung Cancer Group. Chest 1997;112(6): 1480-6.

130. Kalff V, Hicks RJ, Macmanus MP, Binns DS, McKenzie AF, Ware RE, Hogg A, Ball DL. Clinical impact of $(18) \mathrm{F}$ fluorodeoxyglucose positron emission lomography in patients with non-smallcell lung cancer: a prospective study. J Clin Oncol 2001;19(1):111-8. 
Asymptomatic brain metastases in small cell lung cancer: magnetic resonance imaging is useful at initial diagnosis 


\section{Abstract}

\section{Purpose}

In this study we evaluated the usefulness of magnetic resonance imaging (MRI) in the detection of asymptomatic brain metastases (BM) at the initial diagnosis in patients with small cell lung cancer (SCLC) and studied the follow-up of these patients.

\section{Patients and methods}

One hundred and twenty-five patients with SCLC were investigated with MRI.

\section{Resulits}

In 112 patients with normal neurological findings, MRl of the brain demonstrated BM in 17 patients $(15 \%)$. Six of these 17 patients were therefore upgraded to extensive disease (ED). Two of these 17 patients died during chemotherapy because of progressive disease and 3 patients became neurologic symptomalic with progressive disease on MRI of the brain. After completion of chemotherapy a repeated MRI of the brain in the remaining 12 patients showed 1 complete remission, 4 partial remission and 7 progressive disease of the $B M$.

\section{Conclusion}

This study showed that at presentation an unexpectedly high percentage of SCLC patients had asymptomatic BMI on MRI. We propose that MRI of the brain should be included in the staging of SCLC patients for staging, prognosis and therapy. 


\section{Introduction}

Small cell lung cancer (SCLC) is a very aggressive disease that accounts for approximately $20 \%$ of all lung cancers.' Patients with SCLC are classified as having either limited disease (LD) or extensive disease (ED). $L D$ is defined as a fumoral process involving only 1 hemithorax and its regional lymph nodes including the mediastinal and ipsilateral supraclavicular lymph nodes. All other sites of metastases are considered ED.

SCLC has a poor prognosis because it tends to metastasise very rapidly. At the time of diagnosis about $60 \%$ of the patients have detectable metastatic disease. ${ }^{2}$ Clinically manifest brain metastases (BM) are diagnosed more frequently in SCLC than in other types of lung cancer and are detected in approximately $10 \%$ of patients at initial staging. ${ }^{3}$ During the course of the disease the occurrence of $\mathrm{BM}$ is even higher with a cumulative risk around $50 \%$ at 2 years. ${ }^{4.6} \mathrm{BM}$ are an important cause of morbidity and mortality. However recently it has been suggested that patients with $\mathrm{BM}$ as the only site of extrathoracic disease at initial staging have a survival comparable with LD patients when brain radiotherapy (RT) has been started together with combination chemotherapy. ${ }^{7-9}$ Therefore it could be important to exclude $B M$ at initial staging, whether the $B M$ are asymptomatic or not. Routinely performed computed tomography (CT) or magnetic resonance imaging (MRI) in neurological asymptomatic patients for detection of $B M$ is generally not performed as part of the initial staging procedure. It is onlly performed in patients with neurological complaints or neurological signs. It is known however, that BM can be present even in neurological asymptomatic patients but the incidence and impact is not clear. ${ }^{10,11}$ In these patients it is very important to investigate whether BM are present because they could potentially benefit from 'prophylactic' cranial irradiation ( $\mathrm{PCl}$ ).

In this study we have investigated the value of MRI of the brain for detecting asymptomatic BM at initial staging and whether the presence of asymptomatic $B M$ detected by MRI could change the stage of the disease of the patients involved.

\section{Patients and methods}

From 1-3-1990 to 1-6-1998, 125 consecutive patients with histologically or cytologically proven SCLC were prospectively followed during our study. Follow- 
up was until death or till April 2000. At the end of follow-up only I patient was still alive. The patients ranged in age from 32 to 84 years (median 66 years). Nearly all patients were staged for LD or ED according to accepted methodology which included clinical examination with special emphasis on neuralogical symptoms and signs by the neurologist (AT). The staging also consisted of complete blood count and biochemical tesis, CT of the thorax with extension to the upper abdomen, comprising liver and adrenals, MRI of thoracic spine and pelvis. Initially bone scintigraphy and unilateral bone marrow biopsy and aspiration were performed as well but these were abandoned as it was considered that MRI of thoracic spine and pelvis was more sensitive in the staging procedure. ${ }^{12}$ Additionally, MRI of the brain was performed.

\section{Magnetic resonance imaging}

MRI of the brain was performed within 1 month after the pathological confirmation of SCLC, with a 0.5 Tesla system (Gyroscan T5, Philips Medical Systems International, Best, The Netherlands). First a set of transverse spin-echo proton density $T 2$ weighted images was obtained. In the first 42 examinations a conventional spin-echo sequence (TR/TE 3000-3500/30-120 msec, FOV 230 $\mathrm{mm}, 5 \mathrm{~mm}$ slices $205 \times 256$ matrix, NSA1) was used. All later examinations featured a fast spin-echo sequence (TR/TE 4500-6500/30-130 msec, FOV 230 $\mathrm{mm}, 241 \times 256$ matrix, NSA4, echo train length 16). T1-weighted spin-echo images were obtained (TR/TE $600 / 18 \mathrm{msec}$, FOV $230 \mathrm{~mm}, 10 \mathrm{~mm}$ slices $205 \times 256$ matrix, NSA4) before and after IV injection of the MR contrast medium gadolinium DTPA in a dose of $0.1 \mathrm{mmol} / \mathrm{kg}$. The MR findings were blindly reviewed by a neuroradiologist (JTW) with extensive experience in cerebral MRI and a neurologist (AT). The scans were interpreted in the following manner:

(I) Normal or abnormal due to a non-malignant pathologic process and (II) abnormal, compatible with metastasis.

All patients were initially treated with combination chemotherapy, consisting of cyclophosphamide $1000 \mathrm{mg} / \mathrm{m}^{2}$, and doxorubicin $45 \mathrm{mg} / \mathrm{m}^{2}$ on day 1 and etoposide $100 \mathrm{mg} / \mathrm{m}^{2}$ on days 1,3 and 5 , every 3 weeks, for a maximum of 5 cycles. LD patients received local thoracic radiotherapy after completion of chemotherapy or after the third course of chemotherapy. LD patients who were upgraded to ED with MRI of the brain did not receive thoracic RT. Patients with asymptomatic BM did not receive cerebral RT because intracranial metastases seem to respond to chemotherapy ${ }^{13-15}$ and it is not clear whether adjuvant brain RT has additional value in these patients. "

Restaging (by the pulmonologist and neurologist) was performed after 5 cycles of chemotherapy and MRI of the brain was part of the procedure in nearly all 
patients. Complete remission was defined as a total resolution of all detectable lesions. A partial remission was defined as a reduction of $50 \%$ or more of the product of the 2 largest diameters. A reduction of less than $50 \%$ or progression of less than $25 \%$ was classified as stable disease. An increase of more than $25 \%$ was classified as progressive disease.

Survival curves were generated by the Kaplan-Meier method and were compared using the log-rank test. P-values of $\leq 0.05$ were considered statistically significant.

\section{Results}

Thirteen of the 125 patients had symptomatic BM demonstrated with MRI and were treated with chemotherapy. Nine of these patients were also treated with RT of the brain. Because of symptoms and signs we considered it not to be ethical to wait for the possible effect of chemotherapy on the brain.

One-hundred and twelve of the 125 patients had a negative dinical neurological examination. The value of MRI of the brain at initial staging in these asymptomatic patients was assessed. The outcome is shown schematically in figure 2.1. In 17 (15\%) of these 112 patients MRI showed BM. In 6 of these 17 patients the only site of metastatic disease was the brain.

Before MRI of the brain was performed 49 patients were staged as LD and 60 as ED. Three patients could not be completely staged because they were too ill to undergo all the investigations. According to the staging (without MRI of the brain) of the 17 neurological asymptomatic patients 6 had been staged as LD and 11 of the 17 as ED. So the addition of MRI of the brain upgraded 6 patients to ED $(12 \%)$.

The 17 neurological asymptomatic patients in whom BM were detected with MRI were followed until the end of the study or until death (figure 2.2). None of these patients were initially treated with RT to the brain, as they were asymptomatic. The effect of systemic chemotherapy was awaited. Two patients died during chemotherapy because of progression of systemic disease outside the brain. Both patients had ED with brain, liver and bone metastases. Three patients became neurological symptomatic during chemotherapy with progressive disease on MRI. In the remaining 12 patients routine follow-up MRI of the brain was performed after 5 cycles of chemotherapy. One patient achieved complete remission and 4 patients achieved partial remission of the brain lesions. Seven patients showed progressive disease of the BM and became symptomatic within a few weeks after restaging. During follow-up 4 other patients became symptomatic between 2 and 13 months after the end of chemotherapy and 
progression of BM was demonstrated with MRI. They were all treated with palliative cranial RT. One patient died 6 months after the end of chemotherapy because of a myocardial infarction, without neurological symptoms.

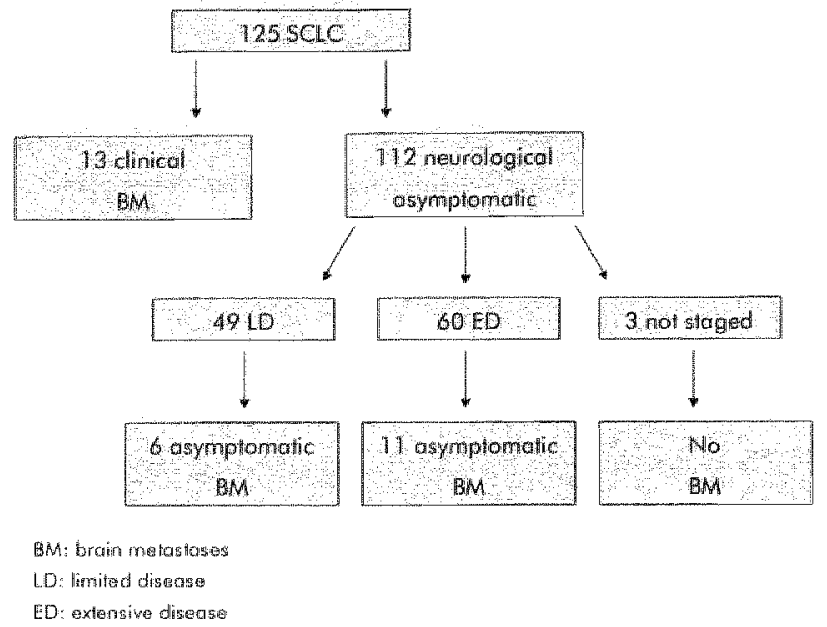

Figure 2.1 Staging SCLC with MRI of the brain.

The systemic response was measured by CT-thorax, performed after 5 cycles of chemotherapy. On indication a repeated MRI of thoracic spine and pelvis or bone scintigraphy were also performed. Table 2.1 shows the systemic response compared to the response in the brain. In nearly all patients treated with chemotherapy alone the systemic response was better than the response in the brain.

The survival of patients with and without $B M$ at initial staging is shown in figure 2.3. Patients with only $B M$ had a median survival of 9.5 months $195 \% \mathrm{Cl}$ : 2.87:16.13). There was no significant difference in survival between symptomatic or asymptomatic $B M$ and no significant difference $(p=0.2)$ compared to patients with LD (12 months $(95 \% \mathrm{Cl}: 10.65: 13.35))$. 


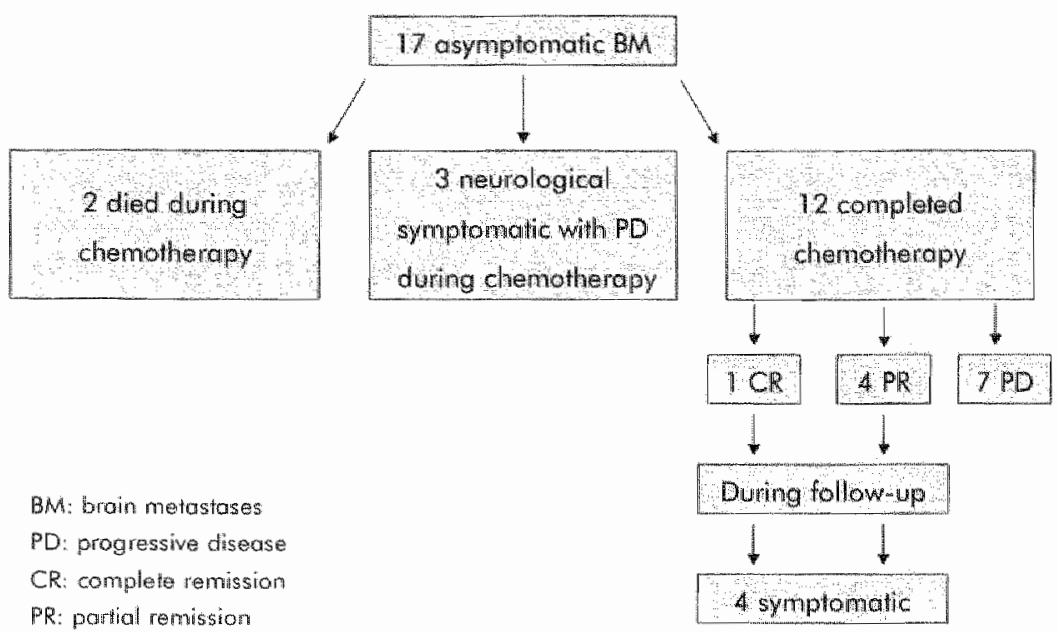

Figure 2.2 Follow-up of BM of 17 asymptomatic patients.

Ninety-five patients were without metastatic disease of the brain at initial staging (figure 2.4). Thirty-eight (40\%) of these patients developed BM during follow-up. Three of these 38 patients developed symptomatic BM during chemotherapy and 2 patients showed asymptomatic $B M$ by MRI during restaging after chemotherapy. In 33 patients $B M$ occurred during the follow-up period. The median survival of these 38 patients was 13 months $195 \% \mathrm{Cl}: 9.60: 16.401$. However time to death after defection of BM was 2.5 months $195 \% \mathrm{Cl}$ : 1.40:3.51). The systemic response had no significant influence on the survival after detection of these BM.

Of the 57 patients left withoul BM at initial staging or during follow-up, 22 died during chemotherapy because of progressive systemic disease. Of the other 35 patients there was no dinical evidence of $B M$ until death. The median survival of these 35 was 11 months ( $95 \% \mathrm{Cl}: 8.85: 13.15)$.

Table 2.1 The systemic and train response of chemotherapy in 15 asymptomatic patients with brain metastases.

Brain response

$\mathrm{CP}$

PR

$\mathrm{SD}$

$\mathrm{PD}$

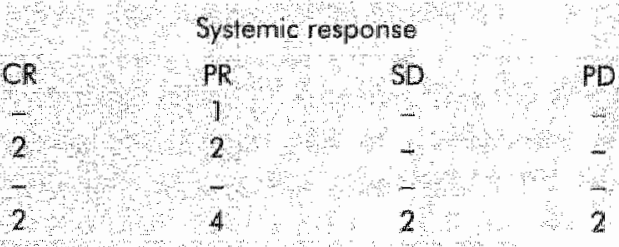

CR complete renission, PR: partial remission, SD stable disease; PD: progressive disense
$\mathrm{PD}$

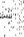

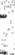

2 
$40 \mid$ Chopter 2

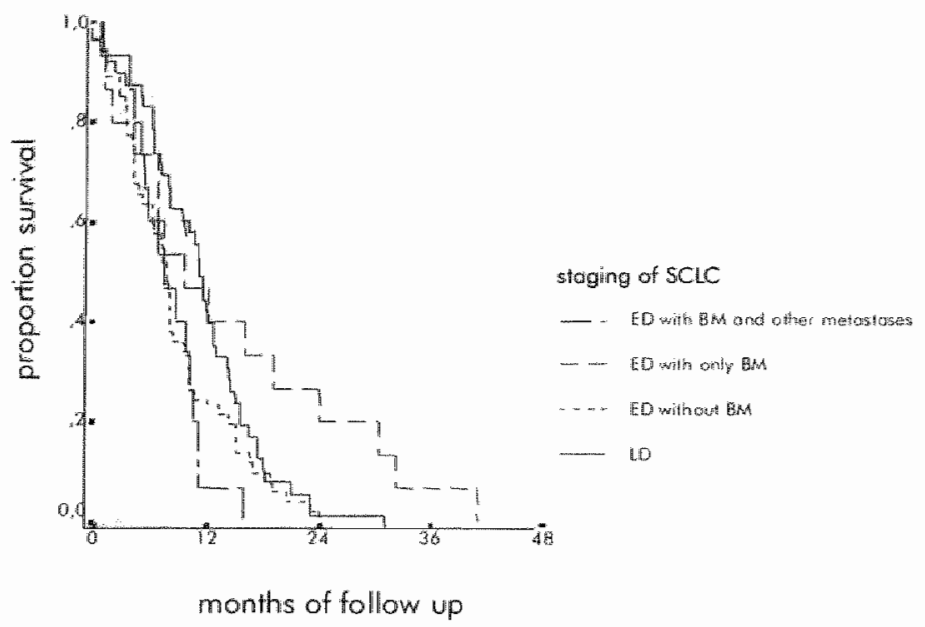

Figure 2.3 The survival of patients with and without BM at initial staging.

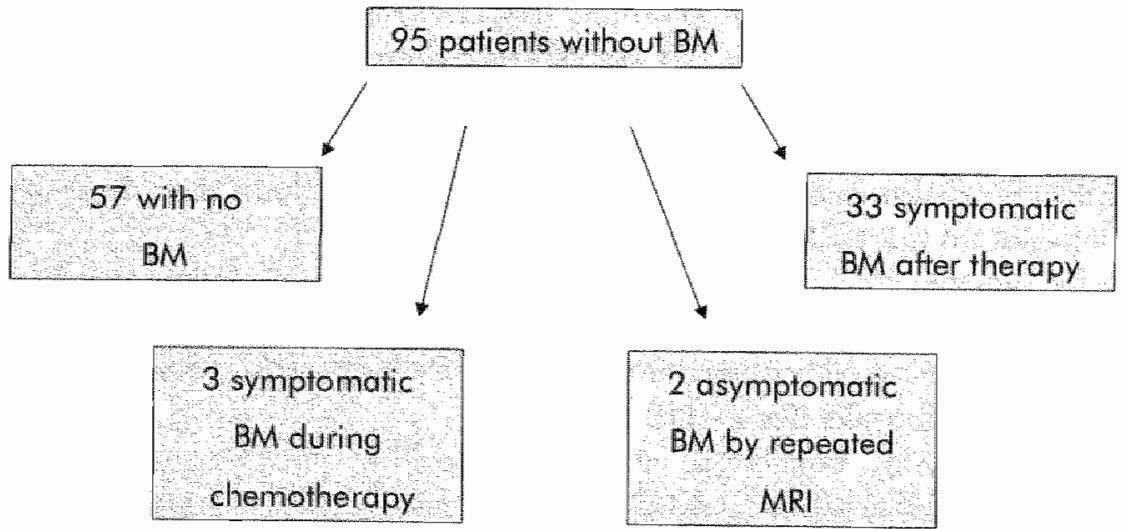

Figure 2.4 Follow-up of 95 patients with no BM at initial slaging. 


\section{Discussion}

Staging of patients with SCLC is necessary because of the therapeutic implications and because of the information it provides about the prognosis. Most patients with BM have neuralogical symptoms and signs. A CT of the brain is routinely performed in symptomatic patients. Habets et al. ${ }^{16}$ however have shown that $C T$ of the brain is not a sensitive method to detect asymptomatic BM. In our study we performed contrast-enhanced MRI of the brain in every consecutive patient with SCLC. In contrast to literature which shows a prevalence of $\mathrm{BM}$ al presentation of $10 \%{ }^{1 \%, 17}$, we found a prevalence of $24 \%$. The difference can be explained by the fact that the prevalence of $10 \%$ is based on clinical signs and confirmation with $\mathrm{CT}$ and/or MRl of the brain in symptomatic patients. We investigated besides the symptomatic patients also all patients without neurological signs or symptoms with, at present, the most sensitive method to detect $B M$, namely MRI. ${ }^{10,18}$ With MRI of the brain included in the initial staging we found indications of $B M$ in 17 out of $112(15 \%)$ asymptomatic SCLC patients, 6 out of 49 LD patients ( $12 \%$ ) could be upgraded to ED.

MRI of the brain is not only important for the staging but it has also implications for therapy, prognosis and prophylaxis of symptoms. In fact 6 patients would have been staged as LD instead of ED and would have been treated with locoregional radiotherapy besides the standard systemic chemotherapy instead of chemotherapy alone, as was the treatment policy in ED patients. Since in a large proportion of SCLC patients with BM at initial diagnosis, BM becomes clinically significant during the course of the disease, it is very important to investigate the best treatment to prevent serious neurological signs and symptoms. Several small studies ${ }^{13.15}$ have demonstrated initial BM response to systemic chemotherapy at a rate comparable to the response rate in extracranial disease buf we could not confirm this. In our present study chemotherapy as the only treatment modality for SCLC patients with asymptomatic BM may be not sufficient. It seems advisable to treat these patients with a combination of chemotherapy and therapeutic RT of the brain." The radiation dose should be higher than in the so-called $\mathrm{PCl}$ and this therapy should start early in the treatment schedule.

In general it is considered that SCLC patients with BM have a worse prognosis than without $B M .{ }^{19}$ However our study and others ${ }^{7.9}$ suggest that the therapeutic outcome in patients with the brain as the single site of metastases at initial diagnosis is similar to that of LD SCLC, especially when brain RT has been started early in the disease. So again it is impartant to exclude BM at initial diagnosis. 
It is known from literature that in about $25 \%$ of patients chemotherapy alone does not prevent the development of symptomatic $B M_{0}{ }^{20,23}$ Therefore several studies have addressed the role of $\mathrm{PCl}$ in patients with SCLC who exhibited complete remission. In 2 recent large trials ${ }^{22,23} \mathrm{PCl}$ significantly reduced the risk of developing $B M$ in patients with complete remission after systemic chemotherapy, with or without thoracic RT, and showed a trend for longer survival. A recent meta-analysis showed a statistically significant 3 years survival rate in pafients who received $\mathrm{PCl}{ }^{24}$ It is very speculative to attribute the reduction in $\mathrm{BM}$ with $\mathrm{PCl}$ to the response of the asymptomatic $\mathrm{BM}$ to $\mathrm{RT}$. To prove this a large randomised study is necessary.

In conclusion we have demonstrated that it is of clinical value to perform MRI of the brain at the initial diagnosis of SCLC both for staging, prognostication and therapy, so MRI of the brain should be included in the staging of all patients with SCLC, irrespective of neurological signs or symptoms. 


\section{References}

1. Viallet J, thade DC. Small cell carcinoma of the lung: climicel and biologic aspects. Crit Rev Oncol Hematol $1991,11(2): 109-35$.

2. Greco FA, Oldham RK. Current concepts in concer: small-cell lung cancer. N Engl I Med $1979 ; 301771: 355-8$.

3. Paitchell RA. Brain mettastases. Neurol Clin 1991;9(4):817-24.

4. Nugent JL, Bunn PA, Mattew MJ, thade DC, Cohen MH, Gazdar A, Minno: JD. CNS metastases in small cell bronchogenic carcinoma: increasing frequency and changing pattern with lengthening survival. Concer 1979;44(5):1885-93.

5. Komaki $R$, Cox JD, Whitson W. Risik of brain metastosis from small cell carcinoma of the lung related to length of survival and prophylactic irradiation. Cancer Treat Rep 1981;85:9$10): 811-4$.

6. Pedersen AG. Diagnasis of CNS metastases from SCLC. Basic and Clinical Aspects, ed. H.e.L. Cancer. 1986, Baston: Martinus Niihoff Publishers. 153-182.

7. van Hazel GA, Scoth Magan RT. The effect of CNS metastases on the survival of patients with small cell cancer of the lung. Cancer 1983,51(5):933-7.

8. Giannone L, Johnson DH, Hande KR, Greca FA. Favorable prognosis of brain metastases in small cell lung cancer. Ann Intern Med 1987;106(3):386-9.

9. Kochhar $R_{r}$, Frytak $S$, Shaw EG. Survival of patients with extensive small-cell lung cancer who have only brain metastases at initial diagnosis. Am J Clin Oncol 1997; 20[2]:125-7.

10. wan de Pol M, wan Oasterhout AGM, Wilmink JT, ten Velde GPM, Twijnstra A. MRI in detection of brain metastases at initial staging of small-cell lung cancer. Neuroradiology $1996 ; 38(3): 207-10$.

11. Hardy J, Smith I, Cherrymain $G$, Vincent $M$, Judson I, Perren $T$, Williams $M$. The value of computed tomagraphic (CT) scan surveillance in the detection and management of brain metastases in patients with small cell lung cancer. Br J Cancer 1990;62(4):684-6.

12. Hochstenbag MMH, Snoep G, Cobben NAM, Schols AM, Thunissen FB, Wouters EF, ten Velde GP. Detection of bone marraw melastases in small cell lung cancer. Comparison of magnetic resonance imaging with standard methods. Eur J Cancer 1996;32A(5):779.82.

13. Kristensen CA, Kristiansen PE, Hansen HH. Systemic chemotherapy of brain metastases from small-cell lung cancer: a rewiew. J Clin Oncol 1992;10(9):1498-502.

14. Positmus PE, Sleiffer DTH. Haaxma-Reiche H, Chemotherapy for central nervous system mettostases from SCLC: a review. Lung Cancer 1989;5:254-63.

15. Sorensen PS, Kristionsen PEG, Wagrer A, Hansen MH. Comparison of clinical neuralogical function and CT response during chemotherapy for initial brain metastases from small cell lung cancer. Acla Neur ol Scand 1994;89/51:372-7.

16. Habets JM, van Oosterhout AG, ten Welde GP, Wilmink JT, Twijnstra A. Diagnostic value of CT in the detection of brain metastasis in small cell lung cancer patients. I Belge Radiol $1992 ; 75(3): 179.81$.

17. Johnson $\mathbb{D H}$, Windham WW. Allen $\mathrm{NH}$, Greco $\mathrm{FA}$. Limited value of $\mathrm{Cr}$ brain scans in the staging of small cell lung cancer. A.JR Am J Roentgenol 1983;140111:37-40.

18. Crane JM, Nellson M, Macdanald J. A comparison of computed tomagraphy and radionuclida scanning for detection of brain metastases in small cell lung cancer. I Clin Oncol $1984: 2(9): 1017-24$.

19. Hirsch FR, Paulson $\mathrm{OB}$, Hansen $\mathrm{HH}$, Larsen SO. Intracranial metastases in small call carcinoma of the lung. Prognostic aspects. Cancer 1983;51(3):529-33.

20. Pederson AG, Kristjansen.PEG, Hansen HH. Prophylactic eranial irradiatian and small cell lung cancer. Cancer Treat Rev 1988;15:85-103.

21. Baglan RJ, Marks JE. Comparison of symptomatic and prophylactic irradiation of brain melastases from aat cell carcinoma of the lung. Cancer 1981;:47(1):41-5. 
22. Arriagada R, Le Chewalier T, Boire F, Riviere A, Chamy P, Monnet $E$, Tardivon A, Viader F, Tarayre M, Benharnou S. Prophyladic craniel irradiation for patients with small-cell lung concer in complete remissiom. J Natl Cancer linsit 1995;87(3):183.90.

23. Gregor A, Cull A, Stephens RJ, Kirkpatrick JA, Yarnold JR, Girling DJ, Macloeth FR, Stowt R, Machin D. Prophylactic eranial irradiation is indicotted following complete response to induction therapy in small cell lung cancer: results of a multicentre randomised trial. United Kingdom Coordinating Cornmittee for Cancer Research (UKCCCR) and the Europiean Organization for Research and Treatment of Cancer (EORTC). Eur I Concer 1997;33(17): $1752-8$.

24. Auperin A, Arriagada R, Pignon JP, Le Pechoux C, Gregor A, Stephens RJ, Kristiansen PE. Johninson BE, Ueoka HH, Aisner J. Prophylactic cranial irradiation for patients with small-cell lung cancer in complete remission. Prophylactic Cranial Iradiation Overview Collaborative Group. N Engl J Med 1999;341(7):476-84. 
Magnetic resonance imaging of the brain of neurologic asymptomatic patients with large cell or adenocarcinoma of the lung.

Does it influence prognosis and treatment?

MMH Hochstenbag, A Twijnstra, PAM Hofman, EFM Wouters, GPM ten Velde 
46 Chopter 3

\section{Abstract}

\section{Purpose}

Brain metastases are common in non small cell lung cancer (NSCLC) potients. The impact on staging of neurological examination by the neurologist and of magnetic resonance imaging (MRI) of the brain was investigated in neurological asymptomotic patients with large cell carcinoma or adenocarcinoma of the lung.

\section{Patients and Methods}

MRI of the brain and extensive neurological examination by a neurologist was performed as part of inifial staging evaluation of 91 neurologic asymptomatic patients with large cell carcinoma or adenocarcinoma of the lung Patients were followed up for at least 6 months.

\section{Results}

Eyidence of metastatic brain disease was dacumented in 13 $14 \%$ patients. Two of these patients were found suspective of brain metastases by the neurologist. The detection of brain metastases resulted in upstaging of 1 (3\%) patient in stage $\mid / 1$, $4(21 \%)$ patients in stage $111 \mathrm{~A}$ and $2(11 \%)$ patients in $111 \mathrm{~B}$.

\section{Conclusion}

Evaluation of the brain with MRI is a sensitive method of detecting brain metastases in neurologic asymptomatic patients and is recommended as part of the initial staging of patients with large cell carcinoma or adenocarcinoma of the lung in stage lil. Especially for patients in stage III upstaging is of importance as aggressive locoregional treatment can be abandoned Additional examination by the neurolagist is of little value to provide information of the neurolegic status. 


\section{Introduction}

Staging of lung cancer is essential for predicting prognosis and determining treatment options. Surgery offers the highest potential for cure, although the 5 years survival for patients with non small cell lung cancer (NSCLC) with curative surgery of the primary lung tumour remains less than $50 \%$, due to local recurrence or disseminated disease. The assumption exists that $40 \%$ of patients with newly diagnosed lung cancer have distant metastases at presentation. Conventional preoperative staging fails to identify a significant proportion of patients with silent metastases.' Furthermore the American Thoracic Society (ATS) and the European Respiratory Society (ERS) recommend that a search of metastatic disease should be restricted to patients with symptoms and signs, suggesting metastases. ${ }^{2}$

Brain metastases (BM) are common in NSCLC patients and the incidence is estimated to be $20 \%$ at diagnosis and may be more than $50 \%$ at autopsy. ${ }^{3.5}$ Moreover the detection rate is rising as a result of routine imaging of the brain and improvement in systemic therapy resulting in an increased life expectancy, and more patients at risk for developing BM. The brain is a common site of treatment failure following curative therapy of the primary lung tumour. There is a substantial incidence of initial and accasionally solitary $B M$ after curative thoracotomy or radical radiation, particularly in patients with non-squamous cell cancers and a disease stage higher than TINO. The frequency of BM is observed more often in adenocarcinoma than in squamous cell cancers, respectively $30 \%$ and $16 \% .^{5-7}$ Mast BM cause specific neurologic symptoms and signs, however approximately 20 percent of patients with BM due to adenocarcinoma are asymptomatic. ${ }^{3}$

Due to the relative high incidence of BM in NSCLC patients computed tomography (CT) of the brain has been performed as part of the staging protocol in neurologic asymptomatic patients. ${ }^{8.11}$ The value of this imaging procedure is controversial because of different outcomes. From literature it is known that with $\mathrm{CT}, \mathrm{BM}$ are found in no mare than $3 \%$ of neurologic asymptomatic patients ${ }^{12,13}$ at diagnosis. However more recent studies have shown that contrast enhanced magnetic resonance imaging (MRI) is more sensitive in detecting asymptomatic BM than CT of the brain. ${ }^{14-18}$

The aim of our sludy is to investigate the impact of neurologic examination by the neurologist and of the MRI of the brain on the staging of neurologic asymptomatic patients with large cell carcinoma or adenocarcinoma of the lung. 


\section{Patients and methods}

Befween 1-1-7996 to 1-1-2000, 91 neurologic asymptomatic patients with histological or cytological proven large cell carcinoma or adenocarcinoma of the lung were included in this study. Patients were evaluated with standard tests and procedures in the outpatient department of pulmonary diseases at the University Hospital Maastricht. All patients underwent physical examination, blood count, measurement of electrolytes, renal and liver function, CT of the thorax and abdomen, comprising liver and adrenals. The pulmonologist classified all patients according to the TNM staging system of the American Joint Committee 1997. All patients were extensively examined by a neurologist (AT) and in all patients a MRI of the brain was performed within one month of the pathological confirmation of NSCLC, irrespective of findings of the neuralogist.

Patients were followed for at least 6 months or until death. Follow-up MRI of the brain was performed on indication only. Negative MRl studies were considered to be false negative if a brain metastasis was detected within 6 months of followup.

\section{Magnetic resonance imaging}

MRI of the brain was performed on a 0.5 Tesla system Gyroscan T5, Philips Medical Systems International, Best, The Netherlands). First a set of transverse spin-echo proton density and T2 weighted images was obtained with a fast spinecho sequence (TR/TE 4500-6500/30-130 msec, FOV $230 \mathrm{~mm}, 241 \times 256$ matrix, NSA4, echo train length 16). TT-weighted spin-echo images were obtained (TR/TE 600/18 msec. FOV $230 \mathrm{~mm}, 10 \mathrm{~mm}$ slices $205 \times 256$ matrix, NSA4) before and after IV injection of gadolinium DTPA in a dose of 0.1 $\mathrm{mmol} / \mathrm{kg}$. One neuroradiologist (PH) and one neurologist (AT) interpreted the MRI brain scans independently in the following manner: llit normal or abnormal due to a non-malignant pathologic process and (II) abnormal, compatible with metastases. Readings were subsequently compared, and consensus was reached by discussion.

\section{Results}

The characteristics and TNM staging according to accepted criteria of 91 neurologic asymptomatic study patients are shown in table 3.7. The results of neurologic examination by the neurologist AT and MRI of the brain of all 
patients are shown in table 3.2 . In 2 neurologic asymptomatic patients, specific neurologic examination showed minimal neurologic abnormalities. In these 2 patients $M R I$ showed $B M$ too. Also in 11 other patients with a normal neurologic investigation MRI showed BM. This means that in 13 of $91(14 \%)$ asymptomatic patients BM were found by extensive examination by the neurologist or by MRI of the brain.

The impact on the clinical stage (according to the ATS/ERS criteria) of neurologic examination and MRI of the brain is shown in table 3.3. Before the experimental examination of the neurologist and the MRI, 1 patient $(8 \%)$ with asymptomatic BM was staged as 11,4 patients (21\%) were staged as IIIA (N2), 2 patients (11\%) were staged as IIIB and 6 patients $(29 \%)$ were staged as $I V$. The 2 patients with signs of BM according to the neurologist had been staged as IIIB and IV. This means that most patients already suffered from advanced disease and that in only 7 of 91 patients $(8 \%)$ there was an upstaging by MRI of the brain.

Of the 78 patients without metastatic brain disease at initial diagnosis, 16 patients died before 6 months due to tumour progression. Clinically there were no neurologic signs before death. During follow-up of the remaining 62 patients without evidence of $B M$ on initial MRl staging, 3 patients developed symptomatic $\mathrm{BM} 9,10$ and 18 months after initial staging.

Table 31 Patient's characteristics of all 91 neurological asymptomatic patients.

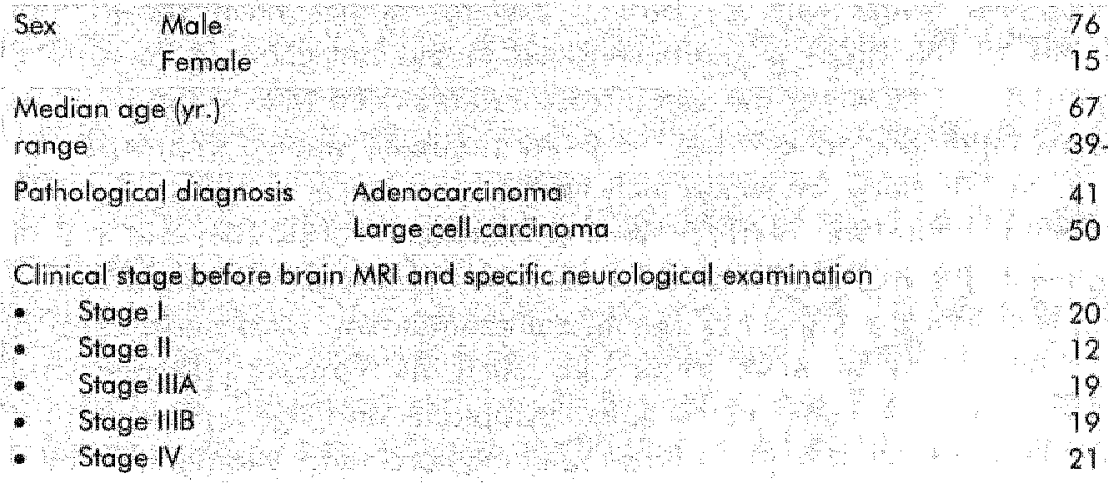

Table 3.2 Results of brain MRI of all 91 patients with or without neurological signs detecred by the neurologist.

MRl normal or non-metastatic MRI metastolic total

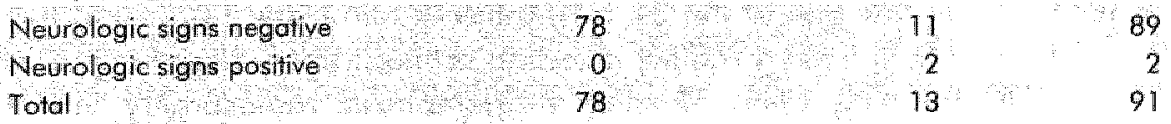


501 Chopter 3

Table 3.3 The incidence of $\mathrm{BA}$ in 91 neurologic asymptomatic patients 1 tumour stage 1 to $1 \mathrm{~V}$.

\begin{tabular}{|c|c|c|c|c|c|}
\hline & $\begin{array}{l}\text { Staige } \\
(20)\end{array}$ & $\begin{array}{c}\text { Strogel } \\
(72)\end{array}$ & $\begin{array}{c}\text { Stgqe } 11 \mathrm{~A} \\
19 \mathrm{l}\end{array}$ & $\begin{array}{c}\text { Stoge } 11 \mathrm{~B} \\
119 \mathrm{y}\end{array}$ & $\begin{array}{l}\text { Stoge W } \\
(21)\end{array}$ \\
\hline$\sigma \mathrm{BM}$ & 20 & 11 & 15 & 17 & 15 \\
\hline Asymplamofic BM & 0 & 1 & 4 & 2 & 6 \\
\hline
\end{tabular}

\section{Discussion}

Staging of lung cancer is very important in the process of selecting the best treatment and to provide prognostic information to the patient and clinician. Staging of the brain in neurologic asymptomatic patients with bronchial carcinoma is not unanimously accepted. The ATS/ERS -guidelines ${ }^{2}$ recommend a cramial CT im patients with newly diagnosed NSCLC only if neurologic symptoms and signs (e.g. headaches, seizures) are present. This is also recommended in patients with nonspecific findings suggesting melastatic disease. The reason for this negative advice for routine $C T$ brain is that a meta-analysis showed BM in less than $3 \%$ patients with a normal neurologic investigation ${ }^{13}$ and because of $11 \%$ false-positive results with CT brain. ${ }^{19}$ Several studies have shown that enhanced MRI of the brain is more sensitive in the detection of metastatic disease than $\mathrm{CT} .^{14-18}$ However the use of routine enhanced MRI of the brain in neurologic asymptomatic patients has not been frequently studied in prospective studies. ${ }^{1 \%, 18,20}$ In our study we found with MRI an incidence of $14 \%$ (13 of 9 ) patients) of BM in neurologic asymptomatic patients at initial staging and in 2 of these 13 patients the neurologist defected discrete neurologic abnormalities. In comparison with MRi the impact of additional examination by a neurologist is very low alhough many other disorders, such as vascular disease and paraneoplastic signs can cause neurological symptoms and signs. However for this group of patients with adeno- or large cell lung carcinoma examination by a neurologist was not of additional clinical value.

Althougth the incidence of asymptomatic BM in our study is substantial the clinical impact depends on the influence of cerebral staging on the tumour stage and treatment. The tumour stage changed in 7 of $91(8 \%)$ of these neurologic asymptomatic patients.

BM was identified in only one of the $32(3 \%)$ patients with stage I or 11 and this patient could still benefit from a radical resection of the primary lung tumour in combination with an early open resection or stereotactic radiosurgery of the $\mathrm{BM} .^{21.24}$ In contrast with our study, Earnest ef al. ${ }^{20}$ found an incidence of $7 \mathrm{BM}$ in 
29 dinically operable patients with NSCLC. However this study contains a small patient population that could bias the real incidence of accult BM in NSCLC. Our results are more in line with those of Yokoi ${ }^{17}$, who previously found a low incidence of BM defected with CT. Also our results support the ATS/ERS guidelines of pre-treatment evaluation of NSCLC, which means that it is not advisable to perform MRI of the brain in stage I or II adenocarcinoma or large cell carcinoma in neurologic asymptomatic patients.

In patients with more advanced NSCLC the incidence of occult BM in our study is much higher. In stage IIIA/IIIB 16\% of the patients had asymptomatic BM. For these patients this upstaging is of importance as aggressive locoregional treatment can be abandoned. According to the current standard, patients with proven IIIA or IIIB with WHO-score 0,1 and 2 are candidates for aggressive locoregional treatment with chemoradiotherapy. Furthermore there is accumulating evidence that preoperative, neoadjuvant chemotherapy may downstage the disease in patients with stage IIIA, N2 disease making resection possible. If in these patients asymptomatic BM are detected, less aggressive therapy or only palliative therapy should be offered as no survival benefit or better quality of life has been demonstrated by treating these patients with chemoradiotherapy.

Cisplatinum-based chemotherapy for stage IV NSCLC patients with goad performance offers a slight but definitive survival benefit ${ }^{25}$ but this is not demonstrated for patients with BM. Since in our study $29 \%$ of the stage IV patients had occult $B M$, only palliative treatment (including palliative chemotherapy in selected cases) is indicated in these patients.

During follow-up of more than 6 months only 3 patients (4\%) developed clinically manifest $B M$. This supports that $M R I$ is at present very sensitive in the detection of asymplomatic BM. One of the reasons could be that with MRI very small lesions can be visualised.

We have not studied the cost-effectiveness. Mayr et al. ${ }^{26}$ suggest that high-dose MRI may be cost-effective in a selected group of patients with symptoms suggestive of BM. From our results it seems clear that no reduction in the treatment costs can be reached in stage I, 11 and stage $\mathrm{V}$. Because of the high incidence of BM in stage III, MRI of the brain could be cost saving. Whether this increased intervention actually would be cost-effective would be determined only by well-designed prospective studies.

In conclusion our study showed that additional examination by the neurologist is of little value to provide additional information of the neurologic status of the patient with adenacarcinoma or large cell carcinoma of the lung. MRI of the brain in neurologic asymptomatic patients with stage I or II adenocarcinoma or large cell carcinoma is also of little value as we detected in only $3 \%$ of the cases 
asymptomatic BM. MRI of the brain, in stage III patients without neurological signs or symptoms, detected BM in $16 \%$ of the patients, which is of influence on prognosis and choice of therapy. In our stage IV patients MRI detected in 29\% of the neurological asymptomatic patients $B M$. This hardly influences the prognosis of these patients.

Therefore, in patients with adenocarcinoma or large cell carcinoma of the lung, MRI of the brain is advisable for all neurologic asymptomatic patients in stage III for who aggressive locoregional therapy as induction chemotherapy followed by radiotherapy or surgery is considered. 
Detection of asyraptomatic brain metastases with MRI in NSCLC

\section{References}

1. Landis SH, Murray T, Bolden S, Wingo PA. Cancer statisfics, 1998. CA Cancer I Clin $1998 ; 48[1]: 6-29$.

2. The American Thoracic Society and The European Respiratory Society. Pretreatment evaluation of non-small-cell lung cancer. Am J Respir Crit Care Med 1997:156(1):320-32.

3. Newman 5J, Hansen HH. Proceedings: Frequency, diagnosis, and treatment of brain metastases in 247 consecutive patients with branchogentic carcinoma. Cancer $1974,33(2)$ : 492-6.

4. Sorensen JB, Hansen HH, Hansen M, Dombernowsky. P. Brain metastases in aidenocarcinomo of the lung: frequency, risk groups, and prognosis. J Clin Oncol 1988;6(9):1474-80.

5. Cox JD, Yesner RA. Adenocarcinoma of the lung: recent results from the Veterans Administration Lung Group. Am Rev Respir Dis 1979;12015): 1025-9.

6. Figlin RA, Piantadosí $S$, Feld R. Intracranial recurrence of carcinoma after complete surgical resection of stage I, II, and III non-small-cell lung cancer. N Engl J Med 1988;318(20): 1300-5.

7. Perez CA, Pajak TF, Rubin P, Simpson JR, Mohiuddin M, Brady LW, Perez-Tamayo R, Rotman $M$. Long-term observations of the patterns of failure in patients with unresectable non-aat cell carcinoma of the lung treated with definitive radiotherapy. Report by the Radiation Therapy Oncology Group. Cancer 1987:59(11):1874-81.

8. Salbeck R, Grau HC, Artmann H. Cerebral tumor staging in patients with bronchial carcinome by computed tomagraphy. Cancer 1990;66(9):2007-111.

9. Kormas P, Bradshaw JR, Jeyasingham K. Preoperative computed tomography of the brain in non-small cell bronchogenic carcinoma. Thorax 1992; $47(2): 106-8$.

10. Ferrigno $D$, Buccheri $G$. Cranial computed tomography as a part of the inifial staging procedures for patients with non-smail-cell lung cancer. Chest 1994; 106 (4):1025-9.

11. Hooper RG, Tenholder MF, Underwood GH, Beechler CR, Spratling L. Computed tomagraphic scanning of the brain in initial staging of bronchogenic carcinoma. Chest 1984;8516):774-6.

12. Hillers TK, Souve MD, Guyatt GH. Analysis of published studies on the detection of extrathoracic metastases in patients presumed to have operable non-small cell lung cancer. Thorax 199:4;9(1):14-9.

13. Silvestri $G A_{r}$ Littenberg $B$, Colice $G$. The dinical evaluation for detecting metastatic lung cancer. A meta-analysis. Am J Respir Crit Care Med 1995,152(1):225-30.

14. Sze G, Milano $E_{i}$ Johnson $C$, Heier L. Detection of brain metastases: comparison of contrastenhanced MR with unenhanced MR and enthanced CT. AJNR Am J Neuroradiol $\left.1990_{i}\right] 1[14]: 785-91$.

15. Davis PC, Hudgins PA, Peterman SB, Hoffman JC, Ir. Diagnosis of cerebral mellastases: double-dose delayed CT ws contrastembanced MR imaging. AJNR Am I Neuroradial $1991 ; 12(2): 293-300$.

16. Lemiere C, Peretti-Viton P, Thomas P, Gaubert JM, di Stefano-Lovineau D, Kleisbavier IP. Spreading evaluation in primitive bronchogenic carcinoma: benefit of cerelbral MRI compared Ho CT scan. Eur J Cancer 1995;31 A(10): 1715.

17. Yokoi K, Kamiya M, Matsuguma $H$, Machida $\$$, Hirase T, Mari K, Tominaga K. Detection of brain metastasis in potentially operable non-small cell lung cancer: a comparison of CT and MRI. Chest 1999:115(3):714-9.

18. Vuh WT, Fisher DJ, Runge VM, Atlas SW, Harms SE, Maravilla KR, Mayr NA, Mollman JE, Price AC. Phase Ill multicenter trial of high-dose gadoteridol in MR evaluation of brain melastases. A.JWR Am J Meuroradiol 1994;15(6);1037.51.

19. Patchell RA, Tibbs PA, Walsh JW, Dempsey RJ, Maruyama Y, Kryscio RJ, Markesbery WR, Macdonald JS, Young B. A randomized trial of surgery in the treatment of single metastases to the brain. N Engl J Med 1990;322(8):494-500. 
20. Earnest FH, Ryu $\mathrm{IH}$, Miller GM, Luetrner PH, Forstrom LA, Burnett OL, Rowand CM, Swensen SI, Midthun DE. Suspected non-small cell lung cancer: incidence of occult brairy and skeletal metastases and effectiveness of imaging for defection-pilot study. Radiology $1999,211(1): 137 \cdot 45$

21. Ryan GF, Ball DL, 5mith IG. Treatment of brain metastases from primary lung cancer. Int $J$ Radiat Oncol Biol Phys 1995:31(2):273-8.

22. Andrews RJ, Gluck DS, Konchingeri RH. Surgical resection of brain metastases from lung cancer, Acta Neurochir (Wien) 1996:138(4):382-9.

23. Vechl CJ, Hoaxma-Reiche H, Noordijk EM, Padberg GW, Voomolen JH, Hoekstra FH, Tans JT, Lambooii N, Metsaars: JA, Wattendorlf AR, et al. Treatment of single brain metastasis: radiotherapy alone or combined with neurosurgery? Ann Neurol 7993;33(6):583-90.

24. Chidel MA, Suh JH, Greskowich JF, Kupelian PA, Barnett GH. Treatment outcome for patients with primary nonsmall-cell lung cancer and synchronous brain metostasis. Radiat Oncol Investig 1999; 7 (5):313-9.

25. Chematherapy in non-small cell lung cancer: a meta-analysis using updated data on individual patients from 52 randomised dinical trials. Nan-small Cell Lung Cancer Collaborative Group. Bmi 1995,311(7010):899-909.

26. Mayr NA, Yuh WT, Muhonen MG, Fisher DJ, Nguyen HD, Ehrhordt JC, Wen BC, Doornbos JF, Hussey DH. Cost-effectivenass of high-dose MR contrast studies in the evaluation of brain metastases. A.NR Am J Neuroradial 1994;15(6):1053-61. 


\section{Detection of bone marrow metastases in small cell lung}

cancer.

Comparison of magnetic resonance imaging with standard methods.

MMH Hochstenbag, G Snoep, NAM Cobben, AMWJ Schols, FBJM Thunissen, EFM Wouters, GPM ten Velde 


\section{Abstract}

\section{Purpose}

In smail cell lung cancer (SCLC) bone marrow metastases are frequently defected by bone scintigraphy (BS) and/or unilateral bone marrow biopsy and aspiration (BMBA). In this study the yolue of magnetic resonance imaging (MRI) of thoracic spine and pelvis was compared with BS and BMBA.

\section{Patients and Methods}

Its clinical implication was evaluated in 42 patients with SCLC. Patients were staged (induding BS, BMBA, CT thorax, liver ECHO) as limited (LD) or extensive disease (ED) before and affer MRI.

\section{Results}

MRI was positive in 12 BS negative $(p=0.003)$ and in 14 BMBA negative patients $(p<0.001)$, while in 8 patients MRI was the anly sign of $E D$, which resulted in a decrease of $L D$ cases from $52 \%$ to $33 \%$. However, in this small group of LD patients, there was no survival difference between LD (MRI pos) and LD (MRI neg) patients.

\section{Conclusion}

MRI can be of value in the staging of SCLC patients with LD, but it has no influence on survival. 


\section{Introduction}

Lung cancer is responsible for many cancer-related deaths. Approximately 20\%$25 \%$ of all lung cancers are of the small-cell variety.' Patients with small cell lung cancer (SCLC) are classified as having either limited disease (LD) or extensive disease (ED). LD is defined as a tumoral process involving only one hemithorax and its regional lymph nodes including the ipsilateral mediastinal, the ipsilateral supraclavicular and the contralateral hilar lymph nodes. All other sites of metastasis are considered ED. ${ }^{2} \mathrm{ED}$ is present in about $60 \%$ of newly diagnosed patients with SCLC. ${ }^{2}$ Bone marrow involvement is a common finding in SCLC. ${ }^{3}$ Examination of bone marrow biopsy and aspiration (BMBA) and bone scintigraphy (BS) for evidence of bone marrow inwolvement is generally performed as part of the initial staging procedure. With these procedures bone marrow involvement at diagnosis is demonstrated in approximately 20 to $30 \%$ of the patients. ${ }^{4}$ However, bone marrow involvement is seen in up to $50 \%$ in bone marrow aspirates immunostained with monoclonal antibodies (Moab). . $^{5.7}$

Magnetic resonance imaging (MRI) is a non-invasive imaging modality that can be used for the defection of bone marrow involvement. ${ }^{8}$ A few studies have been performed suggesting that MRI could detect more frequently bone marrow metastases in SCLC. ${ }^{8-11}$ However these studies compared MRI with BS and BMBA immunostained with MOAb ${ }^{10}$ or they suggested only an advantage of MRI over the other modalities. ${ }^{8 / 1}$ A very recent study ${ }^{12}$ confirmed these results but only in ED patients. The clinical relevance of these MRI-findings is not yet clear.

We performed a prospective study to determine whether MRI of the thoracic spine and pelvis could detect more frequently bone marrow metastases than BS and $B M B A$, procedures at present routinely performed in the staging of SCLC patients. A second aim of the study was to set out if bone marrow metastasis detected by MRI changed the stage of the disease of the involved patients. A third aim of the study was to assess if MRI influences the survival time, especially in patients who had been upstaged from LD to ED by MRI. 


\section{Patients and methods}

From September 1991 to October 1994, 42 consecutive patients with histological confirmed SCLC were included in our study. There was no specific selection of patients. They ranged in age from 32 to 77 years (median, 62.8 years). All patients were staged for LD or ED according to accepted conventional criteria, which included blood chemistry, liver ECHO, CT-ihorax, BS and BMBA. BS of the whole body was performed three hours after injection of $15 \mathrm{mCi}$ technetium $99 \mathrm{~m}$-HDP. BS was considered positive if lesions strongly suggestive of metastases were present.

BMBA specimens were obtained unilaterally from the posterior iliac crest. This sitte was not specifically assaciated with abnormal images in BS. Biopsies were fixed in formalin and embedded in paraffin. Histological slides were stained with haematoxylin-eosin, the cells of the bone marrow smears with Giemsa. After these investigations patients were staged as LD or ED. Additionally, a MRI of tharacic spine and pelvis was performed. The MRl study was performed using a 0.5 Tesla MR imager. (Gyroscan T5, Philips Medical Systems International, Best, The Netherlands). We acquired T1 weighted spin echo (SE) images of the thoracic spine (sagittal, 7, mm slice thickness, TR/TE 400/16 ms) and pelvis (transaxial, $10 \mathrm{~mm}$, TR/TE $400 / 15 \mathrm{~ms}$ ). Additional images with a short time inversion recovery (STIR) sequence were made of the pelvis (transaxial, $10 \mathrm{~mm}$, TR/TI/TE T400/140/22 ms). Metastasis was defined as lacalised areas in the bone marrow on the SE images with a signal intensity considerably lower (figure 4.1 ) than the surrounding bone marrow. In some patients the marrow in virtually the whole imaged port of the axial skeleton showed a signal intensity that was considerably lower than normal fatty tissue (figure $4.1 \mathrm{~b}$ ). These cases were graded as diffuse metastases. In the pelvis metastases were only diagnosed if the low intensity areas on the SE images corresponded to high intensity areas on the STIR images (figure 4.2). The MRI examinations were performed by the radiologist on duty and were reviewed by one senior radiologist (G.S.) without knowledge of the other staging results.

All patients were initially treated with a combination chemotherapy regimen, consisting of Cyclophosphamide $1000 \mathrm{mg} / \mathrm{m}^{2}$, Doxorubricin $45 \mathrm{mg} / \mathrm{m}^{2}$ and Etoposide $100 \mathrm{mg} / \mathrm{m}^{2}$ on day 1,3 and 5 for at most 5 cycles. Chemotherapy was not followed by radiatherapy to the primary tumour site.

All patients were prospectively followed till death or till the end of the study (March 1995).

Statistical analysis of paired categorical data was undertaken using the McNemar Test. Otherwise the Chi-Square lest was used. P-values $<0.05$ were 
considered statistically significant. The statistical analyses were performed using the SPSS/for Windows Release 6.0. ${ }^{13}$

The survival time was calculated from the day of diagnosis till death or end of fallow up (March 1995). Kaplan-Meier survival curves were calculated and compared using the logrank test.
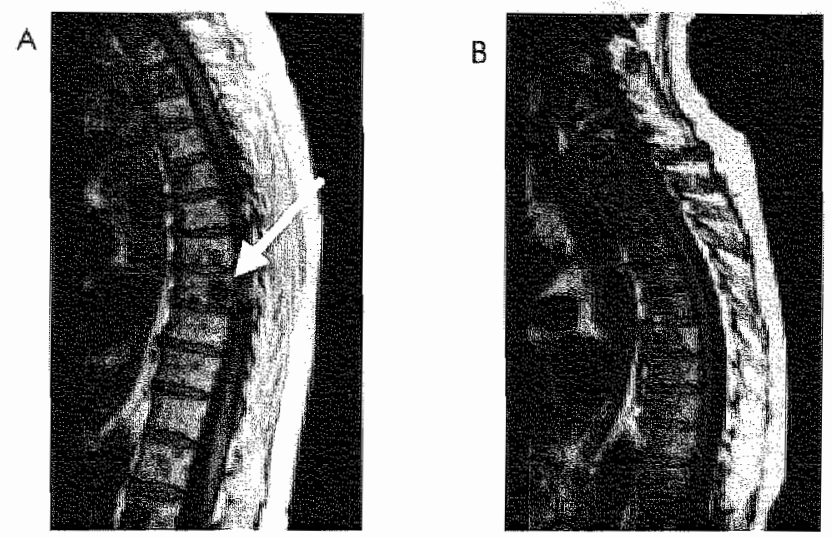

Figure 4.1 A. Lacalised dark patchy metastases (arrow) of the bone marrow on $\mathrm{Tl}$ weighted SE images.

B. Diffuse metastases of the bone marrow of the axial skeleton.

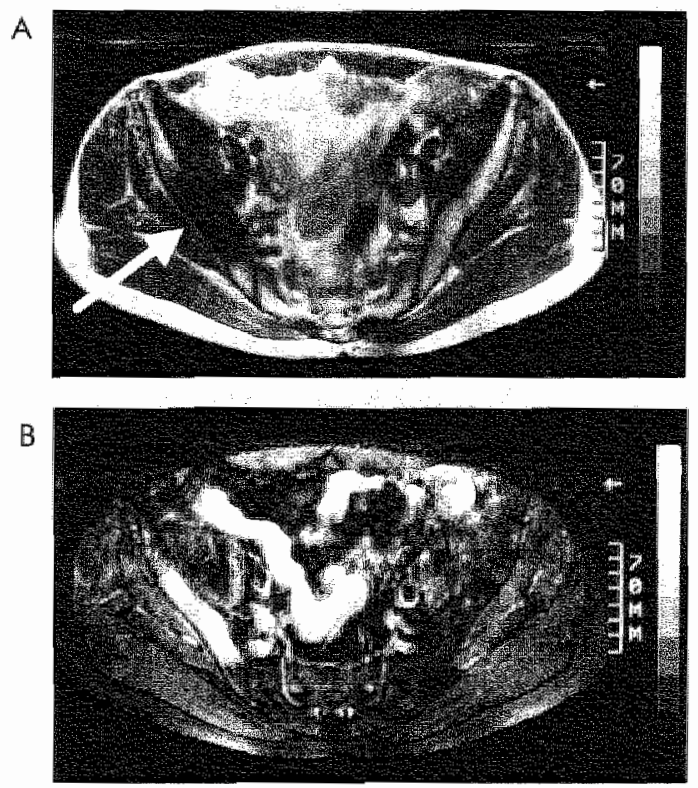

Figure 4.2 A. Pelvic metastases show low intensity areas on SE images.

B. High intensity areas on STIR images. 
$60 \mid$ Ghopter 4

\section{Results}

42 Patients were included in the study to evaluate the value of MRl of thoracic spine and pelvis in the initial staging procedure. In lable 4 . I the results are shown of the comparisons between the bone marrow involvement found by BS, BMBA and MRI. In 12 patients BS was negative for bone marrow metastases, while MRI was positive for bone marrow metastases. All positive BS were confirmed by MRl $(p=0.003)$ except for one patient. In this patient, BS detected a hot spot suggestive of a metastasis in the skull outside the area imaged by MRI.

Bone marrow involvement detected by $B M B A$ was also compared with MRI. In 14 patients, BMBA was negative for bone martow metastases, while MRI was positive. All positive BMBAs were confirmed by MRI $(p<0.001)$, except for the patient with the positive BS in the skull who also had a positive BMBA and yet a completely normal MRI.

Table 4.1 Results of magnetic resanance imaging (MRU) compared with bone scintigraphy (BS) and bone marrow biopsy and aspiration (BMBA):

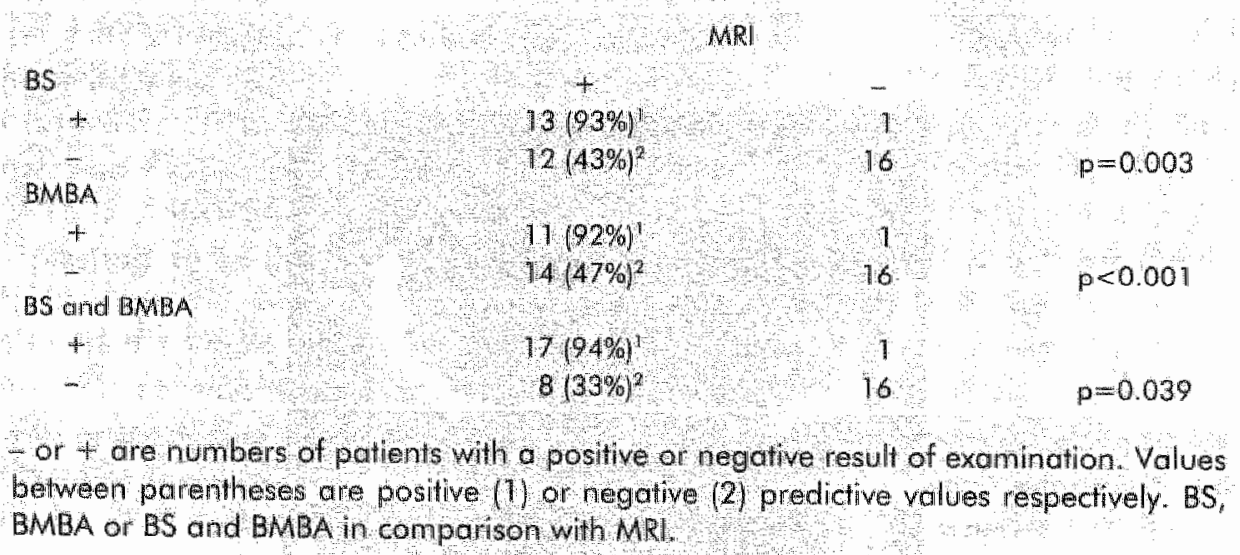

The result of bone marrow involvement found by BMBA and BS together was compared with MRI. In 8 patients BMBA as well as BS were negative, while MRI was positive. All patients with positive BS and/or positive BMBA were confirmed by MRI, with the exception of the patient mentioned above. So in 8 of these 42 patients, anly MRI provided evidence for metastatic disease, which was a significant difference $(p=0.039)$.

The positive predictive value of BS or BMBA in comparison with a positive MRI was very high $193 \%$ and $92 \%$, respectively), whereas the negative predictive 
value was low $(43 \%$ and $47 \%$, respectively), which was aiso true for the combination of BS and BMBA ( $94 \%$ and $33 \%$, respectively) (toble 4.1 ).

According to the conventional staging (as stated in patients and methods), 22 of 42 patients had LD $(52 \%)$ and 20 had ED whereas with the addition of MRI 14 of $42(33 \%)$ had LD and 28 had ED (Chi-square: $3.11, p=0.08$ ).

The survival time of ED and LD is shown in figure 4.3. The median survival time was 11.0 months (95\% Cl: 7.6-15.4) for LD and 6.0 months $(95 \% \mathrm{Cl}: 3.8-8.2)$ ED (logrank, $p=0.0038$ ). To assess the influence of MRI on survival, the 14 patients with LD with negative MRI (median survival 12,5 months, $95 \% \mathrm{Cl}: 7,9$. 17,1 ) and 8 patients with LD with positive MRI (median survival 11,0,95\% Cl: 8,3-13,7) were compared. Koplan-Meier Survivall curves are shown in figure 4.4. There was no significant difference in survival between LD with negative MRI and LD with positive MRI.

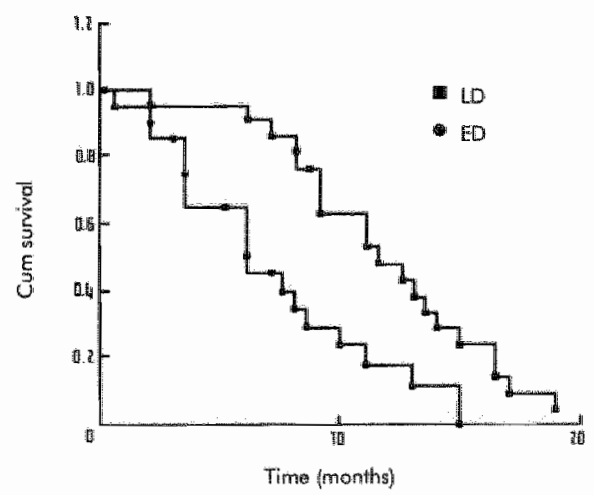

Figure 4.3 Kaplan-Meier survival curves of $L D$ and ED patients. The difference between $L D$ and $E D$ was significant $(P=0.0038)$.

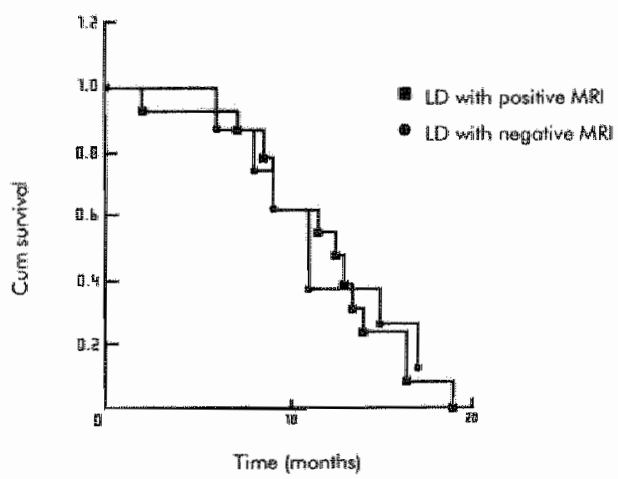

Figure 4.4 Kaplan-Meier survival curves of LD patients with a positive or negative MRI. There was no significant difference in survival. 
62 Chopter 4

\section{Discussion}

SCLC is an aggressive neoplasm, with high risk for metastases in early disease. With current chemotherapy, patients with ED rarely remain disease free beyond 2 years, whereas only $10 \%-15 \%$ of patients with LD can be cured. ${ }^{8}$ Staging procedures to detect possible sites of metastases may be necessary for certain clinical and therapeutic reasons. Firstly, it may be clinically relevant if patients with LD are treated with local and/or prophylactic cranial radiotherapy (during or after chemotherapy), in contrast to ED patients. Secondly, staging results in good prognostic indicators. $3,4,10$

In patients with SCLC, bone marrow metastases are delected in $20 \%$ to $30 \%$ of the patients by BS and BMBA. 4.9 However, bone marrow infiltration is defected in $35-66 \%$ of patients at necropsy $y^{3.10}$ and in up to $50 \%$ of bone marrow aspirates (immunostained with MOAB)..$^{5.7}$ Recently MRI has been introduced as a procedure to detect early bone marrow metastases. ${ }^{14}$

Several questions have been addressed in this study. We found that MRI could enable detection of both diffuse and focal lesions when BS and BMBA were negative. Bone marrow metastases were detected in $18 / 42$ patients $(43 \%)$ by BS and BMBA while MRI detected bane marrow metastases in $25 / 42$ patients $(60 \%)$. This shows that MRI is a more sensitive technique to detect bone marrow metastases in SCLC than BS and BMBA. These findings have also been observed by other groups. ${ }^{10,11,15}$ These differences in detection of bone marrow metastases could be explained by the fact that abnormalities detected by BS reflect predromintratily cortical 'bone involvement. 'A Aithough BMBA is a very specific method in detecting bone marrow metastases it has the disadvantage of an at random biopsy.

In addition, MRI was able to change the staging of a patient, with 8/22 LD patients changed to ED.

With our limited MRI protocol (of thoracic spine and pelvis), no metastases to ribs or appendicular skeleton were detected. However bone metastases in SCLC outside the spine and pelvis are rare. ${ }^{8}$ In addition, in our study BS yielded extra information in only 1 patient (as did BMBA in the same patient). Therefore there is probably no need to perform BS and BMBA routinely in the staging procedure when MRI is performed.

Pathological confirmation of MRI abnormalities lexcept for the posierior iliac crest) was not abtained as it was considered unethical to biopsy vertebrae or pelvis for research purposes only, but in some patients indirect confirmation of bone marrow metastasis could be obtained by changes in MRI before and after chemotherapy. 
There is still some doubt whether bone marrow involvement is of prognostic significance for survival. In a small retrospective study of our institute ${ }^{15}$, no differences were found in survival of patients with or without bone marrow metastases. However a prospective study of bone marrow metastases detected by $B S$ and BMBA showed that patients with bone marrow metastases had a significantly shorter time to progression and a significantly shorter survival time than other patients with extensive disease. ${ }^{16}$ Recently it was also demonstrated that patients with only bone marrow metastases, detected by immuno. cytochemistry with MOAb, had a worse prognosis than patients without bone marrow infiltration and the same prognosis as patients with ED. ${ }^{17}$ This is in contrast with the findings in our study. We only found a significant influence on survival time between LD and ED, but not between patients with LD with or without a positive MRI. Thus, MRI had no significant influence on survival time, not even in patients who had been upstaged from LD to ED. However, the patient groups were small, so the results should be interpreted cautiously.

As MRI of thoracic spine and pelvis is a time-consuming and expensive procedure it may only be justified to apply this investigation to SCLC patients in whom extrathoracic disease has not yet been demonstrated because a positive result could change the stage of the disease in quite a number of patients. However, the findings of MRl have no significant influence on survival. 


\section{References}

1. Siverberg E. Concer statistics, 1983. CA Cancer J Clin 1983,3311/9-25.

2. Hansisen HH, Dombernowiski P, Hisch FR. Staging procedures and prognostic features in small cell anaplastic bronchagenic carcinoma. Semin Oncol $1978,5: 280-98$.

3. Bezwoda WR, Lewis D, Livini N. Bone morrow inwolwernent in anaplastic small cell lung cancer. Diagnosis, hematologic features, and progrostic implications. Concer 1986;58(8):1762-5.

4. Bennett $T$, Doll DC, Ringenberg S. Bone marrow inwolvement in small cell lung cancer: dinical significance and correlation with routine laboralory variables. Cancer $1989 ; 63: 763-6$.

5. Stahel RA, Mabry M, Skorin AT, Speak J, Barnal SO. Detection of bone marrow metastasis in small-cell lung cancer by monoclonal antibody. J Clin Oncol 1985;3(4):455-61.

6. Skov BG, Hirsch FR, Bobrow L. Monaclonal antibodies in the detection of bone marrow metastases in small cell lung cancer. Br J Cancer 1992,65(4):593-6.

7. Berendsen HH, De Ley L, Postimus PE, Ter Haar JG, Poppema S, The TH. Detection of small cell iung cancer metastases in bone marrow aspirates using manodonal antibody direcled against neuroendocrine differentitation antigen. $J$ Clin Pathol 1988;41(3):273-6.

8. Jelinek IS, Redmond III J, Perry JJ, Burrall LM, Benedikt RA, Geyer CA, Peller PJ wacks $L_{\text {w }}$ Wise BJ, Ghaed VN. Small cell lung cancer: staging with MR imoging. Radiology $1990 ; 177(3): 837-42$.

9. Mahta RC, Wilson MA, Perlman SB. False-negative bone scan in extensive metastatic disease: $C T$ and MR findings. I Comput Assist Tomogr 1989;13(4):717-9.

10. Trillet $V$, Reval $D$, Combaret $V$, Fayrot $M$, Loire $R$, Tabib A, Pages J, Jacquemet $P$, Banmartin $A$, Momex JF, et al. Bone marrow metastases in small cell lung cancer: detection with magneatic resonance imaging and monacional antibodies. Br J Cancer 1989;60(1):83-8.

11. Perrin-Resche $\|_{\text {, Bizais }} Y$, Buke Th, Fiche M. How does illac crest bone marrow biopsy compare with imaging in the detection of bone metastases in small cell lung cancer? Eur $\mathrm{J}$ Nucl Med $1993 ; 20(5): 420-5$.

12. Milleron BJ, Le Breton $C$, Carette MF, Cadramel JL, Akoun GM. Assessment of bone marrow involvement by magnetic resonance imaging in small cell liung cancer. No significant change of staging. Chest 1994;106(4):1030-5.

13. SPSS for Windows Release 6.0. 1993, New York: Norusis M.J/SPSS ine.

14. Kattapuram 5V, Khurana JS, Scott JA, elkhoury GY. Negative scintigraphy with positive magnetic resonance imaging in bone metastoses. Skeletal Radial 1990;19(2):173-6.

15. ten Velde GPM, Kuypers-Engelen BTM, Volovics A, Bosman FT. Examination of bone marrow biopsy specimens and staging of small cell llung cancer. Eur I Cancer 1990;26(1)-12): $1142-5$.

16. Zych J Polawiec Z, Wiatr $E$, Broniek A, Rowinska-Zakrzewska $E$. The prognastic significance of bone marrow metastases in small cell lung concer patients. Lung Cancer 1993;10(3-4): 239.45.

17. Manegold $C$, Bücher $M$, Krempien B, et al. Imnunacytological evidence of tumor cells (IETC) spread to the bone marrow and its relationsthip to prognosis in small cell lung cancer (SCLC). Lung Concer 1994:1 1/51),47:0bstr.180. 
Imaging of lung lesions suspected of cancer and staging of non small cell lung cancer by positron emission tomography

MMH Hochstenbag, M Zimny, RJS Lamers, EFM Wouters, GPM ten Velde 


\section{Abstract}

\section{Purpose}

To estimate the diagnostic accuracy of Pasition emission tomography (PET) using 18 fluordeoxyglucose (FDC) for molignan pulmonory nodules ond to compiare the accuracy of FDG-PET and conventional staging of lung cancer patients.

\section{Patients and Methods}

In 91 potients we studied the usefulness of FDG PET in the differentiation of malignant from benign pulmonary tumours (solitary pulmonary nodules and masses) in comparison to bronchoscopy We compared the results of FDGPET and computed tomography (CT) separately with surgical medicstinal staging in 50 operable patients. We compared conwentional staging methods with FDG.PET in the detection of metastatic disease outside the mediastinum an 81 non small cell lung cancer (NSCLCI patients.

Results

The overall sensitivity and specificity of FDG-PET for defecting malignant lung tumours was found to be $99 \%$ and $88 \%$, respectively. The accuracy was $98 \%$. The sensitivity and specificity of FDG -PET for mediastinal staging (NO-NI versus N2-N3) was $81 \%$ and $82 \%$ respectively. The NPV was $90 \%$ and PPV was $68 \%$. For the detection of melastases outside the mediastinum FDG.PET had an accuracy of $94 \%$. Unsuspected distant disease was identified in 8 of 81 patients $(10 \%)$.

\section{Conclusion}

FDG.PET is a non-invasive imaging method, with a high degree of accuracy in differentiating malignant lung tumours from benign lung tumours. FDG.PET is more accurate than CT in the mediastinal staging of NSCLC and more accurate then our conventional staging methods to detect distant metastases. 


\section{Introduction}

Lung cancer is the leading cause of cancer-related death among women and men causing $32 \%$ of all male death and $25 \%$ of all female death in the USA.' In the Netherlands, as in several other developed countries, the incidence is falling in men (1989 male incidence European Standardised Rate (ERS) 108.9 per 100 000 of 88.3 per 100000 in 1997) but is increasing in women (1989 16.9 of 24.3 per 100000 in 1997 ERS). ${ }^{2}$ Despite tremendous research, the overall 5 year survival remains very poor, about $14 \%$ for non small cell lung cancer (NSCLC) and $3 \%$ for small cell lung cancer (SCLC). ${ }^{3}$

Various procedures play an important role in the diagnosis of patients with suspected lung cancer. The exact classification with non-invasive imaging modalities such as chest radiography, computed tomography (CT) and magnetic resonance imaging (MRI) is difficult. These modalities are based on differences in density of tissues and therefore allow good anatomic detail, but the considerable overlap in the characteristics of benign and malignant nodules makes a real differentiation between malignant or benign disease often impossible. ${ }^{4,5}$ Central lung tumours can usually be diagnosed by bronchoscopy. The diagnostic yield ranges from about $70 \%$ to $90 \%$. ${ }^{6}$ For solitary pulmonary nodules (SPNs) the diagnostic yield of bronchoscopy is much lower and ranges from about $20 \%$ to $80 \%$, depending mainly on the tumour size and localisation.? SPNs are defined by their radiographic appearance. The nodule is not greater than 3 to $4 \mathrm{~cm}$ in diameter and surrounded by normal tissue, without radiographic evidence of hillar or mediastinal adenopathy. Lesions not fulfilling these criteria are defined as masses. Most nadules are asymptomatic and $50 \%$ prove to be malignant. "In the presence of negative bronchoscopic findings a transthoracic needle aspiration biopsy (TTP) is frequently indicated. This investigation often gives false negative results and cam be complicated by a pneumothorax. ${ }^{7,10,1 !}$ In 20\%-30\% of patients with a non-diagnostic TTP malignant disease is diagnosed. ${ }^{12}$ If clinical suspicion for malignancy is high despite a negative TTP, a tharacoscopy or even a thoracotomy is indicated for adequate diagnosis and treatment of a SPN. Observation with radiological follow up may not be safe in case of a negative bronchoscopy or even TTP. ${ }^{13}$ It delays diagnosis and treatment when malignancy is present.

Accurate staging for TNM classification is essential in patients with NSCLC as it provides prognostic information and influences treatment. CT of the chest and upper abdomen (including liver and adrenals) is currently viewed as the most important tool for radiological staging of lung cancer. CT is valuable in evaluation of the primary tumour (T-factor). Staging of a $\mathrm{Tl}$ or a $\mathrm{T} 2$ lumour 
depends on the tumour size and is performed well with CT. The accuracy of CT to assess the invasiveness of the fumour in the chest wall (T3) and mediastinum (T4) is not always optimal. CT is also the most commonly used non-invasive staging method in respect of the mediastinal adenopathy ( $N$-factor) but is less accurate than invasive surgical staging. ${ }^{14.16}$ A therapeutic decision could not therefore be based on mediastinal lymph nodes on CT. MRI is equivalent to CT in the detection of mediastinal node metastases and thus inwasive surgical mediastinal staging is still necessary for adequate lymph node staging. ${ }^{4}$

Besides loco-regional evaluation, assessment of metastases in distant organs is mandatory as $40 \%$ of patients with newly diagnosed lung cancer have distant metastases at presentation. "The most common organs involved are brain, liver, adrenal glands, lungs and bones. The role of imaging in the detection of metastases of lung cancer is still controversial. Several studies have indicated that it is not cast-effective to search for distant metastases unless the patient is symptomatic. This is also recommended by the American Thoracic Society (ATS) and European Respiratory Society" ${ }^{18}$, however routine chest CT also includes adrenal glands and liver because this can be done easily at the time of the CT examination of the chest.

Furthermore, the current techniques for diagnosing lung cancer are time consuming based on the sequential approach of the diagnostic process. There is therefore a need for a non-invasive and accurate lechnique to detect locoregional as well as metastatic spread of the malignant process.

Positron emission tomography (PET) using fluorine-18-deoxyglucose (FDG) has the potential to fulfil these requirements. FDG-PET visualises differences in metabolism of tissue. Lung cancer cells have much more intense glucose metabolism than normal cells. FDG, a glucose analogue undergoes the same uptake as glucose but is trapped in the lung cancer cell. The localisation of FDG in the body is visualised by PET. The accumulation of FDG in cancer cells permits differentiation between benign and malignant tissue. FDG.PET provides valuable information about glucose metabolism of lung tumours, mediastinal lymph nodes and of extrathoracic disease.

The purpose of this study is to examine the accuracy and clinical impact of whole body FDG.PET on the detection of malignant disease in pulmonary lesions, especially in SPNs and on the staging of mediastinal lymph nodes and on the detection of distant metastases. 


\section{Patients and methods}

Patients with a suspected tumour on chest $x$-ray were elligible. Patients with insulin-dependent diabetes mellitus were excluded. All patients routinely underwent physical examination, complete blood count and biochemical tests as well as conventional imaging methods including $C T$ scan of the thorax and upper abdomen (including liver and adrenal glands). A bone scan was performed when bone pain or elevated serum alkaline phosphatase or elevated serum calcium was present. AMRI of the brain was performed when the patient had signs or symptoms of central nervous system involvement. In a few patients a MRI of the brain was performed to exclude asymptomatic brain metastases as part of a separate study. In the absence of distant metastases mediastinal sampling was performed, either by mediastinoscopy or thoracotomy, in order to get histological confirmation of mediastinal lymph nodes irrespective of FDGPET. Sites of suspected distant metastases with conventional imaging and/or FDG-PET were evaluated by biopsy if possible, specific imaging or follow up. In the absence of metastases at initial staging patients were followed up during a minimum of 6 months to confirm these findings.

\section{CT of the chest and upper abdomen}

All images were obtained in supine position during full inspiratory breath-hold with a Somatom Plus CT scanner (Siemens, Erlangen, Germany) or a CT Twin CT scanner (Elscint, Haifa, Israel). Scans were obtained with $1.0-\mathrm{cm}$ collimation and $1.0-\mathrm{cm}$ interval from the apices to the adrenals. Acquisition parameters were $140 \mathrm{kV}$ and $165 \mathrm{~mA}$. Images were photographed at lung (level-800 HU; width $1600 \mathrm{HU}$ ) and mediastinal (level $40 \mathrm{HU}$; width $400 \mathrm{HU}$ ) window settings. CT scans were obtained within a maximum of 4 weeks of the FDG-PET scan. All CT-scans were interpreted by an experienced chest radiologist. Image interpretation was performed before surgical staging and without knowledge of the results of other scanning methods. Lymph nodes were considered pathologic if they were $\geq 1 \mathrm{~cm}$ in the longest diameter.

\section{FDG-PET imaging}

Imaging was performed with an ECAT EXACT $922 / 47$ CTI Knoxville Tennessee positron emission tomograph with a field of view of $16.4 \mathrm{~cm}$. All patients were in a fasting state ( $>6$ hours). The concentration of radioactivity in the urinary tract was reduced by forced diuresis $(500 \mathrm{~m} / \mathrm{NaCl}+20 \mathrm{mg}$ furosemide $\mid \mathrm{V})$ or oral 
hydration ( $500 \mathrm{ml}$ tea). The emission scan was started about 60 min after 190 MBq (mean) FDG IV. The scan field covered at least the thorax and abdomen. For measured attenuation correction a fransmission scan of the body was performed before FDG IV in all patients. Acquisition times were $12 \mathrm{~min} / \mathrm{supine}$ position for the emission and transmission scan of the body. After correction for decay, scatter and atfenuation the body scan was reconstructed applying an iterative algorithm (maximum likelihood expectation maximisation; MLEM, 16 steps).

All scans were interpreted independently by a physician experienced in nuclear medicine. Images were analysed by visual interpretation of axial, coronal and sagital slices. They were read as positive or negative for FDG uptake. Scans with and without attenuation correction were available. Mediastinal staging with FDG-PET was considered positive if at least one hotspot was detected. For distant metastases the suspected anatomic localisation was described.

Comparing the histological results (if available) or follow-up imaging, interpretations of CT-scans and FDG-PET were assessed for sensitivity, specificity, positive predictive values (PPV) and negative predictive values (NPV) and accuracy using the standard definitions.

\section{Results}

\section{Primary lung tumour}

91 Patients were included, 61 men and 30 women. Their mean age was 65 years (range 42-85). Histological data are listed in table 5.1. In all 91 patients a bronchoscopy was performed. The pulmonary abnormalities on X-thorax or CT-thorax were divided into 2 groups: 28 SPNs and 63 masses.

Table 5.2 shows the results of the 28 patients with a SPN. In 8 of these 28 patients the diagnosis lung cancer was obtained by bronchoscopy. In 5 patients a TTP was performed: in 1 of these patients NSCLC was diagnosed, in the 4 other patients no malignant cells were detected. Thoracotomy with tumour biopsy however showed malignancy in 3 of these 4 patients. In 12 other patients without a primary diagnosis a thoracotamy was performed: NSCLC was diagnosed in 9 cases and a non-specific inflammatory process in 3 other cases. In the remaining 3 patients the physician decided for longitudinal follow-up and because of disappearance of the radiological abnormalities benign disease was concluded. FDG-PET imaging correctly identified $27(96 \%)$ of the 28 SPNs, as compared with correct diagnosis with bronchoscopy 15 patients (54\%). FDG-PET showed high FDG uptake in all 21 cases with a malignan SPN. In 1 of the 7 
patients with a non-malignant SPN, FDG-PET showed a high uptake: a chronic non-specific inflammation was found by pathologic examination of this lesion.

Table 5.1 Histological findings in SPN and tumour mass in 91 patients.

Histology tumour (SPN)

Large cell

Squamous

Adenocarcinomo

Hiflaminatory process

Benign by follow-up

Histology funour (mass)

$\mathrm{SCLC}$

Lange cell

Squamous

Adenocareinoma

Anlamumatory process

SPN. solitary pulmonary nodule
Number of patients 28

5
8
8
3
4

Number of patients 63

2

23

20

17

1

Table 5.2 Bronchoscopy, FDG-PET and TTP results of diagnosing SPN in 28 pailients.

Voriables (patients)

Brondtoscopy $(28)$

TTP $(5)$

FDG-PET (28)
Paithology non miligniont noulligmant

13

8

3

1.

0

2)
Total

20

8

4

1

6

22

SPN solitary pulmonary nodule

TP: tronsthoratic needle aspiration biopsy

Bronchoscopy showed a sensitivity of $38 \%$, a specificity of $100 \%$, a PPV of $100 \%$ and a NPV of $35 \%$. FDG.PET results compared with the pathology results of the SPNs revealed a sensitivity of $100 \%$, a specificity of $86 \%$, a PPV of $95 \%$ and a NPV of $100 \%$.

The results in the 63 patients with a mass are summarised in table 5.3. In 54 of these patients the diagnosis lung cancer was confirmed by bronchoscopy. In 7 patients a TTP was performed and in 6 of these patients NSCLC was proven. In 
only 3 patients with a suspected pulmonary mass no classifying diagnosis was obtained pre-operatively: in 2 of these patients a SCLC and in 1 of these patients a non-specific inflammatory process was diagnosed during thoracotomy. FDG-PET imaging correctly identified $62(98 \%)$ of the masses as compared with correct diagnosis with bronchoscopy in 55 patients $(87 \%)$. In 61 of 62 patients with a malignant mass, PET showed high FDG uptake. The patient without any uptake had a central lacalised adenocarcinoma of $0.6 \mathrm{~cm}$. The only benign lesion showed no FDG uptake.

Table 5.3 Bronchoscopy, FDG PET and TTP results of diagnosing masses in 63 patients.

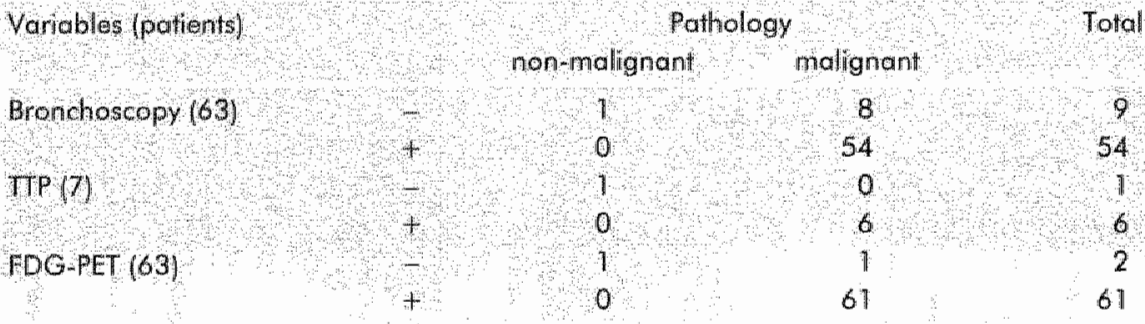

SPN solitary pulmonary nodule

TP trans theratic needle aspination biopsy

Bronchoscopy results compared with the pathology results of the masses revealed a sensitivity of $87 \%$, a specificity of $100 \%$, a PPV of $100 \%$, and a NPV of $13 \%$. FDG-PET results compared with the pathology results of the masses revealed a sensitivity of $98 \%$, a specificity of $100 \%$, a PPV of $100 \%$, and a NPV of $50 \%$.

Of the 91 patients with definitive diagnosis there was 1 false-negative case and I false-positive case with FDG-PET. The overall sensitivity and specificity of FDGPET for defecting malignant lung tumours were $99 \%$ and $88 \%$, respectively. NPV and PPV were $88 \%$ and $99 \%$. The accuracy was $98 \%$.

\section{Mediastinal metastases}

Of the 91 patients, NSCLC was diagnosed in 81. Thirty-one of these 81 patients had distant metastases with only palliative therapeutic options. Mediastinal nodal sampling was performed in 50 patients. In 16 of these patients mediastinal metastases were histologically proved. The results of CT, FDG-PET and histopathological findings of the mediastinum are shown in table 5.4. 
FDG-PET imaging in lung cancer $\mid$

Table 5.4 Results of CT, FDG PET and histopathological staging of mediastinal ymph nodes in 50 patients with resectable $\mathrm{NSCLC}$

\begin{abstract}
Node pathology in 50 patients
\end{abstract}
Not enlarged on CT

PET negative

PET postive

Enlarged an CT

PET negative

PET positive

Total

is number of patients

Bengan
$\mathrm{No}^{*}$

12

3

16

3

34
0

2

3

11

16
12

19

14

50

FDG-PET correctly identified the absence of mediastinal lymph node metastases in 28 of 34 patients with histologically negative lymph nodes. Positive mediastinal lymph nodes were correctly identified by FDG-PET in 13 of 16 patients with histologically positive nodes. In 6 patients FDG-PET was false positive for mediastinal staging. In one of the false positive FDG-PET scans a metastasis in a hilar lymph node was misclassified as a mediastinal lymph node metastasis because of the proximal lacation to the mediastinum: FDG-PET could not distinguish between anatomical localisation of the lymph node (N2 versus N1) in this case. In the other 5 patients anthracotic lesions in lymph nodes were found, possibly contributing to the high FDG uptake. False negative mediastinal findings according to FDG-PET occurred in 3 patients. In 2 of these patients a central lung tumour was present which covered the region of the positive N2 nodes and therefore the N2 nodes were very difficult to discriminate from the lung tumour itself. In the remaining patient a relatively low level of radiotracer was found and histological inspection of these lymph nodes showed only 1 positive node with minimal invasion by malignant cells (minimal N2 disease).

CT correctly identified the absence of mediastinal lymph node metastases in 15 of 34 patients with histologically negative lymph nodes. Positive mediastinal lymph nodes were correctly identified by $\mathrm{CT}$ in 14 of 16 patients with histologically positive nodes.

For diagnosis of the presence or absence of mediastinal nodal disease, CT had a sensitivity of $88 \%$, a specificity of $44 \%$ and an accuracy of $58 \%$. PPV of CT for mediastinal involvement was $42 \%$, and NPV was $88 \%$. FDG-PET had a sensitivity of $81 \%$, a specificity of $82 \%$ and an accuracy of $82 \%$. PPV of FDG-PET for mediastinal involvement was $68 \%$, and NPV was $90 \%$ (table 5.5 ). 
Table 5.5 Results of stoging of the mediastinal lymph nodes with CT and FDG-PET.

\begin{tabular}{|c|c|c|c|c|c|}
\hline Modoly & $\begin{array}{c}\text { Sensilinity } \\
(0) \text { ) }\end{array}$ & $\begin{array}{c}\text { Specificity } \\
\text { (1) }\end{array}$ & $\begin{array}{c}\text { Accuracy } \\
(\%)\end{array}$ & $\begin{array}{l}P P V \\
(\%)\end{array}$ & NPV \\
\hline & $88(14146)$ & $44(15 / 34)$ & $58(29 / 50)$ & $42(14 / 33)$ & $88(15 / 17$ \\
\hline PE & $81(13 / 16)$ & $82(28 / 34)$ & $82(41 / 50)$ & $68(13 / 19)$ & $90(28 / 31)$ \\
\hline
\end{tabular}

\section{Metastases outside the mediastinum}

All 81 patients with NSCLC were staged for distant metastases by conventional imaging methods and by FDG-PET. In 5 patients brain metastases were detected with MRI of the brain (2 were asymptomatic). In 3 of these patients this was the only localisation of metastatic disease outside the medilastinum detected with conventional imaging. Because FDG-PET of the brain was not performed, brain metastases were not included in the comparison FDG.PET/ conventional staging. In case of a suspected hot spot we sought additional confirmation with other radiological investigiations and, if possible, with histology or cytology. Not in all cases could a metastasils be confirmed or excluded but disappearance or unchanged size after a follow-up period of 6 months was considered as a criterion of false positive.

Table 5.6 shows the results of suspected malignant findings outside the mediastinum by conventional staging and FDG-PET. FDG-PET showed 45 hotspots outside the mediastinum in 33 of 81 patients. Thirty-seven hotspots were diagnosed as metastases during follow-up, biopsy or imaging. One hotspot proved to be a colon carcinoma (secondary primary tumour). Seven hotspots proved to be fallse positive: a liver biopsy in a suspected area proved to be benign (cholestasis), a normal sized adienal gland showed no growth on CT during 6 months follow-up, pleural fluid did not contain malignant cells but signs of inflammation and follow-up showed no progression, 2 lesions in the same lobe disappeared and were therefore considered as false positive, 2 abdominal lesions were not seen by additional abdominal CT and colonoscopy. FDG PET correctly identified metastatic disease in 29 of 81 patients. Except for a satellite lesion in one patient with no FDG uptake the lesion had a diameter of $2 \mathrm{~mm}$ all metastases defected with conventional staging were also shown by FDG-PET. 
Table 5.6 Results of CT and FDG PET in the determination of malignant disease outside the mediastinum in 81 patients with NSCLC.

\section{Metastatic sties}

Liver
Bone
Adrenal
Pleural
Nodule same lung lobe
Nodule ather lung lobe
Abdominal
Colon
Supraclavicular

Toial

\begin{tabular}{|c|c|}
\hline TP & $\mathrm{FP}$ \\
\hline 2 & 0 \\
\hline 1 & 0 \\
\hline 2 & 0 \\
\hline 1 & 0 \\
\hline 5 & 1 \\
\hline 3 & 1 \\
\hline 0 & 0 \\
\hline 0 & 0 \\
\hline 1 & 0 \\
\hline 18 & 2 \\
\hline
\end{tabular}

21
FDG PET staging

\begin{tabular}{|c|c|c|c|}
\hline $\mathrm{TP}$ & FP & AN & True \\
\hline 5 & 1 & 0 & 5 \\
\hline 8 & 10 & 0 & 8 \\
\hline 6 & 1 & 0 & 6 \\
\hline 2 & 1 & 0 & 2 \\
\hline 4 & 2 & 1 & 5 \\
\hline 8 & 0 & 0 & 8 \\
\hline 1 & 1 & 0 & 1 \\
\hline 1. & 1 & 0 & 9 \\
\hline 3 & 0 & 0 & 3 \\
\hline & 7 & ] & \\
\hline
\end{tabular}

comfirmation by biopsy, imaging or follow-up

Eight of these 81 patients $(10 \%)$ had no distant metastatic disease with conventional staging. In all 5 patients with brain metastases FDG-PET showed other distant metastases. During follow-up of minimal 6 months no distant metastases were diagnosed in patients without pathologic lesions on FDG-PET.

The sensitivity and specificity of PET for detecting metastatic disease outside the mediastinum were $97 \%$ and $92 \%$ respectively. The PPV and NPV were $88 \%$ and $98 \%$ respectively. The accuracy of FDG-PET was $94 \%$.

\section{Discussion}

This study showed that FDG-PET is an accurate non-invasive imaging test for diagnosis of SPN or larger mass lesions and for slaging of patients with NSCLC in routine dinical practice.

The differentiation between a malignant and a benign lung tumour cannot be made by conventional imaging methods. Currently non-imaging procedures like bronchoscopy, TTP or even thoracolomy are required. In the case of a central tumour there is often endobronchicl pathology visible and the diagnostic yield of bronchoscopy is high. A SPN frequently presents a diagnostic dilemma to the chest physician; bronchoscopy is often nondiagnostic. Our study showed that only $38 \%$ of patients with malignant SPN were diagnosed with bronchoscopy and in more than $50 \%$ of these patients a thoracotomy was necessary to prove a diagnosis. 
FDG PET has been used to address some of the problems of diagnosing of patients with a SPN. Our study showed a high accuracy of $96 \%$ and confirms reports in literature that FDG.PET has a high sensitivity and negative predictive value in evaluating pulmonary nodules for diognosis and treatment options. ${ }^{19-2 *}$ In the study of Lowe the sensitivity was $80 \%$ for nodules less than $1.5 \mathrm{~cm}$ and $96 \%$ when nodules were greater than $1.5 \mathrm{~cm}$.

False-negative results, although rare, may be seen in carcinoid tumours and bronchaalweolar carcinoma which are typically slow growing tumours and may not demonstrate a hypermetabolic state. ${ }^{25,26}$ The negative FDG uptake in a malignant SPN was seen in one patient of our study group with an adenacarcinoma of $6 \mathrm{~mm}$ in size that was oulside the resolution of our PET facility. The spatial resolution of the current generation of PET scanners is 7 to $8 \mathrm{~mm}$.

It is clear that FDG uptake is not specific for malignant tissue and false positive findings can occur in inflammatory conditions such as bacterial pneumonia, active sarcoidosis and infectious granulomas. ${ }^{20.22}$ In our study 1 false positive case was found due to underlying inflammatory pathology.

In NSCLC the preoperative evaluation of the mediastinum for lymph node metastasis is very important for correct staging and in predicting surgical resectability. An important abjective of this study was to determine whether FDGPET allowed accurate staging of mediastinal lymph nodes. FDG-PET clearly demonstrated an advantage over $C T$ in determining the $\mathbb{N}$ status. We found an accuracy of FDG.PET of $82 \%$ in contrast to CT with an accuracy of $58 \%$. In particular PET was more specific $(82 \%)$ with a higher NPV $(90 \%)$ than for CT for mediastinal staging. FDG-PET correctly excluded nodal metastases in 16 of 19 patients with enlarged mediastinal lymph nodes but with histalogical proof of benign lymph nodes. Our results are in line with other well designed studies with sensitivities and specificities of PET reported in the range of $76 \%-100 \%$ and $82 \%-100 \%$, respectively. ${ }^{27.36}$ The moderate accuracy of CT in lymph node staging is explained by the fact that size is a relative criterion; lymph nodes can be enlarged due to other causes and small-sized nodes cam nonetheless harbour metastases.

Despite these goad results false negative and false positive values are possible. in our study these were mainly coused by anatomical vagueness. It was difficult to differentiate between a N1 or N2 localisation and it was also difficult to separate the primary tumour from an adiacent $\mathrm{N} 2$ nodal metastasis. Nonmalignant inflammatory reaction in lacoregional lymph nades was a further reason for false postive FDG uptake. In our study anthracotic lesions in lymph nodes mainly caused this reaction. One case showed no mediastinal FDG uptake despite histolagically proven invasion of 1 Iymph node. Detectability of 
tumour involvement with FGD.PET depends not only on the size of a lesion but also on the concentration of radiotracer; it is likely that a critical mass of metabolically active malignant cells is required for PET diagnosis. ${ }^{37}$ Thus minimal fumour load (minimal N2) and therefore minimal metabolic activity of the fumour is a reason for false negative FDG uptake. It seems however that this false negative result has no influence on treatment because a favourable prognosis can be expected after mediastinal lymph node dissection during lobectomy or pneumonectomy. ${ }^{38.40}$

These results imply that mediastinal sampling is mandatory for patients with FDG.PET positive mediastinum and in patients with a primary tumour adjacent to the mediastinum. Mediastinoscopy is probably not necessary in patients with negative FDG-PET findings of the mediastinum.

FDG-PET has a high accuracy in the detection of distant metastases. Our study demonstrated an accuracy of $94 \%$. There was 1 false negative PET finding but 7 false-positive findings in our study. Unsuspected distant disease was identified in 8 of 81 patients which is within the range of results found in other series. ${ }^{35,41-46}$ Especially the detection of bone metastases in asymptomatic patients and of adrenal metastases is worthy of note but not surprising. Bone scintigraphy is not performed in every patient because of a low yield in NSCLC patients without symptoms or laboratory signs ${ }^{18,47}$ however FDG-PET showed a high incidence of asymptomatic bone metastases. Several other studies have shown a high accuracy of FDG-PET for detecting bone metastases. ${ }^{48,49}$ This study demonstrates that PET is very useful in the evaluation of an adrenal mass but also of malignant adrenals which are normal sized on CT. Other series also found a high sensitivity of FDG.PET in the detection of metastases in adrenal glands. ${ }^{50.51}$ Metastases could be found in up to $12 \%$ in normal sized adrenal glands ${ }^{52,53}$ whilst two-thirds of isolated adrenal masses were found to be an adrenal adenoma. ${ }^{54}$

Our study demonstrated brain metastases in 5 patients and in 3 of them this was a solitary metastasis. These 3 patients were candidates for surgical resection of the primary tumour after stereotactic radiosurgery but FDG-PET found in each patient other distant metastases outside the brain.

The impact on staging and treatment of FDG.PET is high. In 10\% of the patients with formerly a locoregional disease, metastatic disease could be demonstrated which excluded these patients from aggressive treatment. In the 3 patients with a solitary brain metastasis a futile surgical resection of the primary fumaur could be prevented. So in 13 of 81 patients $(16 \%)$ the therapy was changed to a palliative intent. 
The lack of precise anatomical detail is a limitation of FDG-PET. The precise anatomical information on $C T$ can be complementary to the metabolic information images of FDG.PET. The acceptance of FDG-PET as a routine imaging procedure is still limited because of high costs, limited availability and reimbursement restrictions. This situation is rapidly changing because of the spectacular results of FDG-PET in oncology. Results of a randomised clinical trial showed that FDG-PET, employed in addition to conventional staging, could reduce futile operations by $50 \%$. A cost-effectiveness analysis performed in this trial concluded that the additional use of FDG-PET is a cost saving from the clinical and economic perspective..$^{55}$

In conclusion our study demonstrated that the introduction of FDG-PET in the diagnostic work-up of a SPN and staging of NSCLC (in one single examination) is a valuable methodology. FDG-PET can differentiate between benign or malignant lesions and is a valuable method to exclude or to detect mediastinal and distant metastases. 


\section{References}

1. Prager D, CR, Ford J, Figlin Ra. Bronchogrnic carcinoma, in In: Murray JF, Nadel, eds. Textbook of respinatory medicine. Philadelphia: WB Saunders. 2000:1414-48.

2. Lung cancer and mesothelliomo in the Netherlands 1989-1997. Netherlands Cancer Registry. 2000 .

3. American Cancer Sociely. 1998 cancer facts and figures. Allanta: American Cancer Society. 1998.

4. Webb WR, Gatsonis C, Zerhouni EA, Heelan RT, Glazer GM, Francis IR, MoNeil Bj. CT and MR imaging in staging non-small cell bronchagenic carcinoma: repart of the Radiologic Diagnostic Oncology Group. Radiology 1991;178(3):705-13.

5. Erasmus JJ, Connolly JE, McAdams HP, Roggli VL. Solitary pulmonary nodules: Part 1. Morpholagic evaluation for differentiation of benign and malignant lesions. Radiagraphics 2000;20(1):43-58.

6. Arroliga, AC, Mathay RA. The role of branchoscopy in lung cancer. Clin Chest Med $1993 ; 14(1): 87-98$

7. Wallice JM, Deutsch AL. Flexible fiberoptic bronchoscopy and percutaneous needle lung aspiration for evaluating the solitary pulmonary nodule. Chest 1982;81:6):665-71.

8. Khouri NF, Meziane MA, Zerhouni EA, Fishman EK, Siegelman SS. The solitary pulmonary nodule. Assessment, diagnosis, and management. Chest 1987;911(1):128.33.

9. Mack MJ, Hazelrigg SR, Landreneau RJ, Acurf TE. Thoracoscopy for the diagnosis af the indeterminate solitary pulmonary nodule. Ann Thorac Surg 1993;56(4):825-30; discussion $830-2$.

10. Larscheid RC, Thorpe PE, Scott WJ. Percutaneous transthoracic needle aspiration biapsy: a comprehensive review of its current role in the diagnosis and treatment of lung tumors. Chest $1998 ; 114(3): 704-9$.

11. Santambrogio L, Nosotti M, Bellavits $N$, Pavoni G, Radice F, Caputo V. CT-guided fine-needle aspiration cytology of solitary pulmonary nodules: a prospective, randomized study of immediate cytologic evaluation. Chest 1997;1 12(2):423-5.

12. Salazar AM, Westcott JL. The role of transthoracic needle biopsy for the diagnosis and staging of lung cancer. Clin Chest Med 1993;14[1):99.110.

13. Yankelevitz. DF, Henschke $\mathrm{Cl}$. Does 2-year stability imply that pulmonary nodules are benign? AJR Am I Roentgenol 1997; 168(2):325-8.

14. Dillemans B, Deneffe $G$, Verschakelen 1 , Decramer M. Value of computed tomography and mediastinoscopy in preoperative evaluation of mediastinal nodes in non-small call lung cancer. A study of 569 potients. Eur J Cardiothonac Surg 1994:8(1):37-42.

15. Gdeedo A, Schil P, Corthouts B, Van Mieghem F, Var Meerbeeck J, Van Marck E. Prospective evoluation of computed tomagraphy and mediastinoscopy in mediastinal lymph node staging. Eur Respir J 1997,10(7):1547.51.

16. Mcloud TC, Bourgouin PM, Greenberg RW, Kosiulk JP, Templeton PA, Shepard JA, Moore EH, Wain $J C$, Mathisen DV, Grillo HC. Bronchogenic carcinoma: anallysis of staging in the mediastinum with $C T$ by correlative lymph node mapping and sampling. Radiology $1992 ; 182(2): 319-23$

17. Landis SH, Murray $T$, Bolden $S$, Wingo PA. Cancer stlotistics, 1998. CA Cancer I Clin $1998 ; 48111: 6-29$.

18. The American Thoracic Society and The European Respiratory Society. Pretreatmentt evaluation of non-small-cell lung cancer. Am J Respir Crit Care Med 1997;156(1):320-32.

19. Gupla $N$, Gill $H$, Graeber $G$, Bishop $H$, Hurst J, Stephens T. Dymamic positron envission tomography with F-18 fluoradeoxyglucase imaging in differentiation of benign from malignant lung/mediastinal lesions. Chest 1998; 114(4):1105-11.

20. Bury T, Dowlati A, Paulus P, Corhay JL, Benoit T, Kayembe JM, Limet R, Rigo P, Radermecker $M$. Evaluation of the solitary pulmonary nodule by positron emission tomagraphy imaging. Eur Respir $17996 ; 9(3): 410-4$ 
21. Low VJ, Fletcher JW, Gobar L, Lawson M, Kirchner P, Valk P, Koris J, Hubner K, Delbeke D, Heiberg EV, Patz EF, Coleman RE. Prospective investigation of positron emission tomography in lung nodules. J Clin Oncol 1998; 16(3):1075-84.

22. Lee $I_{f}$ Aronchick IM, Alavi A. Accuracy of F.18 fluarodeoxyglucose positron emission tomography for the ewaluation of molignancy in patients presenting with new lung abnormallities: a retrospective review. Ches: 2001;120(6):1791-7.

23. Potz EF Ir, Lowe VI, Hoffman JM, Paine SS, Burrowes P, Coleman RE, Goodman PC. Focal pulmonary abnomalifies: evaluation with F- 18 fluorodeoxyglucose PET scanning. Radiology $1993: 188(2): 487.90$

24. Dewan NA, Gupta NC, Redepenming LS, Phalen Us, Frick MP. Diagnostic efficacy of PET-FDG imaging in solitary pulmonary nodules. Potential role in evaluation and management. Chest $1993 ; 104(4): 997 \cdot 1002$.

25. Erasmus JJ, MCAdams HP, Patz EF Jr, Coleman RE, Ahuja V, Goodman PC. Evaluation of prtmary pulmonary carcinoid tumors using FDG PET. AIR Am J Roentgenol 1998; 70(5):1369. 73.

26. Kim BT, Kim Y, Lee KS, Yoon SB, Cheon EM, Kwon OJ, Rhee CH, Han J, Shin MH. Localized form of bronchioladveolor carcinoma: FDG PET findings. A.JR Am I Roentgenol $1998 ; 170(4), 935-9$

27. Kernstine KH, Stanford W, Mullan BF, Rossi NP, Thompson BH, Bushnell DL, MaLaughlin KA, Kern JA. PET, CT, and MARI with Combidex for mediastinall staging in non-small cell lung carcinoma. Arn Tharac Surg 1999,68(3):1022-8.

28. Vanstemkiste JF, Strooboints SG, De Leyn PR, Dupont PJ, Bagaert J, Maes A, Deneffe GJ; Nackaerts KL, Verschakelen JA, Lerut TE, Mortelmans LA, Demedts MG. Lymph node staging in non-small-cell lung cancer with FDG-PET scan: a prospective study on 690 lymph node stations from 68 patients. J Clin Oncol 1998; $6(6): 2142-9$.

29. Bury T, Palulus P, Dowlati A, Corhay JL, Weber T, Ghaye B, Schaffers J, Limet R, Albert A, Rigo $P$. Radermecker $M$. Staging of the mediastinum; value of positron emissian tomography imaging in non-small cell lung cancer. Eur Respir J 1996,9(10):2560-4.

30. Weng E., Tran L, Rege $\$$, Scfa A, Sadeghi A, Juillard $G$, Mark $R$, Santiago $S$, Brown $C$, Mandelkern M. Accuracy and clinical impact of mediastinal lymph nade staging with FDG-PET imaging in potentially resectable lung cancer. Am J Chin Oncol 2000;23(1):47-52.

31. Steinert HC, Hawser M, Allemann $F$, Engel $H$, Berthold $T$, von Schulthess GK, Weder W. Nonsmail cell lung cancer: nodal staging with FDG PET wersus $C T$ with correlative lymph node mapping and sampling. Radiology 1997;202(2):441-6.

32. Patz EF Jr, Lowe VJ, Goodman PC. Herndon J. Thoracic nodol staging with PET imaging with 18FDO in patsents with bronchogenic carcinoma. Chest 1995;108(6):1617-21.

33. Chin R Jr, Ward R, Keyes JW, Choplin RH, Reed JC, Wallenhaupt S, Hudspeth AS, Haponik EF. Mediastinal staging of non-small-cell lung cancer with positron emission tomography. Am J Respir Crit Core Med 1995; 152(6 P\$ 1):2090.6.

34. Scott WJ, Gobar LS, Terry JD, Dewan NA, Sunderland JJ. Mediastinal lymph node staging of non-small-cell lung cancer: a prospective comparison of computed tomography and positron amission tomography. I Thorac Cardiavasc Surg 1996,111(3):64:2-8.

35. Pieterman RM, van Putten JW, Meuzelaar JJ, Mooyaart EL, Vaalburg W, Koeter GH, Fidler V, Pruim ل, Groen HJ. Preoperative staging of nom-small-cell lung cancer with positron-emission tomography. N Engl I Med 2000;343(4):254-61.

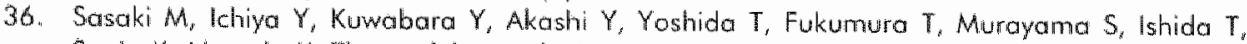
Sugio $K$, Masuda $K$. The usefulness of FDG positron emission tomography for the detection of mediastinal lymph node metastases in patients with nan-small cell lung cancer: a comparative study with X-ray computed tomography. Eur J Nicl Med 1996;23(7):741-7.

37. Wahl RL, Hutchins GD, Buchsbaum DJ, Liebert M, Grossman HB, Fisher 5. 18F-2-deoxy-2. fluoro-D-glucose uptake into human tumar xenografts. Feasibility studies for cancer imaging witli positron-emission tomography. Camcer 1991;67(6): 1544-50. 
38. Vansteenkiste JF, De Leyn PR, Deneffe GJ, Stalpaeri G, Nackaerts KL, Lerut TE, Demedts MG. Surwival and prognostic factors in resected N2 non-small cell lung cancer: a shudy of 140 cases. Leuven Lung Concer Group. Anm Thorac Surg 1997;63(5): 1441-50.

39. Yano T, Fukuyama $Y$, Yokoyama $H_{*}$ Kuninaka $S$, Terazaki $Y$, Uehara $T$, Asoh $H$, Ichinose $Y$. Longuterm survivors with $\mathrm{pN} 2$ non-small cell lung cancer after a complete resection with a systematic mediastinal node dissection. Eur J Cardiothorac Surg 1998; 14(2): 152-5.

40. Martini N, Burt ME, Bains MS, McCormack PM, Rusch WW, Ginsberg RJ. Survival after resection of silage II non-small cell lung cancer. Amn Thorac Surg 1992;54(3):460-5; discussion 466 .

41. Valk PE, Pounds TR, Hopkins DM, Haseman MK, Hofer GA, Greiss HB, Myers RW, Lutrin CL. Staging nan-small cell lung cancer by whole-body positron emission tomographic imaging. Ann Thorac Surg 1995;60(6): 1573-81; discussion 1581-2.

42. Weder W, Schmid RA, Bruchhaus $H$, Hillinger S, von Schulthess GK, Steinert HC. Detection of extrathoracic metastases by positron emission tomography in lung cancer. Ann Thorac Surg $1998,66(3): 886-92$; discussion 892-3.

43. Marom EM, McAdams HP. Erasmus JJ, Goodman PC, Cuhane DK, Coleman RE, Herndan JE, Patz EF Jr. Staging non-small cell llung cancer with whole-body PET. Radiology $1999 ; 212(3): 803-9$.

44. Bury T, Dowlati A, Paulus P, Corhay IL. Hustinx R, Ghaye B, Radermecker M, Rigo P. Wholebody $18 F D G$ positron emission tomography in the staging of nom-small cell lung cancer. Eur Respir J1997;10(11):2529-34.

45. Vansteenkiste JF, Stroobants SG. The role of positron emission tomograply with 18F-fluoro-2. deoxy-D-glucose in respiratory oncology. Eur Respir J 2001;17(4):802-20.

46. Kalff $V$, Hicks RJ, MacManus MP, Binns DS, McKenzie AF, Ware RE, Hogg A, Ball DL. Clinical impact of $(18)$ F fluorodeoxyglucose positron emission fomography in patients with non-smallcell lung cancer: a prospective study, J Clin Oncol 2001; 19(1):111-8.

47. Michel $F$, Soler $M$, Imhof $E$, Perruchoud AP. Initial staging of nom-small cell lung cancer: value of routine radioisolope bone scanning. Thorax 1991;46(7):469-73.

48. Bury T. Barreto A, Daenen F, Barthellemy N, Ghaye B, Rigo P. Fluorine-18 deoxyglucase positron emission tomagraphy for the detection of bone metastases in patients with non-small cell lung cancer. Eur I Nucl Med 1998;25(9): 1244-7.

49. Schirmeister H, Glatting G, Hetzel J, Nussle K, Arslandemir C, Buck AK, Dziuk K, Gabelmann A Reske SN, Hetzel M. Prospective evaluation of the dinical value of planar bone scans, SPECT, and (18)F-labeled NaF PET in newly diagnosed lung cancer. J Nucl Med 2001;42(12): IBOO-4.

50. Erasmus JJ, Patz EF Jr, MCAdams HP, Murray JG, Herndon J, Coleman RE, Goodman PC. Evaluation of adrenal masses in patients with bronchagenic carcinoma using $18 \mathrm{~F}$. fluorodieoxyglucose position emission tomography. ARR Am J Roentgenol 1997; $168(5): 1357$. 60.

51. Mourea S, Mainalfi C, Bazzicalupo L, Panico MR, Imparato $C$, Alfano B, Ziviello M, Salvatore M. Imaging of adrenal fumors using FDG PET: comparison of benign and malignant losions. A.JR Am J Roentgenol 1999;173(1):25-9.

52. Pagani J1. Non-small cell lung carcinoma adrenal metastases. Computed tomography and perculaneous needle biopsy in their diagnosis. Cancer 1984:53(5):1058-60.

53. Salvatierra A, Banamonde C, Llamas 1 M. Cruz F, Lopez. Pujol J. Extrathoracic siaging of bronchogenic carcinoma. Ches 1990;97(5): 1052-8.

54. Oliver TW Jr, Bernardino ME, Miller Jl, Mansour K, Greene D, Davis WA. Hsolated aidrenal masses in ronsmall-cell bronchogenic carcinama, Radiology 1984;153(1):217-8.

55. van Tinferen $H$, Hoekstra OS, Smit EF, van den Bergh $M H$, Schireurs AJ, Stalloert RA, van Velthoven PC, Comans EF, Diepenhorst FW, Verboom P, van Mourik JC, Postrmus. PE, Boers M, Teule GJ. Effectiveness of positron emission tomogrophy in the preaperative assessment of patients with suspected non-small-cell lung cancer: the PLUS multicentre randomised trial. Lancet 2002;359(9315):1388-93. 
82 
Mediastinal staging of lung cancer with 2-(fluorine-18)-

fluoro-2-deoxy-D-glucose

positron emission tomography

and a dual-head coincidence

gamma camera

M Zimny, MMH Hochstenbag, RJS Lamers,

P Reinartz, U Cremerius, GPM ten Velde,

U Buell 


\section{Abstract}

\section{Purpose}

(a) To evoluate mediastinal staging in potients with lung cancer with 2-(fluorine-18)-fluoro-2-deoxy-D-glucose (FDG) using a coincidence gaimma camera (hybrid PET) in comparison with dedicated positron emission tomography (PET) and compuled tomography (CT). (b) To assess the feasibility to determine siondardised uptake values (SUM with hybrid PET.

\section{Patients and Methods}

Forty patients were included in the study Hybrid PET wos perfomed with and without attenuation correction. Data were rebinned with single-slice (SSRB) or Founier rebinning (FORE). The SUVs of primary fumours were calculated with hybrid PET and compared with SUVs determined by dedicated PET.

\section{Results}

Diagnostic accuracy for hybrid with or without attenuation correction was $80 \%$ or $74 \%$ compared with $82 \%$ for dedicated PET and $63 \%$ for CT Attenuation-corrected hybrid PET revealed a higher specificity than CT $(83$ ys. $52 \% ; \mathrm{p}<0.05)$. The SUVs of primary fumours were similar to thase of hybrid PET and dedicated PET with o mean relative difference of $20.8 \pm 16.4 \%$. The FORE improved the agreement of SUVs with a mean relative difference of $13.8 \pm 9.9$ ws. $36.0 \pm 17.9 \%$ for SSRB $(p<0.001)$.

\section{Conclusion}

Hybrid PET with attenuation correction is more specific than $\mathrm{CT}$ for mediastinal staging in patients with lung cancer $(p<0.05)$. It: reveals similar results in comparison with dedicated PET. Caleulation of SUVs with hybrid PET is feasible: 


\section{Introduction}

Lung cancer is the leading cause for cancer-related deaths warldwide as stated by the 1998 WHO report. Histological subtypes include non small cell lung cancer (NSCLC) and the less frequent small cell lung cancer (SCLC). Treatment options for NSCLC depend on tumour size, locoregional lymph node involvement, and distant metostases, and include surgery, chemotherapy, radiotherapy, or a combination. Patients without lymph node involvement (NO) or ipsilateral hilar lymph nodes (NI) and a primary tumour classification less than T4 (stages 1 and II) are candidates for complete surgical resection of the tumour. There is a clear advantage to the use of neoadiuvant chemotherapy prior to surgery for locally advanced resectable disease with ipsilateral mediastinal lymph node involvement (stage IIIA). ${ }^{1,2}$ In locally advanced unresectable disease with contralateral mediastinal or supraclavicular lymph node metastases or tumour classification T4 (stage IIIB) combined-modality therapy with chemotherapy and radiotherapy provides best results. ${ }^{3,4}$ Patients with distant metastases (stage IV) or with malignant pleural effusion are treated with palliative intent with or without cytotoxic drugs; therefore, accurate presurgical staging is of paramount clinical interest to avoid unnecessary thoracotomy. ${ }^{5}$

The standard procedure for non-invasive staging of lymph node metastases is CT; however, size-related CT criferia fail to detect small lymph node metastases and reveal a considerable number of false-positive results in enlarged lymph nodes. ${ }^{6}$

Several reports on the use of 2-[fluorine-18]-fluoro-2-deoxy-D-glucose positron emission tomography (FDG-PET) for mediastinal lymph node staging of NSCLC showed that PET is more accurate for lymph node staging than $\mathrm{CT}^{7.9}$ Moreover, it has been recently shown by a randomised multicenter trial that FDG-PET can prevent unnecessary surgery in a considerable number of patients with NSCLC. ${ }^{10}$ However, the acceptance of FDG.PET as a routine imaging procedure is still low because of high costs, limited availability, and reimbursement restrictions. Recently, dual-headed gamma cameras, capable of both single photon emission CT and PET (henceforth referred to as hybrid PET) have been introduced as an alternative to dedicated PET for the diognosis and staging of lung cancer. ${ }^{11.12}$ However, comparative studies of nodal staging with firstgeneration non-attenuation-corrected hybrid PET vs. dedicated PET revealed a lower sensitivity for hybrid PET, ${ }^{12,13}$ 
The aim of the present sfudy was to compare the diagnostic performance of hybrid PET, dedicaled PET, and CT for mediastinal staging of lung cancer, and to assess the impact of non-uniform attenuation correction.

\section{Patients and methods}

Forty patients (age range $43-79$ years) with proven or suspected lung cancer were prospectively studied. Thirty-seven patients underwent a dedicated PET scan on the same day priar to hybrid PET. Informed consent was obtained from each patient. The study was approved by the local ethics committee.

\section{Study protocol}

All patients were in a fasting state for at least $6 \mathrm{~h}$ controlled by blood glucose levels (median $6.1 \mathrm{mmal} / \mathrm{l}$ ). Two initially hyperglycemic diabetics received regular insulin prior to FDG administration.

Dedicated PET (ECAT EXACT 922/47, Siemens CTI, Knoxville, Tenn.) was started $64 \pm 17$ min after intravenous administration of $229 \pm 40 \mathrm{MBq} F \mathrm{FD}$. Applying a 1-day protocol, hybrid PET (Solus MCD/AC, ADAC Labs, Milpitas, Callif.) followed $66 \pm 22 \mathrm{~min}$ after the start of dedicated PET and $129 \pm 30 \mathrm{~min}$ after administration of FDG.

Hybrid PET was performed using the following parameters for acquisition and reconstruction: emission scanning in coincidence mode covering $180^{\circ}$ with 32 steps with an average acquisition time of $39 \mathrm{~s}$. The detector radius was $30.96 \mathrm{~cm}$ for all studies. The emission scan was followed by $360^{\circ}$ transmission scanning in singles mode with 96 azimuths and an acquisition time of $2 \mathrm{~s}$ each. The acquisition matrix was $128 \times 128$ pixels. The emission data were corrected for decay by adjusting the frame duration of each step. A dual-window technique was used, accepting coincidences between photopeak events and photopeak and Compton events. The preset windows (photopeak $511 \mathrm{keV} \pm 15 \%$, Compton $310 \mathrm{keV} \pm 15 \%$ were adjusted for each scan. The Compton window was set relative to the photopeak window according to the manufacturer guidelines. After single-slice rebinning $(n=14, S S R B)$ or Fourier rebinning ( $n=26$, FORE) into 96 projections, an iterative algorithm fordered subset expectation maximisation, eight subsets, 16 steps) was applied for reconstruction. Addditionally, a non-attenuation corrected data set was reconstructed. The field of view extended from the supraclavicular region to the kidneys corresponding to one bed position with an axial extension of $38.5 \mathrm{~cm}$. For dedicated PET the field of view extended from the base of the skull to the pelvis. The acquisition parameters of seven studies performed with the ECAT 7.0 
acquistion software were as follows: five to six bed positions with an acquisition time of 10-12 min per bed position for emission scanning, preceded by a transmission scan of 12-15 min per bed position with 68-Ge rod sources performed prior to FDG administration. Attenuation correction was performed applying measured attenuation coefficients. Data were transferred to ECAT 6.4 file format and reconstructed using a modified algorithm (maximum likelihoad expectation maximisation; 16 steps) based on the algorithm of Shepp and Vardi. "Thirty studies were performed with the whole-body tool implemented in the standard software ECAT 7.1. Acquisition time was $8 \mathrm{~min}$ for emission and 4 min for transmission. A segmented attenuation map with empirical attenuation coefficients was used for attemuation correction. For iterative reconstruction an ordered subsets expectation maximisation algorithm $(30$ subsets, 1 step) implemented in the standard software was used.

\section{Computed tomography}

All images were obtained in supine position during full inspiratory breath-hold with a Somatom Plus CT scanner (Siemens, Erlangen, Germany) or a CT Twin CT scanner (Elscint, Haifa, israel). Scans were abtained with 1.0-cm collimation and $1.0 \mathrm{~cm}$ interval from the apices to the adrenals. Acquisition parameters were $140 \mathrm{kV}$ and $165 \mathrm{~mA}$. Scanning started $30 \mathrm{~s}$ affer injection of $100 \mathrm{ml}$ iadinated contrast material by a mechanical power injector (injection rate $3 \mathrm{~m} / \mathrm{s}$ ). Images were photographed at lung (level $-800 \mathrm{HU}$, width $1600 \mathrm{HU}$ ) and mediastinal (llevel $40 \mathrm{HU}$, width $400 \mathrm{HU}$ ) window settings. Both PET and CT were performed within a maximum of 4 weeks and a median of 1 week.

\section{Image analysis}

Hybrid PET with and without attenuation correction $(\mathrm{AC} / \mathrm{noAC})$ and dedicated PET were evaluated by one experienced observer $(M . Z$.) without knowledge of clinical data and results of other imaging or staging procedures using a grayscale or colour-scale screen display. The three PET modalities were analysed sequentially starting with non-atternuation corrected hybrid PET followed by attenuation corrected hybrid PET and finally dedicated PET. The data sets were analysed with regard to primary tumour and lymph node metastases. The CT (primary tumour and mediastinum) was interpreted by one experienced radiologist (R.L.). For classification of lymph node metastoses the ATS-LCSG map was applied. ${ }^{15}$

The findings of dedicated PET, hybrid PET, and CT were compared with the final staging obtained from histology after thoracotomy and/or mediastinoscopy, and from follow-up. Ait mediastinoscopy lymph nodes of stations two, four, and seven were sampled. At thoracotomy visible ipsilateral lymph nodes were 
removed. Histopathological analysis of the lymph nodes was performed according to a standard protocol. After formalin fixation and embedding in paraffin, 4-um sections were cut and stained with hematoxylin and eosin.

Contrast- and signal-to-noise ratio (SNR) of the primary tumour and lymph node metastases were assessed with rectangular regions of interest (ROI) of $4 \times 4$ pixels $\left(2.4 \mathrm{~cm}^{2}\right)$ for hybrid PET and $3 \times 3$ pixels $\left(2.3 \mathrm{~cm}^{2}\right)$ for dedicated PET. The ROIs were defined using hybrid PET (AC) and then copied to the corresponding slices of hybrid PET (nOAC). The corresponding slices of dedicated PET were defined with internal landmarks, e.g., mediastinum, heart, or dome of the liver. The lesion ROI was centred over the lesion using the slice with the maximum FDG uptake. The background regions of interest were placed in the non-affected ipsiand contralateral lung $(n=10)$ for the primary tumour or surrounding the mediastinal lesion for lymph node metastases $(n=6)$. Contrast- and signal-tonoise ratio were determined as follows: $C=(L-B) / B$ and $S N R=(L-B) / S$ where $L$ is the lesion ROI value, $B$ the mean value of the background ROls, and $S$ the standard deviation of the background ROIs. ${ }^{16}$ Standardised uptake values (SUM) of primary lesions were calculated for hybrid PET and dedicated PET as described in detail elsewhere. ${ }^{17}$ Briefly, hybrid PET was callibrated applying single-count rate-related calibration factors to measure absolute radioactivity concentrations. The calibration factors were obtained from phantom studies with variable amounts of lotal radioactivity in the field of view. The SUV then represents the regional radioactivity concentration normalised far injected dose and body weight. ${ }^{18}$ Mean relative differences between SUVS determined with hybrid PET and dedicated PET were calculated as fallows ${ }^{19}$ :

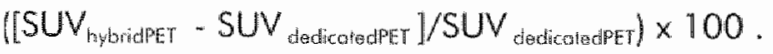

\section{Statistics}

Sensitivity, specificity, negative predictive value, positive predictive value, and accuracy were calculated for hybrid PET (AC/noAC), dedicated PET, and CT. Differences were tested for significance with McNemar's test for sensitivity, specificity, and accuracy or with the chi-square test for positive and negative predictive values. Lesion contrast, SNR, and standardised uptoke values of primary lesions are shown as mean \pm SD. Differences between these parameters for hybrid PET (AC), hybrid PET (noAC), or dedicated PET were compored using the Wilcoxon test for paired samples. Mean relative differences between SUVS determined with dedicated PET and Fourier-rebinned (FORE) hybrid PET or single slice-rebinned (SSRB) hybrid PET were compared using the Mann-Whitney test for unpaired samples. 


\section{Results}

Final histolagy was adenocarcinoma of the lung in 8 patients, squamous cell cancer in 15 patients, large cell cancer in 10 patients, SCLC in 2 patients, and other malignancies in 3 patients; the latter were excluded from further analysis. In 2 patients a malignant tumour was excluded by fallow-up with CT. Median tumour size as assessed by CT $(n=14)$ or histology $(n=21)$ was $3 \mathrm{~cm}$ (range 1 $8 \mathrm{~cm}$ ). Definitive stage of lymph node metastases of patients with a malignant lung tumour by surgical procedures or follow-up was NO in 20 patients, NI in 3 patients, N2 in 10 patients and N3 in 2 patients. The median size of metastatic lymph nodes was $1.5 \mathrm{~cm}$ (range $0.5-5 \mathrm{~cm}$ ). Histopathological analysis revealed microscopic lymph node involvement only in 1 patient.

The primary lesion was detected by $C T$, hybrid PET (AC), hybrid PET (nOAC), and dedicated PET in all patients. The CT was false positive in 2 patients and hybrid PET (noAC) in 1 patient. The CT correctly predicted N-stage in 21 of 35 patients $(60 \%)$, hybrid PET (AC) in 24 of 35 patients $(69 \%$ ), hybrid PET (noAC) in 22 of 35 patients $(63 \%)$, and dedicated PET in 24 of 33 patients (73\%)(table 6.1$)$. With respect to the detection of mediastinal lymph node involvement, i.e., the differentiation of $\mathrm{NO} / \mathrm{N} 1$ and $\mathrm{N} 2 / \mathrm{N} 3, \mathrm{CT}$ was correct in 22 of 35 patients $(63 \%)$, hybrid PET (AC) in 28 of 35 patients (80\%), hybrid PET (noAC) in 26 of 35 patients (74\%), and dedicated PET in 27 of 33 patients (82\%)(table 6.2). The CT understaged 2 patients and overstaged 11 patients, hybrid PET (AC) 3 and 4 patients, hybrid PET (nOAC) 4 and 5 patients and dedicated PET 2 and 4 patients respectively. In comparison with $C T$, hybrid PET (AC), hybrid PET (noAC) and dedicated PET carrectly changed the $N$-stage with respect to mediastinal involvement in 10 of 13 patients, 11 of 13 patients, and 10 of 13 patients, respectively (figure 6.1 and 6.2). Hybrid PET (AC) and dedicated PET revealed concordant results in 32 of 33 patients $(97 \%)$ sfudied with both madalities. In 1 patient hybrid PET missed small, partly necrotic N2 nodes with maximum diameters of $0.9 \mathrm{~cm}$ and $1.4 \mathrm{~cm}$, only the latter identified by dedicated PET (figure 6.3). 
Table 6.1 Results for nodal staging in lung cancer using CT, hybrid PET (AC), hybrid PET (noAC), or dedicaled PET compored wilh definite nodal stage (defN).

\begin{tabular}{|c|c|c|c|c|}
\hline & defliso & deflNi: & defN2 & defl: \\
\hline \multicolumn{5}{|c|}{ Nodial stiage on CT } \\
\hline $\mathrm{NO}$ & 11 & 0 & 1 & 1 \\
\hline $\mathrm{N}$ & 0 & 1 & 0 & 9 \\
\hline $\mathrm{N} / 2$ & 7 & 2 & 8 & 0 \\
\hline $\mathrm{NB}$ & 2 & 0 & 1 & 1 \\
\hline \multicolumn{5}{|c|}{ Nodal stage on hybrid PET AC) } \\
\hline No & 14 & 0 & 3 & 0 \\
\hline N1 & 3 & 2 & 0 & 0 \\
\hline 12 & 1 & 1 & 6 & 0 \\
\hline $\mathrm{N13}$ & 2 & 0 & 1 & 2 \\
\hline \multicolumn{5}{|c|}{ Nodal stage on hybrid PET (noACI } \\
\hline No & 13 & 1 & 4 & 0 \\
\hline N1 & 2 & 2 & 0 & 0 \\
\hline N2 & 2 & 0 & 5 & 0 \\
\hline$N 3$ & 3 & 0 & 1 & 2 \\
\hline \multicolumn{5}{|c|}{ Nodal stage on dedicated PET $(n=33)$} \\
\hline 10 & 14 & 0 & 2 & 0 \\
\hline $\mathrm{N1}$ & 1 & 2 & 0 & 0 \\
\hline N2 & 1 & 1 & 6 & 0 \\
\hline N3 & 2 & 0 & 2 & 2 \\
\hline
\end{tabular}

Table 62 Results of CT, hybrid PET (AC), hybrid PET (noAC), and dedicated PET for mediastinal lymph node staghing ( $\mathrm{NO} / \mathrm{N} 1$ /s $\mathrm{N} 2 / \mathrm{N} 3$ ):

\begin{tabular}{|c|c|c|c|c|c|}
\hline & Sensitivity $(\%)$ & Specificity $(\%)$ & NPV $(\%)$ & PPV $[\%]$ & Accurccy $[\%]$ \\
\hline Cl & 83 & 52 & 86 & 48 & 63 \\
\hline Aybride & 75 & 83 & 86 & 69 & 80 \\
\hline Gybrid PET ( $\mathrm{BoAC})$ & 67 & 78 & 82 & 62 & 74 \\
\hline edcotad PET & 81 & 83 & 90 & 71 & 82 \\
\hline
\end{tabular}

NPV negative predictive value, PPV positive predictive volue.

pero,os 


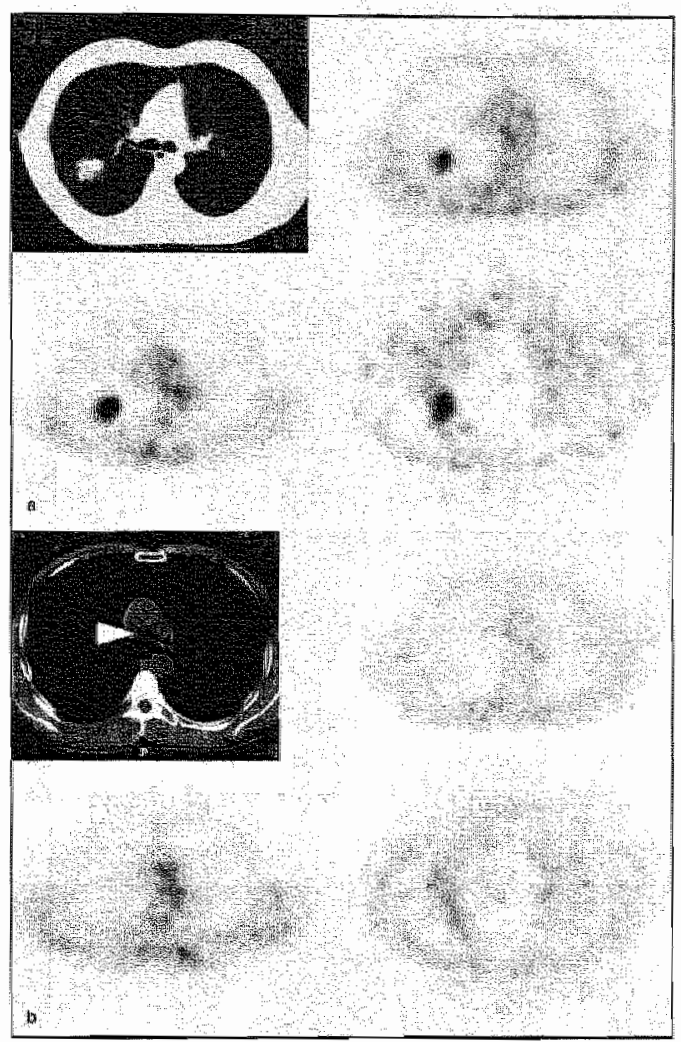

Figure 6.1 A. Adenocarcinomo of the right lung (NOMO). CT (top left), hybrid PET AC/noAC (right top/bottom), and dedicated PET (bottom left) clearly delineate the primary tumour.

B.CT shows an enlarged subcarinal lymph node (left top, arrowhead). Lymph node metastases were excluded by hybrid PET and dedicated PET.

The contrast- and signal-to-noise ratios of the primary tumour and mediastinal or hilar lesions for dedicated PET, hybrid PET (AC) and hybrid PET (noAC) are shown in table 6.3. Contrast-and signal-to-noise ratio of primary lesions were significantly higher for dedicated PET compared with hybrid PET. Hybrid PET (AC) revealed a significantly higher conirast and SNR for primary lesions compared with hybrid PET (noAC). For mediastinal lesions contrast was higher with non-attenuation-corrected hybrid PET whereas signal-to-noise ratio was higher with attenuation-corrected hybrid PET. The SUVS of primary lesions for hybrid PET and dedicated PET are listed in table 6.4. There was a significant correlation of SUVs determined with hybrid PET and SUVs determined with dedicated PET $\{r=0.89 ; p<0.001)$. The mean relative difference was $20.8 \pm 16.4 \%$. In the subgroup of dato sets rebinned with FORE the correlation 
$92 \mid$ Chapter 6

coefficient was 0.94 compared wh 0.85 for SSRB. The mean relative difference significantly decreased from $36.0 \pm 17.9 \%$ for SSRB to $13.8 \pm 9.9 \%$ for FORE $(p<0.001)$.

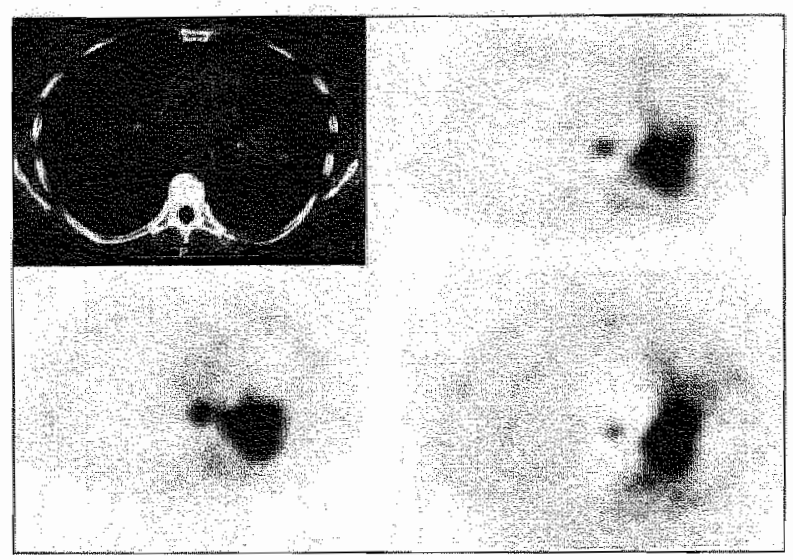

Figure 6.2 Large cell carcinoma with mediastinal lymph node metastases. Lymph node metastases are positive with hybrid PET (AC/noAC) and dedicated PET and negative with CT (for sequence of images see figure 6.1)

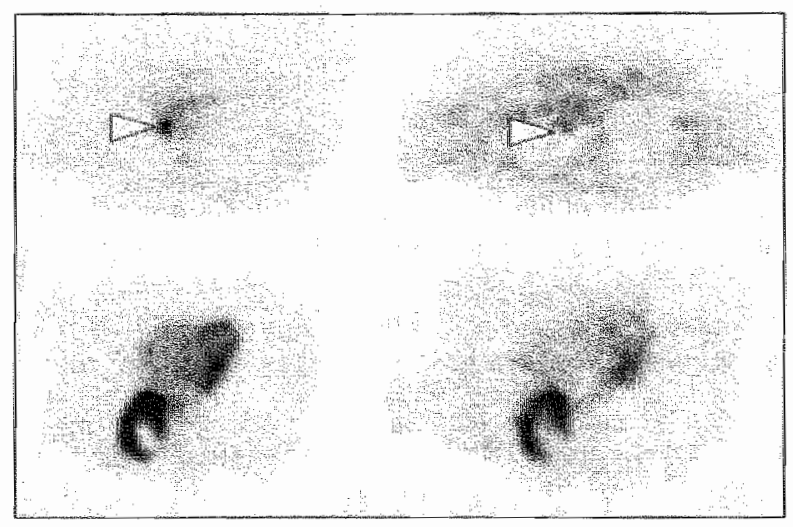

Figure 6.3 Squamous cell carcinoma of the right lung with paratracheal and subcarinall lymph node metastases. Primary fumour with central necrosis shown by dedicated PET (bottom left) and hybrid PET (bottom right). Paratracheal lymph node (arrowhead) depicted by dedicated PET (top left) but missed by hybrid PET (top right) 
Table 6.3 Contrast and signal to noise ratio of primary lung cancer or / ymph node metastases with hybrid PET (AC), hybrid PET (noAC), and dedicated PET.

\begin{tabular}{|c|c|c|c|c|}
\hline & Contrast & Pavalue & SNR & Problue \\
\hline \multicolumn{5}{|c|}{ Primary tumour $(n-33)$} \\
\hline Hybrid PET (AC) & $12.5 \pm 8.4$ & $<0,001$ & $45.4=47$. & $<0,001^{\circ}$ \\
\hline Hybrid PET ( $\cap \circ A C)$ & $62+45$ & $\begin{array}{l}\times 0,0011 \\
\times 0,0015\end{array}$ & $22.9 \pm 169$ & $\begin{array}{l}<0,0010 \\
<0,001\end{array}$ \\
\hline Dedicated PET & $204 \pm 13.8$ & & $86.3+71,6$ & \\
\hline \multicolumn{5}{|c|}{ Lymph node melastioses $(n=14)$} \\
\hline Hybrid PET $(A C)$ & $19=15$ & $<0.05^{\circ}$ & $93+104$ & $\mathrm{n}_{\mathrm{s}} \mathrm{s}$ \\
\hline Hybrid PET ( $N A C$ ) & $30+25$ & $<0.01^{1}$ & $6.6 \pm 5,4$ & $\mathrm{~ns}^{\mathrm{B}}$ \\
\hline Dedicated PET & $3.5 \pm 2.8$ & & $117 \pm 104$ & \\
\hline
\end{tabular}

Gybrid PET (AC) vs hybrid PET (noAC), HHybrid PET (AC) ws, dedicated PET,

Hybrid PET InOAC) Ys. dedicated PET

SNR signal-to-noise ratio, n.s. not significant.

Table 6.4 Standardised uptake values (SUV) of primary lung cancer assessed with hybrid PET or dedicated PET.

SUV hybrid PET \& SUV dedicated PET P value $\mathrm{r}+\triangle \mathrm{H}$

\begin{tabular}{|c|c|c|c|c|c|}
\hline All $(n-32)$ & $101 \pm 6.8$ & $11.1=62$ & 006 & 0.89 & $208+164$ \\
\hline $\operatorname{SSRB}(n=10)$ & $97+77$ & $126+5.8$ & 0.07 & 085 & $360 \pm 179$ \\
\hline FORE $(n=22$ & $103 \pm 6.6$ & $10.5+6.4$ & 0.45 & 094 & $13.8 \pm 99$ \\
\hline
\end{tabular}

Not significant, $p<0.001$

SSRB, single-slice rebinning, FORE, fourier rebinting, ror corlotion coefficient, $\triangle$ \% mean relofiva difference.

\section{Discussion}

The selection of treatment for NSCLC requires exact nodal staging. The noninvasive standard procedure for this purpose is CT however CT has substantial limitations, since the criterion of size alone cannot reliably differentiate benign and malignant enlarged lymph nodes. Arita et all. reported metastases in nonenlarged mediastinal lymph nodes in 14 of 19 patients with NSCLC. ${ }^{20}$ Furthermore the authors observed comparable diameters for benign and malignant lymph nodes. ${ }^{21}$ These limitations were confirmed by a meta-analysis 
of 29 peer-reviewed articles from 1990 to $1998 .{ }^{22}$ Dwamena ef al. showed a mean sensitivity for CT of $60 \%$ with a range of $25-89 \%$. The mean specificity was $77 \%$ with a range of $44-95 \%{ }^{22}$ The results of the present study for CT are within these ranges. Sensitivity and specificity of CT for the detection of mediastinal lymph node involvement were 83 and $52 \%$ respectively. The role of FDG-PET for lymph node staging in lung cancer has been evaluated by numerous studies. $8,22,23$ The meta-analysis of Dwamena ef al. based on 14 comparative studies of CT and FDG-PET revealed a mean sensitivity for FDGPET of $79 \%$ (range $62-97 \%$ ) and specificity of $91 \%$ (range $79-99 \%)^{22}$ These results are based on sfudies with dedicated PET scanners. Stokkel et al. reported comparable results for FDG-PET using hybrid PET." The sensitivity and specificity of this first-generation hybrid PET for lymph node staging were 90 and $97 \%$, compared with 61 and $89 \%$ for CT. Tatsumi al. compared hybrid PET using the same system with a dedicated PET scanner in 23 patients. ${ }^{13}$ They reported a diagmostic accuracy of $87 \%$ for both systems however dedicated PET yielded a higher sensitivity than hybrid PET and the specificity was lower for dedicated PET. Weber et al. showed that hybrid PET failed to detect lymph node metastases that were detected by dedicated PET in 3 of 11 patients. ${ }^{12}$ In the present study we used a modified hybrid PET capable of non-uniform attenuation correction and compared the results af attenuation and non-attenuation-corrected data with CT and dedicated PET. As a trend, hybrid PET with attenuation correction yielded a higher accuracy for mediastinal staging than non-attenuation-corrected hybrid PET ( 80 ws. $74 \%)$. Furthermore, hybrid PET with attenuation correction was more specific than CT $(83$ vs. $52 \% ; p<0.05)$. In comparison with dedicated PET, attenuation-corrected hybrid PET revealed concordant results with respect to mediastinal lymph node metastases in 32 of 33 patients $(97 \%)$.

Coleman ef al. showed in a phantom situation that attenuation correction improves imoge quality of intrapulmonary lesions for dedicated PET and hybrid $\mathrm{PET}_{2}{ }^{16}$. The present study confirms these abservations in a patient situation. Quantitative analysis of image quality revealed a higher signal-to-noise ratio for attenuation-corrected hybrid PET compared with non-attenuation-corrected hybrid PET for primary tumours and, as a trend, also for lymph node metastases; however, in comparison with dedicated PET, the signal-to-noise ratios of primary tumours for attenuation-corrected hybrid PET are sfill lower. Furthermore, non-uniform attenuation correction enables calculation of standardised uptake values with hybrid PET as previously published. ${ }^{17}$ It has been reported by Vansteenkiste et al. that standardised uptake values yielded significant prognostic information in patients with NSCLC. ${ }^{24}$ The present study shows that calculation of SUVs with hybrid PET is feasible for primary lung *umours. Analysis of SUVs determined with dedicated PET or hybrid PET revealed a close correlation ( $r=0.89)$ and similar mean SUVs; however, the comparison 
of SUVS determined with hybrid PET or dedicated PET showed a considerable difference of SUVS on a lesion-to-lesion analysis. The mean relative difference was $20 \%$ with a range of $0.5-70.6 \%$. In the present study two algarithms were used for rebinning. Initially, single-slice rebinning was applied. This algorithm regards all lines of response within the axial acceptance angle as perpendicular to the detector face and thus decreases resolution and contrast for lesions distant to the axis of rotation. ${ }^{25}$ In contrast, Fourier rebinning takes into account the axial angle of the line of response of two coincident events. In the present study, the agreement of SUVs obtained with hybrid PET or dedicated PET was further improved by Fourier rebinning. If Fourier rebinning was applied the mean relative difference was $14 \%$ compared with $36 \%$ for single-slice rebinning $(p<0.001)$.

\section{Limitations}

We acknowledge that the very similar results for mediastinal staging with hybrid PET and dedicated PET are based on a small number of unselected patients with lymph node metastases $(n=15)$; therefore, this study does not allow to transfer the results to a highly selected patient population (e.g., patients who are nodal negative by $\mathrm{CT}$ ).

We are aware that the 1-day protacal with dedicated PET and hybrid PET, performed consecutively after a single administration of FDG, may bias the results with a potential advantage to hybrid PET; however, this approach was used to minimize possible effects of other variables (e.g., tumour metabolism, blood glucose levels) on FDG uptake or SUV calculation and, furthermore, to reduce the radiation burden to the patients.

\section{Conclusion}

Hybrid PET with attenuation carrection is more specific than CT for staging of lymph nodes in patients with lung cancer. It reveals similar results in comparison with dedicated PET. Attenuation correction improves lesion contrast- and signalto-noise ratios. Calculation of SUVs with hybrid PET is feasible and further improved by Fourier rebinning. 


\section{References}

1. Roth JA, Atkinson EN, Fosella F, Komaki R, Bemadefte RM, Putnam JBJ, Lee JS, Dhingra $H_{\text {, Da }}$ Caro $L$. Chasen $M$, Hong WK. Long-tern follow-up of pothents enrolled in a randomized trial comparing perioperative chemotherapy and surgery with surgery allane in resectoble stage IIIA mion-small-cell lung cancer. Lung Cancer 1998;27(1):1-6.

2. Rosell, R, Gomez-Codina J, Camps C, Javier SJ, Maestre I, Padilla J, Canto A, Abad A, Roig J. Preresectional chemotherapy in stage llth nori-small-call lung cancer: a 7 -year assessment of a randomized confralled frial. Lung Cancer $1999 ; 26(1): 7.14$.

3. Souse WT. The role of radiotherapy in non-small cell lung cancer. Chest $1999 ; 116(65)$ : 504 Sin.

4. Dancey $J_{i}$ Le Chevalier T. Non-small cell lung cancer: an overview of current management. Eur J Cancer 1997,33 $51: 52-7$.

5. Bunn PA Ir, Mault J, Kelly K. Adjuvant and neoadiuvant chemotherapy for non-small cell lung cancer: a time for reassessmeni? Chest 2000;117/4 S1):1195-22.

6. American Society of Clinical Oncology. Clinical practice guidelines for the treatment of unresectable norm-small-coll lung concer. J Clin Oncol 1997;15;8):2996-3018.

7. Vansteenkiste JF, Stroobants SG, De Leyn PR, Dupont PI, Verschakelen JA, Nackaerts KL, Mortelmans LA. Mediastinal lymph node staging with FDG.PET scan in patients with potentially operable non-small call lung cancer: a prospective analysis of 50 cases. Leuven Lung Cancer Group. Chest 1997;1 12(6):1480-6.

8. Bury T, Paulus $P_{*}$ Dowlati A, Corhay Jt, Weber T, Ghaye B, Schoffers J, Limet R, Albert A, Rigo $\mathbb{P}$, Redermecker M. Staging of the mediastinum: value of positron emission tomography imaging in non-small cell lung cancer. Eur Respir 1 1996:9(12):2560-4.

9. Chin R Jr, Ward R, Keyes JW, Choplin RH, Reed JC, Wallenhaupt S, Hudspeth AS, Haponik EF. Mediastitial staging of non-small-cell lung cancer with positron emission tomography. Am J Respir Crit Care Med 1995,152(6 Pt 1):2090-6.

10. wan Tinteren $H$, Hoekstra $O S$, Smit EF, van dern Bergh JH, Schreurs AJ, Stallaert RA, van Velthoven PC, Comans EF, Diepenhorst FW, Verboom P, van Mourik JC, Postmus PE, Bioers M, Teule GJ. Effectiveness of positron emission tomography in the preoperative assessment of patients with suspected non-small-cell lung cancer: the PLUS multicentre randomised trial. Lancet 2002;359(9315):1388-93.

11. Stokkel MP, Bakker PF, Heine R, Schlosser NJ, Lammers JW, Rijk PP. Staging of lymph nodes with FDG dual-headed PET in patients with non-small-cell lung cancer. Nud Med Commun $1999.201111: 1001-7$

12. Weber WA, Newerse J, Sklarek J, Ziegler SI, Bantenstein P, King B, Treumam T, Enterrottochar A, Krapf $M$, Haussinger KE, Lichte $H$, Praver HW, Thetter $O$. Schwaiger $M$. Imaging of lung cancer with fluorine-18 fluorodeoxyglucose: comparison of a dual-head gamma camera in coincidence mode with a full-ring positron emission tomography system. Eur I Nuicl Med $1999,26(4): 388-95$

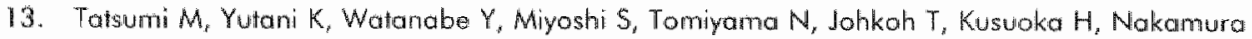
H. Nishimura T. Feasibility of fluoradeoxyglucose dual-head gamma camera coincidence imaging in the evaluation of lung cancer: comparison with FDG PET. J Nud Med 1999;40(4): $566-73$

14. Shepp LA, Vardi $Y$. Maximum likelihood reconstruction for positron emission tomagraphy. IEEE Trans Med maging 1982;2;713-22.

15. Mountain CF, Dresler CM. Regional lymph noda dassification for lung cancer staging. Chest 1997;111(6):1718-23

16. Coleman RE, Laymon CM. Turkingtan TG. FDG imaging of lung nodules: a phantom study comparing SPECT, camera-based PET, and dedicated PET. Radiology 1999; $210(3): 8233.8$.

17. Zimny $M$, Kaisen HJ Wildberger J, Nowak $B$, Cremerius $U_{x}$ Sabri $O$, Buell U. Analysis of FDG uptake with hybrid PET using standardised uptake values. Eur I Nucl Med 2001:28151:586-92. 
18. Strauss LG, Conti PS. The applications of PET in clinical oncolagy. I Nuct Med 1991; $32(4): 623.48$; discussion 649-50.

19. Minn H, Zasadiny KR, Quint LE, Waht RL. Lung cancer: reproducibility of quantitative measurements for evoluating 2-[F-18]-fluoro-2-deoxy-D-glucose uptake at PET. Radiology $1995 ; 19611): 167-73$.

20. Arita T, Kuramitsu $T$, Kawamura M, Matsumoto $T$, Matsunaga $N$, Sugi K, Esato $K$. Bronchogenic carcinoma: incidence of metastases to normal sized lymph modes. Tharax 1995;50(12):1267-9.

21. Arita T, Matsumoto T, Kuramitsu T, Kawamura M, Watsunaga N, Sugi K, Esato Ka ls it possible to differentiate malignant mediastinal nodes from benign nades by size? Reevaluation by $C T$. tronsesophageal echocardiography, and nodal specimen. Chest $7996 ; 110(4): 1004.8$.

22. Dwamena BA, Sonnad 5S, Angobaldo JO, Wahl RL. Metastases from non-small cell lung cancer: mediastinal staging in the 1990s-meta-analytic comparison of PET and CT. Radiology $1999 ; 213(2): 530-6$

23. Weng $E$, Tran L, Rege $S$, Safa $A$, Sadeghi A, Juillard $G$, Mark $R$, Santiago S, Brown $C$, Mandelkern M. Accuracy and clinical impact of mediastinat lymph node staging with FDG.PET imaging in potentially resectable lung cancer. Am J Clin Oncol 2000;23:1):47-52.

24. Vansteenkiste JF, Stroobants SG, Dupont PJ, De Leyn PR, Verbeken EK, Deneffe Gl, Mortelmans LA, Demedis MG. Prognostic importance of the standardized uptake value on (18)F-fluora-2-deoxy-glucase-positran emission tomography scan in non-small-cell lung cancer: An analysis of 125 cases. Leuven Lung Cancer Group. J Clin Oncol $1999 ; 17110): 3201-6$.

25. Zimny M, Nowak B, Kaiser HJ, Sabri O, Buell U. Effects of Fouriel rebinuing an resalution and contrast of hybrid PET. J Nucl Med 2001:42:198-9. 
98 
${ }^{111}$ In-octreotide scintigraphy in staging of small cell lung cancer

MMH Hochstenbag, GAK Heidendal, EFM Wouters, GMP ten Velde

Clin Nud Med 1997;22(12):811-6 
100 Chaster 7

\section{Abstract}

\section{Purpose}

Small cell lung cancer (SCLC) fumours have neuroendocrime features. In vitro and yivo studies have demonstrated that $50 \%$. $75 \%$ of SCLC fumours express receptors for somatostatin. This might enable in vivo localisation of the primary fumour and its metastases by using scintigraphy with a radiolabelled somatostatin analogue, such as octreotide. The efficacy of scanning with 1"In labelled octreotide foctreotide scanl was studied in the staging of SCLC patients and compared with the results of conventional staging fliver $\mathrm{ECHO}$, bone scintigraphy, magnetic resanance imaging (MRI) of the brain and of the spine and pelvis).

Patients and Methods

Mmaging was performed in 29 patients witth histologically confirmed SCLC at 4,24 and $48 \mathrm{~h}$ after intravenous injection of $185 \mathrm{MBg}$ "/n-octreotide.

\section{Results}

In 24 out of 29 patients the primary fumour was visualised. In these 24 patients 26 metastases were demonstrated with conventional staging of which only 9 were visualised with octreotide scan. Octreotide scan showed 2 metastases in the broin, not visualised by MRI In the other 5 patients 5 metastases were demonstrated with conventional staging. Only 2 of these were detected with octreotide scan. However octreotide scan did show a further metastasis in the brain not visualised by MRI.

\section{Conclusion}

Octreotide scan has a limited use in the detection of SCLC metastases compared to conventional staging. If might have some specific value in the detection of brain involvement in patients with limited disease (LD). 


\section{Introduction}

Small cell lung cancer (SCLC) is an aggressive neoplasm that accounts for about $25 \%$ of all lung cancers. The prognosis is poor because it tends to spread rapidly to the regional lymph nodes, bone marrow, liver, central nervous system and some of the endocrine glands. The median survival for patients with limited disease $(L D)$ is 16 months with 5 -year survival being achieved in $7 \%$ of all patients. For patients with extensive disease (ED) the median survival time is 9 months with a 5 -year survival rate less than $1 \%$. Therefore adequate staging is valuable as a prognostic indicator. ${ }^{1.2}$ Staging can also have influence on the management of patients.

The sites of the primary tumour and metastases are usually well detected with conventional staging procedures such as chest radiography, ultrasound, bone scintigraphy, CT and more recently magnetic resonance imaging (MRI). It would, however, be very convenient and probably cheaper if the primary tumour as well as possible metastases could be detected in the same procedure. Somatostatin receptor scintigraphy has been developed recently and it was thought that by this procedure the primary tumour as well as distant metastases could be visualised simultaneously in somatostatin receptor positive SCLC patients.

Somatostatin is a peptide hormone consisting of 14 amino acids and is synthesised in the nervous system, the gastrointestinal tract (pancreas, stomach and intestine), salivary glands and thyroid. If acts as a hormone releaseinhibitory factor, neuromodulator, cell growth inhibitory factor and immunomodulator. 3,4 Somatostatin receptors are present in so-called somatostatin target tissues ${ }^{5}$ but also cells of other tissues may possess these recepiors, such as lymphocytes and many tumour cells of neuroendocrine origin. ${ }^{5.8}$ To date, five subtypes of human somatostatin receptors have been identified on the cell membrane."

It is well known that SCLC tumours have neuroendocrine features ${ }^{10.12}$ and in vitro and in vivo studies have demonstrated that $50-75 \%$ of these tumours express receptors for somatostatin., 5,13.18 The effective plasma half-life of somatostatin itself is very short (2-5 min), which makes it useless for therapeutic or diagnostic procedures, however actreotide, a potenf somatostatin analogue, has a high metabolic stability and prolanged duration of action. ${ }^{19.20} 111 \mathrm{ln}$ labelled octreotide has been shown to bind to somatostatin receptors in vivo in both malignant and non-malignant tissue. Therefore it has been proposed for the detection and lacalisation of SCLC tumours and metastases. ${ }^{21}$ The results of several previous studies are conflicting. While the earliest studies were very encouraging, detecting SCLC tumours and metastases in $86.100 \%$ of patients, 
later reported data were more disappointing. In these siudies the "In-actreotide scintigraphy (octreotide scan) missed a rather large number of metastases and even the primary tumour. ${ }^{21.26}$ Therefore, to further the discussion of the validity of this method, we analysed the efficacy of octreotide scan in 29 patients for the detection and localisation of the primary fumour and metastases of SCLC and its contribution in the staging of this disease and compared this with conventional staging procedures.

\section{Patients and methods}

Twenty-nine patients with histologically confirmed SCLC were evaluated 16 women and 23 men). The patients ranged in age from 44 to 79 years (median 64 years). All patients were staged for LD or ED. This staging procedure included blood chemistry, CT-thorax, liver ECHO, bone scintigraphy and MRI of thoracic and lumbar spine, pelvis and brain. MRI of the brain was performed before and after gadolinium-DTPA $0.1 \mathrm{mmol} / \mathrm{kg}$. In two patients CT-brain was performed instead of MRI.

LD was defined as a tumoral process involving only one hemithorax and its regional lymph nodes including the ipsilateral mediastinal, the ipsilateral supraclavicular and the contralateral mediastinal lymph nodes. All other sites of metastases were considered $\mathrm{ED}$. $^{2}$

Scintigraphy was performed after the administration of an intravenous bolus injection of $185 \mathrm{MBq}$ "'In-octreotide (Mallinckrodt Medical, The Netherlands). A laxative was administered to clear the bowel a day before the octreotide scanning. In 4 patients we studied the "'In-actreotide biodistribution after 4 and 24 hours with planar images of the thorax (anterior and posterior view), pelvis and abdomen (anterior and posterior view). We used the imaging after 24 hours as standard. In all patients images of the thorax, pelvis, abdomen and head were obtained after 24 hours. The planar images were followed (also after 24 hours) by single photon emission computerised tomography (SPECT) of the thorax and abdamen. SPECT has a better sensitivity and resolution than planar imaging for scans of the thorax and abdomen. This is a result of the attenuate correction of SPECT and its ability to remove the contribution from underlying and overlying organs (particularly valuable for detecting liver metastases). ${ }^{27}$ In 9 patients SPECT of the abdomen also was performed after 48 hours because the 24-hour images were considered ambiguous. SPECT of the head also was performed. SPECT permits better anatomic delineation in the head than planar imaging and therefore a better differentiation between a metastasis of the skull and a brain metastasis. Because the total time for SPECT of the thorax, abdomen and head was considered prohibitive SPECT of the head was 
performed in only 4 patients. After image reconsiruction, frontal, sagittal and transwerse slices were obtained (figure 7.1 ).

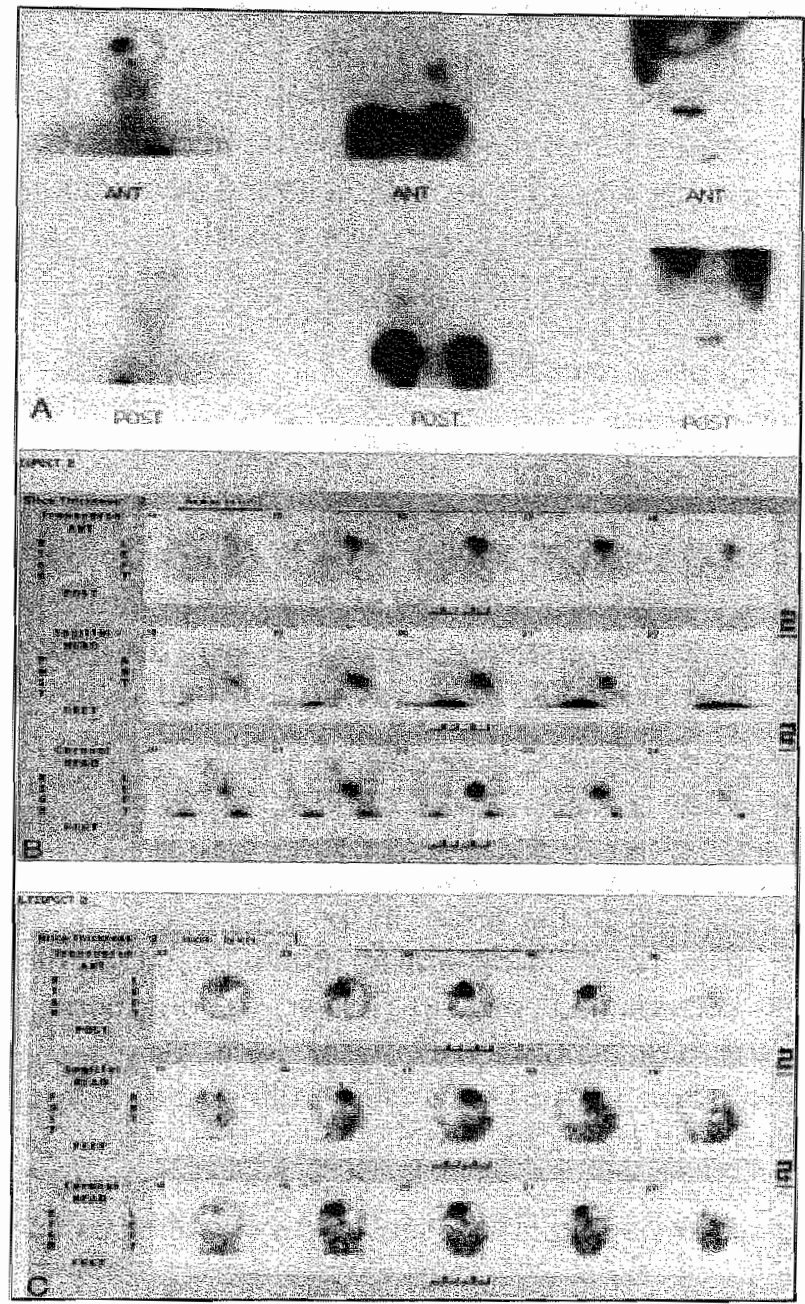

Figure 7.1 A. Planar "In-octreotide scintigraphy at 24 hours. Note "In-octreatide uptake in the lung tumour and brain metastasis. Normal "In-actreotide uptake is present in the liver, spleen, bowel, kidneys, and bladder.

B. SPECT "In-octreotide scintigraphy of the thorax at 24 hours shows the lung fumaur on the left anterior side.

C. Twenty-four hour SPECT 1 "In-octreotide scintigraphy of the head shows better delineation of the brain metastasis than was seen on planar imaging. 
Imaging was performed with a double-head, large-field-of-view gammacamera (Multi-SPECT-II-Siemens) fitted with medium-energy parallel-hole collimators. Two energy peaks of ${ }^{11} \mathrm{In}, 173 \mathrm{keV}$ and $247 \mathrm{keV}$, were used by centering the pulse height analyser spectrameter around those peaks with a $15 \%$ window width. Each planar view of thorax and abdomen was composed by the collection of $500 \mathrm{k}$ counts. Each planar view of the head was composed by the collection of $300 \mathrm{k}$ counts. Digital data were collected by a computer (ICON-APSiemensi from a $128 \times 128$ matrix. Ninery wiews, each of 45 seconds duration were obtained for the reconstruction of the SPECT images. The scintigraphic images were analysed by 2 nuclear medicine specialists who had no knowledge of the outcome of the other investigations.

\section{Results}

There were no side effects seen after the administration of ${ }^{11} / \mathrm{n}$-octreotide. No difference in uptake was seen between 4 and 24 hours. The primary fumour was visualised in 24 of 29 patients (83\%). In these 24 patients, 26 metastases (table 7.1) were demonstrated with conventional staging (7 liver, 12 bone/bone marrow and 7 brain). Of these 26 metastases only 9 (35\%) were visualised ( 3 liver, 3 bone/bone marrow and 3 brain) by octreotide scanning (figure 7.2). Otherwise, the actreotide scan of two patients showed two brain lesions, which were not visualised by MRI of the brain. In the 5 patients in whom the primary tumour did not take up "1"n-octreotide (table 7.2), 5 metastases were demonstrated with conventional staging (1 liver, 2 bone/bone marrow and 2 brain) of which 2 (brain) of these metastases were visualised with octreotide scan. A further metastasis was demonstrated in the brain with octreotide scan, which was not found with MRI of the brain.

With conventional staging 8 patients were classified as LD and 21 as ED. With only the octreotide scan staging, 18 patients were classified as LD and 11 as ED (table 7.3).

Table 71 Sites and numbers of metastases in 24 patients with octreatide scan positive SCLC tumours.

sile of metostases

liver

bone/bong marrow

brain conventional staging

7

12

7 octreotide scan staging

2. metostases detected only with octreotide scan 
Table 7.2 Sites and numbers of metastases in 5 patients with octreotide scan negative SCLC tumours.

site of metastoses

liver

bone/bone marrow

brain conventional staging

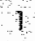

2

2 ocheotida sican staging

(n)

0

$2+8$

I": metastasis detected only with actreoticle scon
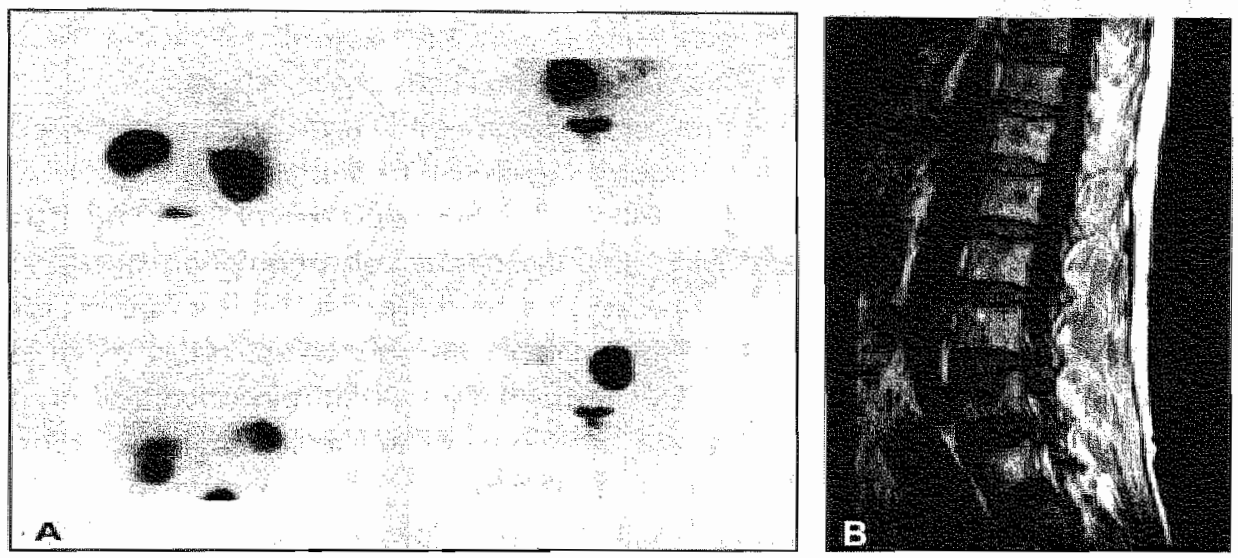

Figure 7.2 A. Planar ${ }^{111}$ In-octreotide scintigraphy in the posterior and anterior positions of a patient with SCLC of the right lung. No metastases were seen.

B. MRI of the spine in the same patient showed dark patchy bone marrow metastases on Tl-weighted spin echo images.

Table 7.3 Staging of SCLC

Stage

$\mathrm{LD}$

E

$$
\begin{gathered}
\text { conventional } \\
\text { sloging }
\end{gathered}
$$

8

21 octreolide scan

slaging

18

11

LD: limited disecuse, ED: exfensive disease 


\section{Discussion}

In this study we confirmed that SCLC fumours and their metastases can indeed be visualised affer injection of ${ }^{111}$ In-actreotide. In a total of 29 patients with SCLC, the primary tumour was demonstrated in 24 patients $(83 \%)$ but only 11 of the 31 (35\%) known metastases were visuallised by this technique. However in 3 pattients octreotide scan demonstrated metastases in the brain not found with conventional staging. Furthermore the observation that in 5 patients no primary tumour was demonstrated, whereas 3 metastases were still visualised, suggests that a negative scan for the primary tumour is not necessarily predictive for a negative outcome regarding the detection of metastases.

Failure to visualise primary SCLC tumours with octreotide scan can be explained by different factors. First, different somatostatin receptor subtypes could exist in one tumour, expressing high or low affinity for the radioligand. . Second it is possible that SCLC is composed of a heterogeneous cell population and that many cells do not express specific somatostatin binding sites, as is assumed for necrotic tumour cells. ${ }^{28}$. This heterogeneity of the primary tumour and variable expression of somatostatin receptors might affect the uptake and visualisation of radiolabelled octreotide. This also could explain why metastases could be found in a patient while the primary tumour was not seen.

The detection rate of metastases in this study is very low, which is in accordance with other reports in which only $50 \%$ of the metastases were detected in patients with ED using the actreotide scan. ${ }^{22,23}$ This rate of detection is inferior in comparison with other staging facilities. This low rate of detection of metastases can be explained by different factors. First, the primary tumour can have receptors for 111 In-actreotide but the metastases may have different types of receptors, may not have the same receptor density for adequate visualisation or may have no receptors at all. ${ }^{15,16}$. Second, it is possible that the primary SCLC tumour itself does not express somatostatin binding sites but that cells involved in the inflammatory response (such as activaled lymphocytes) around the fumour express somatostatin receptors and only these inflammatory cells are visualised by the radiolabelled actreotide. ${ }^{6,7}$ From this perspective, metastases could not be visualised when they are not surrounded by inflammatary cells. Third, site and size of metastatic lesions can affect the scintigraphic result. In this way liver metastases are difficult to visualise because even normal liver cells accumulate the radiopharmaceutical, resulting in a low target to background ratio. 22,23

The use of SPECT might enhance the imaging of lesions especially in the liver and the abdominal region. However in the present study planar and SPECT 
imaging show too much liver activity after 24 and even after 48 hours in order to reliably detect solid lesions.

In addition to a low sensitivity of the octreotide scan in SCLC even the specificity is hampered because octreotide scan cannot differentiate SCLC tumours from other primary lung tumours. Non-small-cell lung cancer fumours as well as pulmonary inflammation can give positive images. ${ }^{7,21,22,25}$ The non-specific uptake of radioactivity in the spleen, kideys, urinary tract, gastrointestinal tract, pituitary gland and thyroid gland can further compromise the interpretation of this procedure.

The detection of unknown lesions is important for the evaluation of the extent of the disease. In this study actreotide scan detected 3 unexpected brain lesions. There is some disagreement in the literature about brain metastases detected with octreotide scan in SCLC. It is believed that "IIIn-octreotide cannot sufficiently pass the blood brain barrier to make visualisation of tumour cells possible. ${ }^{22}$ In at least in 2 patients with octreotide positive brain processes, the presence of malignant cells was proven or could be suspected by sterotaxic biopsy and by therapy response after chemotherapy. It can be hypothesised that in malignant diseases such as SCLC the blood-brain barrier could be disrupted so that "In-octreotide can pass the blood-brain barrier sufficiently making visualisation of brain metastases possible.

The brain metastases only found with the actreotide scan in the present study had no impact on the final staging because these patients already presented bone marrow and liver metastases.

In conclusion, this study demonstrates that octreotide scan is of limited value in the detection of SCLC metastases compared to conventional staging. Conventional staging will not be replaced by octreatide scan. Octreotide scan could be of possible value for the assessment of brain involvement in patients who are otherwise diagnosed as LD. 


\section{References}

1. Honsen HH, Dombernowsky P, Hirsch FR. Staging procedures and proginostic fieatures in small cell anaplastic bronchogenic carcinoma. Semin Oncol 1978,5/3:280-7.

2. Minna JD, Harvey $P$, Glatstein EJ. Cancer of the lung, in Cancer principles and proctice of oncology. 1989.

3. Reichlin S. Somatostatin. N Engl J Med 1983;309(24):1495-501.

4. Lamberts SW, Krenning EP, Reubi JC. The role of somotostatin and its analogs in the diagnosis and treatment of tumors. Endocr Rev 1991; 12(4):450-82.

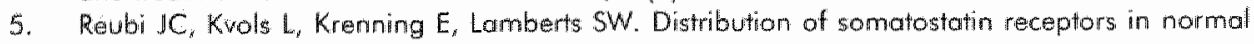
and tumor tissue. Metabolism 1990,39(9 52):78-81.

6. Nakamura H, Koike T, Hiruma K, Sato T, Tomioka H, Yoshida S. Identification of lymphoid call lines bearing receptors for somalostatin. Immunalogy $1987 ; 62(4): 655-8$.

7. Sreedharan SP, Kodama KT, Peterson KE, Goetzl EJ. Distinct subsets of somatostatin receptors on culured hiuman lymphocytes. J Biol Chem $1989 ; 264(2): 949-52$.

8. Reubi JC, Maur $R$, von Werder K, Torhorst J, KJin JG, Lamberts SW. Sometosiatin receptors. in human endocrine fumors. Cancer Res 1987;47(2):551-8.

9. Yamada Y, Kagimoto S, Kubola A, Yasuda K, Masuda K, Someya Y, lhara Y, Li Q, Imura H, Seino $S$, et al. Cloning, functional expression and pharmacological characterization of a fourth (TSSTR4) and a fitth (hSSTR5) human somatostatin receptor subtype. Biochem Biophys Res Commun $1993 ; 19512): 844-52$.

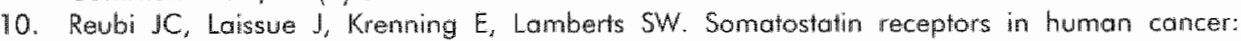
incidence, characteristics, functional correllates and clinical implications. I Steroid Biochem Mol Bial $1992 ; 43(1-3): 27-35$.

11. Sidhu GS. The endodermal origin of digestive and respiratory iract APUD cells. Histopathologic evidence and a review of the literature. Am J Pathol 1979;96(1):5-20.

12. Baylin SB, Jackson RD, Goodwin G, Gazdar AF. Neuroendacrine-related biochemistry in the spectrum of human lung cancers. Exp Lung Res 1982;3(3-4):209-23.

13. Reubi JC, Waser B, Sheppard M, Macaulay V. Somatostatin receptors are present in small-cell but not in non-small-cell primary lung carcinomas: relationship to EGF-receptors. Int J Cancer $1990,45(2): 269: 74$.

14. Taylor JE, Coy DH, Moreau JP. High affinity binding of [1251-Tyr] I] somatastatin-14 to human small cell lung carcinoma (NCl-H69). Life Sci 1988;43(5):421-7.

15. Sagman U, Mullen JB, Kovacs K, Kerbel $R_{n}$ Ginsiberg R, Reubi JC. Identification of samatastatin receptors in human small cell lung carcinama. Concer 1990;66(10):2129-33.

16. Biogden AE, Taylor JE, Moreau JP, Coy DH, LePage D. Response of human lung tumor xenogralts to treatment with a somatostation analogue (Somatuline). Cancer Res $1990 ; 50(14): 4360-5$.

17. Reubi JC, Kvols $L_{\text {, Krenning }} E_{\text {, Lamberts }} \mathrm{SW}$, In vitro and in vivo derection of somatostatin receptors in human malignant tissues. Acta Oncol 1991;30(4):463-8.

18. Macaulay VM, Smith IE. Everard MJ, Teale JD, Reubi JC, Millar JL. Experimental and clinical situdies with somatostatin analogue actreotide in small cell lung cancer. Br J Cancer $1991: 64(3): 451-6$.

19. Marbach P, Briner U, Lemaire M, Schweitzer A Terasaki T. From somatostatin to sandostatin: pharmacodynamics and pharmaco-kinelics. Meltabolism 1992:41(9 \$2):7-10.

20. Bakker WH, ot al. [ In-DTPA-D.Phe]]-actreotide, a potential radiopharmaceutical for imaging of somatostatin receptor-positive tumors: synthesis, radiolabeling and in vitro validation. Life Sei 1991;49(22):1583-91.

21. Krenning EP, Kwekkeboom DJ, Bokker WH, Breeman WA, Kooil PP, Oei HY, van Hagen M, Postema PT, de Jong M, Reubi JC, et al Somotostatin receptor scintigraphy with [" "In-DTPA.D. Phe1]- and [1231-Tyr3]-octreotide: the Rotterdam experience with more than 1000 patients. Eur I Nucl Med 1993;20(8):716-31. 
22. Kirsch CM, yon Pawel $d_{s}$ Grau I, Tatsch K. Indium- 111 pentetreotide in the diagnostic work-up of patients with bronchogenic carcinoma. Eur J Nucl Med 1994;21(12):1318-25.

23. O"Byrne KJ, Ennis JT, Freyne PJ, Clancy LU, Prichord JS, Carney DN. Scintigraphic imaging of simall-cell lung cancer with ["inlpentetreotide, a radiolabelled somatastatin analogue. $\mathrm{Br} J$ Cancer 1994:69(4):762-6.

24. Maini $C_{L}$, Tofani A, Venturo I, Pigorini F, Sciuto R, Semprebene A, Boni S, Giunta S, Lopez Mh. Somatostatin receplor imaging in small cell lung cancer using $11 / \mathrm{m}$-DTPA-octreotide: a preliminary study. Nuel Med Commun 1993; 14(11):962-8.

25. Kwekkeboom DJ, Kho GS, Lamberts SW, Reubi JC, Laissue JA, Krenning EP. The valwe of octreotide scinfigraphy in patients with lung cancer. Eur J Nucl Med 1994:21110):1106-13.

26. Berenger $N$, Moretti $J L$, Boaziz $C$, Vigneron $N$, Morere IF, Breau JL. Somatostatin receptor imaging in small cell lung cancer. Eur J Concer 1996;32A(B):1429-31.

27. Englisch RJ, Brown SE. Single photon emission computerised homography, 1988, New York: Society of Nuclear Medicine.

28. Kwekkeboam DJ, Krenning EP, Bakker WH, Oei HY, Splinter TA, Kho GS, Lamberts SW. Radioiodinated somatostatin analog scintigraphy in small-cell lung cancer. I Nucl Med $1991 ; 32110): 1845-8$. 
General discussion and summary 
112 Chopter 
Surgical excision is the oldest and most evaluated therapeutic modality for the treatment of lung cancer however during the past decades the limitations of surgical therapy became clear as this technique is only effective in the area of the primary fumour or regional lymphatics and ignore the neoplasm outside the operative field. It therefore became important to identify and to exclude from primary surgical therapy those patients who would not benefit from attempts at resection. Staging systems that organise information about local and distant disease into categories of prognostic and therapeutic importance became useful in planning and evaluating the efficacy of therapy. The TNM system, classifying disease according to characteristics of $T$ (primary tumour), $N$ (regional lymph nodes), and $M$ (distant metastases) and then defining stage on the basis of the TNM patterns has become routine and has been applied in daily clinical practice for treatment planning of lung cancer patients.

The TNM system is exclusively based on the anatomic extent of the tumour, using state of the art imaging techniques in oncological practice. Sophisticated imaging facilities certainly contribute to a better anatomic delineation of the tumour process and therefore to a more optimal selection of candidates for primary surgical therapy but one may question the validity of such a staging system for patient stratification and outcome evaluation of lung cancer when if does not incorporate a clear algorithm of procedures to be applied or quantify the diagnostic yield of these procedures.

Another important objective of the TNM staging system is the improved communication between clinics and cancer groups, for instance comparing therapeutic interventions in defined groups of patients. There are, however, still problems and controversies about the staging. A discrepancy is seen in the clinical and pathological staging and variable results of survival data are found. The stage specific survival data are also disappointing. For example the 5 years survival of surgically treated patients with stage I NSCLC is only $65 \%$. Historical data demonstrated that in patients who died within 30 days of a "curative" surgical resection of lung cancer persistent tumour tissue is present in $35 \%$ of those patients." The current staging method is not sensitive enough to detect all tumour at the time of diagnosis while it has to be realised that lung cancer, even at initial diagnosis, is frequently a disseminated disease. It is therefore desirable to search for more effective staging methods, to better discriminate between those patients with potentially operable disease and those where detectable distant metastases preclude surgical therapy, thus improving decision making in lung cancer patients in general.

Besides these limitations of the TNM staging system other discussions concern the definitions used in the current system, which is the second major revision of this system since its development in 1974. ${ }^{2}$ The definitions of $T, N$ and $M$ are more or less defined comparing historical patient groups for survival but this 
seems arbitrary and largely based on consensus rather than on powerful statistical evidence. For instance in the present staging a distinction in the prognosis is made between $T 1$ (a tumour smaller or equal to $3 \mathrm{~cm}$ in diameter) and $T 2$ (a lumour greater than $3 \mathrm{~cm}$ ) tumour. This seems arbitrary as a survival difference can be found between several sizes of tumours. ${ }^{3.5}$ Also this TI stage does not differentiate for very small tumours discovered by screening which are supposed to have a better survival. So it is still questionable whether or not a tumour diameter of $3 \mathrm{~cm}$ is the optimal cut off point in the decision making process of the indiwidual lung cancer patient. Several authors have suggested that the biological characteristics of the tumour are prabably more important for prognosis than assessment of the diameter of the fumour at the time of diagnosis. ${ }^{6.8}$

The definitions of T3 versus T4 are similarly based on anatomical findings. Tumours classified as T3 are neoplasms that have grown beyond the lung parenchyma to involve structures still amenable to resection (invasion of the thorax, mediastinal pleura or the pericardium, diaphragm, superior sulcus or endobronchial tumours located within $2 \mathrm{~cm}$ of the carinal. These currently applied tumour characteristics are not supported by epidemiolagical data. Indeed, the extent of tumour invasion in the chest wall is a determinant factor of pragnosis in NSCLC patients: minimal parietal pleural invasion has a more favourable prognosis than muscular and bone invasion. 9.10 Furthermore mediastinal pleural or pericardial invasion, invasion of the diaphragm or superior sulcus tumours have a different prognosis compared to lesions with thorax wall invasion. 11.14

T4 defines those tumours with extensive extrapulmonary extension, usually precluding curative or camplete resection (invasion in great vessels, main carina, trachea, oesophagus, heart or vertebra! body). Maligmant pleural effusion is also classified as T4. However it is questionable whether this is correct as this finding has a worse prognosis and survival equals stage IV patients. "The T4 descriptor also includes tumaurs with satellite nodules located within the same lobe. Satellite nodules located in the ipsilatenal non-primary tumour lobe(s) of the lung are designated M1. However it remains difficult to stage the tumour accurately using this staging system in care of similar histological classification of such a nodule and the original tumour. More sophisticated methods such as the use of biological markers or genetic characteristics are therefore needed to differentiate between a second primary tumour and a metastasis. Indeed studies showed that the survival of two synchronously detected primary neoplasms was not as bad as a stage $\mathrm{W}$ tumour and even better than stage IIIB, 16,17

The clinical value of the currently applied $\mathrm{N}$ classification gives rise to even more debate. It is not clear whether survival is dependent upon anatomical 
involvement of lymph nodes, subclassified in N1-N2-N3. A different survival has certainly been observed for metastases to intralobar N1 nodes and hilar N1 nodes. ${ }^{18,18}$

Similar heterogeneity has been reported regarding N2 lymph nodes. Metastases in subcarinal lymph nades and extracapsular spread in the metastatic mediastinal lymph nodes have been associated with a worse prognosis. ${ }^{20-22}$ Furthermore, sometimes subclassifications are applied within the $\mathrm{N}$ classification based on pathological findings although these are not generally accepted. If a pre-operative mediastinoscopy shows only one positive lower mediastinal node station, without invalvement of the subcarinal nodes, it is defined as minimal N2 disease. If only intracapsular disease at histological examination is found this is classified as strictly minimal N2. Unforeseen N2 is defined in patients with N2 disease at thoracolomy but with a negative pre-operative mediastinoscopy. The number of involved lymph nodes and pathological aspects of the lymph nodes have not yet been included in the decision making process in lung cancer patients although several authors have stressed the point that the prognosis of the patient is dependent on the number of lymph nades involved. ${ }^{23,24}$ This is in line with other cancer types like breast cancer: a worse prognasis is found when four or more lymph nodes are involved in the cancer process.

Morphological imaging methods such as CT are still the methods of choice for the TNM staging of lung cancer. Limitations of these morphological imaging procedures in the delineation of the stage of the disease have to be considered in the decision making process of lung cancer patients. Besides variations in the diagnostic accuracy this methodology does not provide any information on the biological properties of the pathological findings. Information about biological characteristics of a pathological lesion such as proliferation, malignancy and differentiation can be expected to contribute to a more appropriate staging of the NSCLC patient.

In this respect, functional methods such as positron emission tomagraphy (PET) using tracers of tumour metabolism are potentially very useful in the elinical assessment of the cancer patient. PET makes use of organic compounds, which are analogous to naturally occuring molecules and are metabolised following normal metabolic pathways. For example fluorine-18-deoxyglucose (FDG), which is metabolised in the same way as glucose can be used to measure glucose metabolism. Most lung tumours exhibit enhanced metabolic activity and therefore have a greater uptake of FDG than normal tissue. This technique is becoming widely used for differentiating benign from malignant nodules. A solitary pulmonary nodule (SPN) is usually discovered incidentally and is defined as a nodule not greater than 3 to $4 \mathrm{~cm}$, surrouncled by normal lung tissue and 
116 Chopter

without other abnormalities. Lesions larger than this are called masses. When a SPN is identified a whole battery of invasive and non-invasive investigations are necessary to obtain a diagnosis. Moreover bronchoscopy and transthoracic needle aspiration biopsy (TTP) are often not accurate with a false negative rate up to $80 \%$ for bronchoscopy and $30 \%$ for MP, depending on size and localisation of the SPN. FDG.PET may also provide information about mediastinal lymph node inwolvement and distant metastases. The current imaging techniques for staging mediastinal pathology and distant metastases are not optimal and often time consuming. The aim of the study presented in chapter 5 was to investigate the accuracy of FDG-PET for diagnosing malignant pulmonary lesions and more specifically for diagnosing SPNs and for the staging of NSCLC. Ninety-one patients with a suspected tumour on chest $x$-ray were included in the study (28 SPN and 63 masses). The overall sensitivity and specificity of FDG.PET for detecting malignant lung tumours were $99 \%$ and $88 \%$, respectively. FDG-PET correctly identified 27 of the 28 SPNs, with a sensitivity of $100 \%$ and specificity of $86 \%$. Of the 91 patients NSCLC was diagnosed in 81 patients. In 50 operable patients with NSCLC the accuracy of mediastinal staging of FDG-PET was investigated. The sensitivity and specificity of FDG-PET for mediastinall staging (NO-N1 versus N2-N3) was $81 \%$ and $82 \%$ respectively. For the detection of metastases outside the mediastinum, the sensitivity and specificity of PET were $97 \%$ and $92 \%$, respectively. Eight of these 81 patients (10\%) had no distant metastatic disease with conventional staging, but FDG-PET correctly identified metastases. These results demonstrated that FDG-PET is a valuable methodology in the diagnastic work-up of a SPN and staging of NSCLC.

PET is a unique source of information on biological characteristics but it does not provide precise anatomic details. Therefore FDG.PET combined with a CT in one piece of equipment would be an excellent staging technique combining anatomical and biological investigations together. This will be available in the near future. This combined modality can also have implications for therapeutic options, for example for patients who should undergo radical radiatherapy, because this technique will make it possible to visualise adequately the anatomical areas where cancer cells are located. A better delineation the target volume is provided and this would lead to both a reduction of geographic miss and to a decrease of radiation induced lung damage.

The acceptance of FDG.PET as a routine imaging procedure is still limited because of high costs, limited availability and reimbursement restrictions. Dualheaded gamma cameras capable of both SPECT and PET and hence referred to as hybrid PET have therefore been intraduced as an alternative for the so called dedicated PET in the diagnosis and staging of NSCLC. Comparative studies of 
nodal staging with first-generation non-attenuation corrected hybrid PET versus dedicated PET revealed o lower sensifivity for hybrid PET. ${ }^{25,26}$ The aim of the study presented in chapter $6^{27}$ was to investigate the diagnastic performance of hybrid PET compared to dedicated PET and CT for staging of the mediastinum in lung cancer patients and to assess the impact of non-uniform atteruation correction. The feasibility of determining standardised uptake values (SUV) with hybrid PET was also investigated. Fonty patients were included in the study. Hybrid PET was performed with and without altenuation correction. The SUNS of primary fumours were calculated with hybrid PET and compared with SUVS determined by dedicated PET. With respect to the detection of mediastinal lymph node invalvement the diagnostic accuracy for hybrid PET with and without attenuation correction was $80 \%$ and respectively $74 \%$ compared with $82 \%$ for dedicated PET and $63 \%$ for CT. Funthermore, hybrid PET with attenuation correction revealed a higher specificity than CT $(83 \%$ vs $52 \% ; p<0.05)$ for mediastinal staging. In comparison with dedicated PET, attenuation-corrected hybrid PET demonstrated concordant results. The SUVs of primary tumours were similar to those of hybrid PET and dedicated PET. In conclusion hybrid PET with attenvation correction is mare specific than CT for mediastinal staging in patients with lung cancer. It reveals similar results in comparison with dedicated PET. Calculation of SUVs with hybrid PET is feasible. These findings suggest that hybrid PET with attenuation correction may be a cheaper and therefore more accessible alternative to dedicated PET.

A CT scan of the chest and upper abdomen (including adrenals and liver) is part of the current staging. However tharough staging including the search for bone or brain metastases is at present only considered beneficial and costeffective in symptomatic patients. ${ }^{28}$ It is questionable whether this is correct. Indeed, in lung cancer up to $50 \%$ of patients develop brain metastases in the course of the disease, after locoregional or symptomatic treatment and also as an isolated finding. ${ }^{29}$ Several studies have found a low yield of brain CT screening for brain metastases in asymptomatic lung cancer patients. ${ }^{26}$ Recently it was demonstrated What MRI is more sensitive in the detection of brain metastases than CT. ${ }^{30}$ There is consensus that patients with multiple brain metastases should not be exposed to aggressive locoregional therapy because of the short survival. The aim of the study in chapter $3^{\text {il }}$ was to investigate the value of MRI of the brain in detection of metastases in neurologically asymptomatic potients with NSCLC. Ninety-one patients were included in this study. MRI of the brain and extensive neurological examination by a neurologist was performed as part of initial staging. Evidence of metastatic brain disease was documented in $13(14 \%)$ patients. Two of these patients were found by the neurologist to have symptoms suggestive of brain metastases. The detection of brain metastases resulted in upstaging of 1 ( $3 \%$ ) patient in stage $1 / 11,4(21 \%)$ patients in stage $111 \mathrm{~A}$ and $2(11 \%)$ patients in $11 \mathrm{~B}$. 
It was demonstrated that evaluation of the brain with MRI is a sensitive method of detecting brain metastases in neurologic asymptomatic patients and that especially in stage 1.11 patients with adenocarcinoma or large cell carcinoma, screening of neurologic asymptomatic patients with brain MRI is worthwhile and this might be implemented in the staging procedure before lacoregional therapy is started.

In conclusion it has been demonstrated by our staging studies in NSCLC using dedicated PET, hybrid PET and in certain cases MRI of the brain, significant improvements in the value and applicability of the current staging process can be obtained. These investigations contribute to a better staging with much improved discrimination.

In small cell lung cancer (SCLC) the simplified staging system provides just two categories of disease; limited disease (LD) and extensive disease (ED). The definition, which has now been in use for 25 years, was originally based on the therapeutic options available: limited disease implied that all detectable tumour could be encompassed within one radiotherapy port, extended disease implied that therapeutic options were limited to chemotherapy.

This system has clear limitations, for example the presence of an ipsilateral pleural effusion. This is categorised as LD whilst these patients are almost always excluded from LD treatment protacols. Similar imprecision is seen in lymphadenopathy where no consensus exists on whether contralateral supraclavicular adenopathy or contrallateral hilar adenopathy belong to LD or not. Some studies include them while in others they are excluded.

In the last three decades, however, significant progress has been made in the management of LD SCLC. The use of combination chemotherapy, concurrent thoracic radiotherapy and prophylactic cranial irradiation has contributed not anly to a better local contrall, but also to a better survival compared to chemotherapeutic treatment alone. ${ }^{32}$

The existence of a wider range of therapeutic options and the approach that is taken to relate therapy to survival chance has led to the need for a more refined staging and improved techniques to make this possible. In particular the detection of silent metastases can improve the management of SCLC patients.

The TNM classification could perhaps usefully be applied to SCLC to provide a more detailed and reproducible staging system. For example in stage I SCLC patients, initial surgical resection and postaperative adjuvant chemotherapy is a very good therapeutic option. ${ }^{33}$

As SCLC fumour progression is usually rapid and associated with early development of metastases. Early and accurate detection of metastatic disease is 
important and it would be very advantageous if these divers lesions could be detected using a single technique. In the search for a biological target for diagnosis and staging "In-octreotide (actreotide scan), which is a radiolabeled analogue of the naturally occurring neuropeptide somatostatin, was considered very promising for applications in the scintigraphic localisation of neuroendocrine tumours containing somatostatin receptors. SCLC tumours have neuroendocrine features and express receptors for somatostatin. ${ }^{34.35}$ The abjective of the study in chapter $7^{36}$ was to evaluate the efficacy of octreotide scan in the staging of SCLC patients and compare it with the results of conventional staging. Imaging was performed in 29 patients with SCLC. In 24 of 29 patients the primary tumour was visualised. Only $9(35 \%)$ of the 26 known metastases were detected by actreotide scan. This low rate of detection of metastases can be explained by different factors. First, the primary tumour can have receptors for "'In-actreotide but the metastases may have different types of receptors, may not have the same receptor density for adequate visualisation or may have no receptors at all. ${ }^{34,37}$ Second, it is possible that the primary SCLC tumour itself does not express somatostatin binding sites, but that cells involved in the inflammatory response (such as activated lymphocytes) around the fumour express somatostatin receptors and only these inflammatory cells are visualised by the radiolabelled octreotide. ${ }^{38,39}$ From this perspective, metastases could not be visualised when they are not surrounded by inflammatory cells. Third, site and size of metastatic lesions can affect the scintigraphic result. These results demonstrated that actreotide scan is of limited value in the detection of primary SCLC tumours and their metastases compared to conventional staging.

Metastases of SCLC are found particularly in the brain, bones, bone marrow and liver even in asymptomatic patients. MRI of the brain and bone marrow was investigated as a means to achieve a more refined staging of the disease.

The objective of the study in chapter $2^{40}$ was to evaluate the usefulness of MRI in the detection of asymptomatic brain metastases at the initial diagnosis. One hundred and twenty-five patients with SCLC were investigated with contrastenhanced MRI of the brain. In 112 patients with normal neurological findings, MR-imaging of the brain demonstrated brain metastases in 17 patients (15\%). As a consequence of this additional information $12 \%$ of the patients were classified as ED rather than LD. This study showed that at presentation an unexpectedly high percentage of SCLC patients had asymptomatic brain metastases. The MRI results contributed to the more accurate selection between those patients who would be treated with chemotherapy combined with locoregional radiatherapy and those who were excluded from this treatment modality. 
$120 \mid$ Chopter 8

Bone marrow metastases are known to be common in SCLC patients. Bone and bone marrow are closely related organs, having a common blood supply, and Humours with a propensity to metastasise to bone, such as SCLC, often show marrow involwement. For many years unilateral of bilateral iliac crest biopsy was proposed in the staging of SCLC patients to demonstrate possible bone marrow involvement. In coses of bone pain, bone scintigraphy is generally performed.

Since MRI allows for non-inwasive evaluation of large volumes of bone marrow and is a sensitive imaging modality, its walue in the staging of SCLC was investigated and described in chopter $4^{4}$ Forty-iwo patients with SCLC were included in the study. Patients were staged fincluding bone scintigraphy, unilateral bone marrow biopsy and aspiration, CT thorax, liver ECHOJ as LD or ED before and after MRI. MRI was positive in 12 bone scinfigraphy negative $(p=0.003)$ and in 14 bone marrow biopsy and aspiration negative patients $(p<0.001)$. In 8 patients MRI was the only sign of $E D$, which resulted in a decrease of $L D$ cases from $52 \%$ to $33 \%$. MR of the thoracic spine and pelvis is a more sensitive evaluation technique than bone scintigraphy or intrusive bone marrow biopsy. It permits better detection of bone marrow metastases and therefore a more refined staging.

In conclusion it has been demonstrated by our staging studies in SCLC that using actreotide scan is of limited value in the staging of SCLC. MRI of the brain and of the thoracic spine and pelvis contributes to a more adequate staging with therapeutic consequences.

In this thesis the current approach to staging lung cancer has been reviewed, in particular the relationship between staging and both therapeutic options and prognosis. A number of techniques have been evaluated for their usefulness in improving the staging of lung cancer.

The current staging modalities do not take into account the biological features or genetic changes of the tumour. In this thesis modalities were inwestigated which enabled improved anatomical detection but also a number af modalities were investigated which depend upon the biological and genetic characteristics of lumours.

FDG PET was shown to be a valuable tool to provide additional information about solitary pulmonary nodules, in particular being mare accurate than bronchoscopy for the diagnosis of peripheral tumours. It was also shown to be more accurate than conventional modalities in the staging of NSCLC. The high sensitivity of FDG.PET for detecting metastases suggests that it could also be valuable in the staging of SCLC and this could form the basis of future studies.

FDG.PET is an expensive technique and Medical Technology Assessment (MTA) studies are necessary to place to assess the efficacy of this technique. In this study FDG.PET was found a more accurate madality than CT for the staging of 
NSCLC. Based on the reported accuracy of FDG-PET this imaging technique has to be evaluated not only as an additional staging modality but also as a primary imaging procedure in the assessment of pulmonary neoplasm. A study has been initiated to evaluate this possibility and the results are currently pending.

In a subsidiary study a preliminary evaluation was carried out on the suitability of hybrid PET for the staging of lung cancer. The first results on NSCLC were encouraging and suggest that a thorough evaluation should be undertaken.

The fact that FDG.PET cannot be used to detect brain metastases constitutes a limitation of the technique. MRI of the brain was found to be a valuable complement to FDG-PET and of significant value in the staging of both NSCLC and of SCLC.

In the staging of SCLC MRI was also found to be a valuable tool for the detection of bone marrow metastases. This study raises the question, however, whether FDG-PET alone could suffice for the staging of SCLC rendering MRI obsolete in this case.

In an attempt to develop a tracer technique for the detection of SCLC and metastases the suitability of octreotide as a cell marker was evaluated. The sensitivity of this imaging modality was, however, found to be unacceptably low. This technique was not considered applicable for staging.

The advent of FDG.PET has led to a lively debate and re-thinking of the current staging system. It could be expected that the combination of both anatomical and biological data will lead to significantly improved staging for lung cancer, more appropriate therapy and enhanced prognosis and that this approach should be addressed in the following revision of the International Staging System in 2007. 


\section{References}

1. Matthews MJ, Kairhouwa S, Pickren J, Robinette D. Frequency of residual and metastatic fumar in patients undergoing curative surgical resection for Iung cancer. Cancer Chemother Rep 3 $1973: 4(2): 63-7$

2. wan Meerbeeck JP. Staging of non-small cell lung cancer: consensus, controversies and challenges. Lung Cancer 2001;34 52:595-107.

3. Bronchogenic Carcinoma Cooperative Group of the Spanish Society of Pneumology and Thorack Surgery. Clinical tumour size and prognosis in lung concer. 1 GCCB-S\%. Eur Respir I $1999 ; 14141: 812-6$

4. Koike T, Terashima M, Takizawa $T$, Watanabe $T$, Kurita $Y$, Yokoyama A. Clinical analysis of small-sized peripheral lung cancer. I Thorac Cardiovase Surg 1998; $115(5): 1015 \cdot 20$.

5. Padilla $J_{j}$ Calvo V, Penolver JC, Sales G, Morcillo A. Surgical results and prognostic factors in early rion-small cell lung cancer. Ann Thorac $5 u$ rg 1997;63(2):324-6.

6. Cox $G$, Jones $\mathrm{JL}$, Andi $A$, Waller $D A_{s}$ O'Byrne $K J$. A, biological staging model for operable nonsmail cell lung cancer. Thorax 2001,56(7):561-6.

7. Manzo M, Rosell R, Felip E, Astudillo J, Sanchez JJ, Maestre J, Martin C, Font A, Barnadas A, Abad A. A novel anti-apoptosis gene: Re-expression of survivin messenger RNA as a prognosis marker in non-small-cell lung cancers. J Clim Oncol 1999;17(7):2100-4.

8. Mountitain CF. New prognostic factors in lung cancer. Biologic prophets of cancer cell aggression. Chest 1995; 108 [1]:246-54.

9. McCaughan BC, Martini N, Bains MS, MCCormack PM. Chest wall invasion in carcinoma of the lung. Therapeutic and prognostic implications. J Thorac Cardiovasc Sung 1985;89(6):83641.

10. Downey RJ, Martini N, Rusch WW, Bains MS, Korst RJ, Ginsberg RJ. Exteryt of chest wall inwasion and surwival in patients with lung cancer. Ann Thorac Surg 1999,68(1):188-93.

11. Detterbeck FC, Socinski MA. $\| B$ or not IIB; the current question in staging non-small cell lung cancer. Chest 1997;112(1):229-34

12. Gould PM, Bomner JA, Sawyer TE, Deschamps C, Lange CM, Li H. Patterns of failure and overall survival in patients with completely resected T3 NO MO non-small cell lung cancer. Int 1 Radial Oncol Biol Phys 1999;45(1):91-5.

13. Martini N, Yellin A, Ginsberg RJ, Bains MS, Burt ME, MCCormock PM, Rusch WW. Management of non-small cell lung cancer with direct mediastinal imwolvement. Ann Thorac Surg $1994,58(5): 1447-51$.

14. Yokoi K, Tsuchiya R, Mari T, Nagai K, Furukawa T, Fujimura S, Nakagawa K, Ichinose $Y$. Results of surgical treament of lung cancer involving the diaphragm. J Thorac Cardiovasc Surg $2000 ; 120(4): 799 \cdot 805$.

15. Sugiura $S$, Ando $Y$, Minami $H$, Ando $M$, Sakai S, Shimokata K. Prognostic value of pleurat effusion in patients with non-small cell lung cancer. Clin Cancer Res 1997;3(1):47-50.

16. Vansteenkiste JF, De Belle B, Deneffe GJ, Demedts MG, De Leyr PR, Van Raemdonck DE, Lerut TE; Leuven Lung Cancer Group. Practical approoch to patients presenting with multiple synchronous suspect lung lesions: a reflection on the current TNM classification based on 54 cases with complete followewp. Lung Cancer 2001;34(2):169-75.

17. Okada M, Tsubotia $N$, Yoshimura M, Miyamato $Y$, Nakai R. Evaluation of TMM aldssification for lung carcinoma with ipsilateral intrapulmonary metastasis. Ann Thorac Surg 1999,68(2): 326-30; discussion 33 ?

18. Riquet M, Manach D, Le Pimpec-Biarthes F, Dujon A, Chehab A. Prognostic significance of surgical-pathologic N1 disease in non-small cell carcinoma of the lung. Ann Thorac Surg $1999 ; 67(6): 1572-6$

19. van Velzen E, Snijider RI, Brutel de la Riviere A, Elbers HR, van den Bosch IM. Lymph node type as a prognostic factor for survival in T2 N1 MO non-small cell lung carcinoma. Ann Thorac Surg $1997 ; 63(5): 1436-40$. 
20. Regnard JF, Magdeleinat $P$, Azoulay D, Dartevelle P. Deneuville $M$, Rojas-Miranda $A_{*}$ Levasseur $P$. Results of resection for bronchogenic carcinoma with mediastinal lympl node metastases in selected potients. Eur J Cardiothorac Surg $1991,5(11): 583.6$; discussion 587.

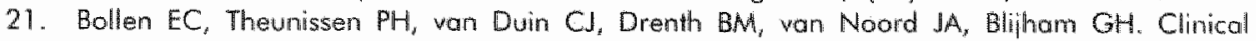
significance of intranodal and extranodal growth in lymph node metastases of non-small cell lung cancer. Scand J Thorac Cardiovase Surg 1994;28(3-4):97-102.

22. Isthida $T$, Tateishi M, Kaneko S, Sugimachi K. Surgical treatment of patients with nonsmall-cell lung cancer and mediastinal lymph node involwement. J Surg Oncol 1990;43(3):161-6.

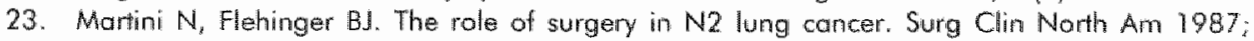
$87(5): 1037-49$

24. Mountain CF. Surgery for stage IIlla-N2 non-small cell lung cancer. Cancer 1994,73110): $2589-98$.

25. Weber WA, Neverve J, Sklarek I, Ziegler SI, Bartenstein P, King B, Treumam T, Enterrothacher A, Krapf $M$, Haussinger $K E$, Lichte $H$, Praver $H W$, Thetter $O$, Schwoiger M. Imaging of lung cancer with fluorine-18 fuoradeoxyglucose: comparison of a duathead gammo camera in coincidence mode with a full-ring positron emission tomography system. Eur I Nucl Med $1999 ; 26(4): 388-95$.

26. Talsumi $M, M$, Yutani $K$, Watanabe $Y$, Miyoshi $S$, Tomiyama $N$, Johkoh $T$, Kusuoka $H$, Nakamura $H$, Nishimura $T$. Feasibility of fluorodeaxyglucose dual head gamma camera coincidence imaging in the evaluation of lung cancer: comparison with FDG PET. II Nucl Mad $1999 ; 40(4): 566-73$.

27. Zimny $M$, Hochstenbag $M$, Lomers $R$, Reinarlz $P$, Cremerius $U$, ten Velde $G$, Buell $U$. Mediastinal staging of lung cancer with 2-[ffuorine-18]-fluoro-2-deoxy-D-glucose positron emission tomography and a dual-head comcidence gamma camera. Eur Radiol 2003; 13(4): $740-7$

28. Hillers TK, Sauve MD, Guyatt GH. Analysis of published studies on the detection of extrathoracic metastases in patients presumed to have operable non-smail cell lung cancer. Thorax $7994 ; 49(1)=14-9$.

29. Quint LE, Tummala S, Birisson LJ, Francis IR, Krupnick AS, Kazerooni EA, lannetroni MD, Whyte RI, Orringer MB. Distribution of distant metastases from newly diagnosed non-small cell lung cancer. Ann Thorac Surg 1996;62(1):246-50.

30. Yokoi K, Kamiya N, Matsuguma H, Machida S, Hirose T, Mori K, Tominaga K. Detection of brain metastasis in potentially operable non-small cell lung cancer: a comparison af CT and MRI. Chest 1999;1 15(3):714.9.

31. Hochstenbag MMH, Twinstra Hofman P, Wouters EFM; ten Velde GPM. MRe-imaging of the brain of neurolagic asymptomatic pattients with large cell or adenocarcinoma of the lurng. Does it influence prognosis and treotment? Lung Concer 2003: in piress.

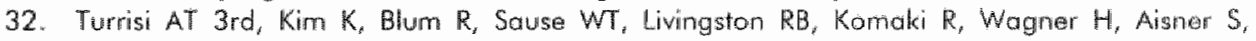
Johnson $\mathrm{DH}$. Twicendaily compared with once-daily tharacic radiotherapy in limited small-cell lung concer treated concurrently with cisplatin and etoposide. N Engl I Med 1999;340(4): 265.71.

33. Coolen L, Van den Eeckhout A, Deneffe G, Demedts M, Vansteenkiste J. Surgical treatment of small cell liung cancer. Eur J Cardiathorac Surg 1995;9(2):59-64.

34. Sagman U, Mullen JB, Kovacs. K, Kerbel R, Ginsberg R, Reubi JC. Identifization of somatostatin receptors in human small cell lung carcinoma. Cancer 1990;68(10):2129.33.

35. Reubi $C_{C}$, Waser $B$, Sheppard M, Macaulay $W$. Somatostatin receptors are present in small-call but not in non-small-cell primary lung carcinomas: reliationship to EGF-receptars. Int I Cancer $1990 ; 45[2]: 269-74$.

36. Hochstenbag MM, GAK Heidendal, EFM Wouters, G Ien Velde. Hillo-octreotide ingaging in slaging of simall cell lung cancer. Cin Nucl Med 1997,22(12):811-6.

37. Bogden AE, Taylor JE, Moredu JP, Coy DH, LePage DJ. Response of human lung tumor xenografts to treolment with a somatostatin analogue (Somotuline). Cancer Res 1990,50(14): 4360.5 . 
38. Nakanura H, Kaike T, Hiruma K, Sato T, Tomioka H, Yoshida S. Identification of lymphoid cell lines bearing receplors for somatostatin. Immunology $1987 ; 62141 \cdot 655-8$.

39. Sreedharan SP, Kadama KT, Peterson KE, Gaetzl EJ. Distinct subsets of somatostatin receptors an culfured human lymphocytes. J Biol Chem 1989;264(2):949-52.

40. Hochstenbog MM, A Twinstro, JT Wilmink, EFM Wouters, GPM ten Velde. Asymptomatic brain metastages (BM) in small cell lung cancer (SCLC): MR-imaging is useful at initial diagnosis. J Neurooncol 2000;48(3):243-8.

41. Hochstenbag MM, G Snoep, NAM Cobben, AMWJ Schols, FBJM Thumissen, EFM Wouters, GPM ten Velde. Detection of bone marrow metastases in small cell lung cancer. Comparison of magnetic resonence imaging with standard methods. Eur I Cancer 1996;32 A(5):779.82. 
Samenvatting voor

"niet-ingewijden" 
126 Chapter 
Longkanker is een van de meest voorkomende kankersoorten en is wereldwiid een belangriike doodsoorzaak bij mannen en vrouwen. In Nedertand is het na borstkanker, het meest voorkomende type kanker. Na een forse stijging in de jaren 60 en 70 van de vorige eeuw, is er in Nederland een daling van de incidentie bii mannen, maar is er bij vrouwen nog steeds een stijging waar le nemen. De prognose is slecht. De gemiddelde 5-jaarsoverleving is $15 \%$. Roken van sigaretten is verantwoordelijk voor $90 \%$ van de longcarcinomen. Nauwkeurige histologische classificatie van longkanker en bepaling van het stadium van de ziekte is essentieel voor behandeling en prognose-inschatting. Een veel gebruikte classificatie is het kleincellig longcarcinoom (SCLC) en het niet kleincellig longcarcinoom (NSCLC). Vifftien tot viffentwintig procent van alle longcarcinomen bestaat uit SCLC.

Het stadium van de ziekte wordt bepaald door de omvang en uitbreiding van het longcarcinoom en de aanwezigheid van vitzaaiingen (metastasen). Bii NSCLC wordt het stadium van de ziekte vastgelegd door de TNM-indeling. Hierbij staat $T$ (tumor) voor de grootte en uitbreiding van de tumor (T1-4); $N$ (nodus) staat voor lymfkliermetastasen in long, hilus of mediastinum (NO-3): $M$ (metastasen) staat voor metastasen op afstand (MO-1) bijvoarbeeld in de lever of bijnieren. Verschillende T, $N$ en $M$ combinaties zijn mogelijk, die vervolgens weer het stadium van de ziekte bepalen (stadium I tot en met stadium M. Bij SCLC is deze TNM indeling niet van toepassing. Hier wordt onderscheid gemaakt tussen locoregionale ziekte (limifed disease) en uitgebreide ziekte met metastasen op afstand (extensive disease).

Vaststellen van het stadium wordt onder andere bepaald door beeldvormende diagnostiek. Hierbij wordt voornameliik gebruik gemaakł van röntgenfoto's, computertomografie (CT), 'magnetic resonance imaging' (MRI), botscan en echografie. Een röntgenfoto is goedkoop en kan in ieder ziekenhuis gemaakt worden. Tumoren zijn zichtbaar vanaf een bepaalde grootte, echter uitgebreidheid van de tumor is niet altijd goed te beoordelen. Ook is een juist oordeel ten aanzien van mediastinale lymfklieren niet mogelijk. Met behulp van de CT-scan kan een inschatting gegeven worden van de groatte en anatomische uitbreiding van de tumor. Ook kan mediastinale lymfkliervergroting aangetoond worden. Een lymiklier groter dan, of gelijk aan $1 \mathrm{~cm}$ kan een teken zijn van tumorvitzaciing in de lymfklier. In hett algemeen wordt een CT van de borstholte uitgebreid met een CT van de bovenbuik om ook de lever en bijnieren te kunnen beoordelen op metastasen. Toch geeft de CT-scan geen zekerheid over de werkelijke tumoruitbreiding. Zo kan mediastinale doorgraei die op de CTscan wordt verondersteld, tijdens de operatie niet aanwezig zijn, zodat de tumor toch in totaliteit verwijderd kan worden. Verder is het niet mogelijk om een 
goedaardige van een kwaadaardige tumar te anderscheiden. Vergroting van mediastinale lymiklieren op de CT-scan is geen bewils voor de aanwezigheid van kwaadaardige cellen. Lymfklieren kunnen ook door infectie of ontsteking vergroot ziin. Ook kunnen lymfklieren van normalle grootte kwaadaardige cellen bevatten. De graotte van de lymfklier alleen is dus geen criterium voor de diagnose van metastatische lymfklieren. Veertig procent van de patiënten met longkanker heeft op het ogenblik van de diagnosestelling metastasen op afstand. Longkanker metastaseent bij voorkeur naar hersenen, lever, biinieren, longen, beenmerg en botten.

Zorgvuldige beoordeling van de primaire tumor en metastasen is aldus van groot belang. Beeldvorming speelt hierbii een belangrijke ral. Vanuit dit oogpunt is gekeken naar methodieken om het stadiëringstraject te optimaliseren en mogeliik zelfs te vereenvoudigen.

Positronemissietomografie (PET) is een relatief niet-invasieve techniek om fysiologische en biochemische eigenschappen van weefsels af te beelden. De glucosestofwisseling van een tumor is verhoogd. Door gebruik te maken van een radioactief gelabeld suikeranaloog zoals 18-fluoro-deoxyglucose (FDG), kan deze verhoogde stofwisseling in beeld gebracht worden middels een PET camera. De meest gebruikte opnamemethode is de "whole body-scan". Resultaten van een studie waarbii FDG-PET wordt toegevoegd aan de zogenaamde conventionele diagnosestelling en stadiëring van NSCLC worden beschreven in hoofdstuk 5 . Bij de diagnostiek van een verdachte longharard op de röntgenfoto en CT-scan is een bronchoscopie (longspiegeling) de eerste keuze van benadering. Soms is een transtharacale longpunctie noodzakeliik. Vooral bij de diagnostiek van een kleine solitaire longhaard kunnen beide onderzoekmethoden tekortschieten. In 91 patiënten met een verdachte longhaord werd FDG.PET vergeleken met deze conventionele diagnostiek. FDGPET was zeer betroumbaar voor de differentiatie tussen goedaardige en kwaadaardige longhaarden met een accuraatheid van 98\%. In 81 patiënten werd de diagnose NSCLC gesteld. In 8 van deze 81 patiënten werden metastasen op afstand aangetoond $(10 \%)$ die niet werden aangetoond met conventionele stadiëringstechnieken. In 50 operabele patiënten met NSCLC werden mediastinale lymfklieren beoordeeld met FDG.PET en CT. FDG.PET bleek veel efficiënter in het differentiëren tussen goedaardige en kwaadaardige lymfklieren dan $\mathrm{CT}$ met een accuraatheid van $82 \%$. Ondanks deze verbetering in diagnostiek en stadiëring vonden wij toch enkele foutieve vitslagen. Deze waren voornamelijk gerelateerd aan de geringe anatomische informatie van FDG-PET, opname van FDG in ontstekingscellem en een te lage biologische 
activiteit van de kwaadaardige cellen zich vitend in het ontbreken van FDG opname.

De acceptatie van FDG-PET als routineonderzoek wordt momenteel geremd door de hoge kosten en de geringe beschikbaarheid. De goedkopere gammacamera zou een goed alternatief kunnen zijn vaor FDG detectie. Omdat een deel van de vitgezonden straling door het lichaam geabsorbeerd wordt kan dit de beeldkwaliteit benadelen. De beeldkwaliteit kan verbeterd worden door te corrigeren vaor weefselverzwakking van de stralen (attenuatiecorrectie). Op deze wijze kan tevens naast een visuele beoordeling het glucoseverbruik gekwontificeerd worden door middel wan 'standardised uptake value' (SUV). In hoofdstuk 6 is de waarde onderzocht van FDG detectie met een dubbelkops coincidentiegammacamera (hybrid-PET). In deze studie is gekeken naar de nauwkeurigheid van hybrid-PET met en zonder attenuatiecorrectie in vergelijking met PET en CT voor het vaststellen van mediastinale lymfkliermetastasen bii 35 patiënten met longkanker. De accuraatheid van hybrid-PET met attenuatiecorrectie was beter voor mediastinale stadiëring dan van hybrid-PET zonder attenuatiecorrectie. De accuraatheid yan hybrid-PET was tevens beter dan de accuraatheid van CT. In vergelijking met PET liet hybrid-PET met attenuatiecorrectie dezelfde resultaten zien voor mediastinale stadiëring. Ook kwamen de gemeten SUV waarden van hybrid-PET met attenuatiecorrectie overeen mei de SUV waarden van PET. Dit onderzoek, weliswaar gebaseerd op een klein aantal patiënten, toont aan dat ook door middel van de goedkopere hybrid-PET een adequate mediastinale stadiëring kan worden verricht.

Klinisch manifeste hersenmetastasen worden frequent gediagnosticeerd bii langkankerpatiënten tijdens initiële stadiëring. Ook in de loop van de ziekte nemen hersenmetastasen duidelijk toe. Ze zijn een belangrijke oorzaak wan morbiditeit en mortaliteit. Daar het aantonen van hersenmetastasen ook belangrije therapeutische gevolgen heeit is het van belang ook asymptomatische hersenmetastasen vit te sluiten tijdens initiële stadierring. Onderzoek in het verleden heeft echter aangetoond dat CT geen adequate stadieringstechniek is voor het opsporen van asymptomatische hersenmetastasen. In haofdstuk 2 is gekeken naar de waarde van MRI in de detectie van asymptomatische hersenmetastasen bii SCLC. In 112 SCLC patiênten zonder neurologische symptomen werd een MRI van de hersenen verricht. In 17 patiënten (15\%) werden asymptomatische hersenmetastasen aangetoond. In 6 van deze 17 patienten was dif de enige aanwilzing voor gemetastaseerde ziekte. In hoofdstuk 3 is gekeken naar de waarde van MRI van de hersenen voor het aantonen van asymptomatische hersenmetastasen fijdens initiële stadiëring van NSCLC en is ook speciaal gekeken naar de bijdrage van 
een klinisch neurologisch onderzoek. Als onderdeel van het initiele stadiäringsonderzoek ondergingen 91 patienten zowel een MRl als een uitgebreid neurologisch onderzoek. In 13 van de 91 meurologisch asymptomatische patienten $(14 \%)$ werden hersenmetastasen met MRI aangetoond. In 2 wan deze patienten was het onderzoek van de neuroloog toch verdacht voor hersenmetastasen. Hierdoor veranderde de klinische stadiering in 7 patienten; 6 van deze 7 patiênten waren gediagnostiseerd als stadium III. De conclusie van deze studie is dat MRI van de hersenen een adequaat onderzoek is en kan bijdragen in de stadiëring van neurologisch asymptomatische potianter.

SCLC staat bekend om zin agressief gedrag en snelle melastasering in een vroeg stadium van de ziekte. Het is therapeutisch van belang om deze metastasen vroegtijdig op te sporen. SCLC tumoren hebben neuro-endocriene kenmerken. Somatostatinereceptoren zilin vaak aanwezig in neuro-endocriene tumoren. Octreotide is een somatostatineanaloog en bindt zich alan somatostatinereceptoren. Deze kunnen dan gedetecteerd worden door een actreotidescan. Het zou dus mogelijk kunnen zijn om middels één onderzoek de tumoi en metastasen in het hele lichaam te kunnen detecteren met deze scan. In hoofdstuk 7 worden de resultaten beschreven van de warde van de octreotidescan in de detectie van de primaire tumor en mogelijke metastasen in 29 patiënten met SCLC. In 24 wan de 29 patiënten werd de longtumor gedetecteerd. Echter maar 9 van de 26 (35\%) metastasen werden aangetoond. Deze slechte resultaten kunnen veroorzaakt worden door verschillende receptoren en door de lagere dichtheid van receptoren op de metastasen. De conclusie is dan ook dat de octreotidescan niet geschikt is voor stadiëring van SCLC.

Bot- en beenmergmetastasen worden frequent aangetoond bif SCLC. Ten tijde van dit onderzoek was een batscan en een beenmergpunctie een standaard stadiëringsanderzoek in SCLC. Dit laatste is een pinnlijk onderzoek waarbii tevens maar een klein gedeelte van het beenmerg onderzocht kan worden. De betrouwbaarheid wan een botscan is laag in asymptomatische patienten. Met MRI kan een groot volume beenmerg onderzocht worden. In hoofdstuk 4 is gekeken naar de warde van MRI van het bekken en wervelkolom voor het aantonen wan bot en beenmergmetastasen tijdens de initiele stadiering van 42 patiënten met SCLC. MRI was positief in 72 botscan negatieve patienten en in 14 beenmergpunctie negatieve patiënten. In 8 patiënten was een positieve MRI het enige teken var gemetastaseerde ziekte. 
Aanbeveling:

Ons onderzaek heeff aangetoond dat een MRI van de hersenen uitgevoerd zou moeten worden in stadium III A en B NSCLC vóórdat overgegaan wordt tot locoregionale behandeling. Verder dient bij de stadiëring wan SCLC een MRI wan de hersenem, van het bekken en wan de wervelkolom verricht te worden: indien nog géen extensive disease is vastgesteld. Tenslotte heeft ons onderzoek aangetoond dat FDG-PET vitgevoerd dient te worden bii NSCLC vórdat overgegaran wordt tot mediastinoscopie, chirurgische resectie of locoregionale radiotherapie. 
Dankwoord 


\section{Tot slot...}

Om eerlijk te zijn... promoveren is topsport. Het boekje is er nu, gelukkig. Het was een marathon met horden. De combinatie van werk, thuis en promotie was een hele opgave en het ging zo dikwills niet vanzelf. Het doorgronden van de materie was één zaak, het kunnen amgaan met een computer was een andere.

Het was mijn co-promotor dr. Guul ten Velde die me coachte, me aanspoorde en altijd voor me klaar stond. Ziin inbreng was van onschatbare waarde, ziin bezorgdheid en geduld nief minder. Daarnaast gaf mijn promotor prof. $d r$. Emiel Wouters mij steeds het vertrouwen en leverde met zijn kritische blik een zeer waardevalle bijdrage. Ik maakte kennis met de afdeling nucleaire geneeskunde te Aken en werd daar door prof. dr. Ulderich Buell en drs. Michael Zimny ingewiid in de were d van de PET-scan. Ik had zo toegang tot het ultieme medium naast de vele CT-scans van dr. Rob Lamers en de MRI's van dr. Gabriel Snoep, dr. Paul Hofman en prof. dr. Jan Wilmink. Voor het vitwerken van het neurologisch deel en de beoordeling daarvan, stond mijn andere co-promotor dr. Albert Twiinstra garant. Daarnaast verzorgde de afdeling nucleaire geneeskunde onder leiding van prof. dr. Guido Heidendal de vele botscans en actreotidescans. De afdeling pathologie beoordeelde de coupes.

De commissie bestaande uit prof. dr. B. Mochiar, prof. dr. H.J.M. Groen, prof. dr. G. Heidendal, prof. dr. C.C.E. Koning en prof. dr. J. Manni gaf haar goedkeuring aan dit proefschrift en voorzag hel van waardevol commentaar.

Dan waren daar mijn fantastische collega's die de loper voor me vitrolden en me de ruimte gaven waarop ik recht meende te hebben. De dames van het secretariaat longziekten assisteerden mii op hun joviale manier en de labaranten van de radiodiagnostiek organiseerden de mooie "plaatjes". Uiteindelijk kwam alles in een stroomwersnelling toen John Maguire mijn Engels transformeerde naar deze "thesis", het gaf mii de "boost" die ik nodig had. Marion Elfferich en Lily Tulkens zetten de punten op de evenzovele i's. Cécile Geurts zorgde voor de grafische vormgeving en Tiny Wouters stelde dit boekwerk samen, u ziet het resultaat. En dan Eva Creutzberg natuurliik, omdat mijn vitlaatklep eerder een kiepwagen was. Jacky Wolfs en Nicolle Cobben, want mijn paranimfen zijn van goud. 
Dankwoond 135

Thuis werden de moeilijkste vragen gesteld, maar mijn ouders, schoonouders, Resie en Ine hebben ze naar grote tevredenheid beantwoord. En dat brengt mij bil mijn kanjers: Marcel, Iron en Ruben, jullie liefde, hulp en begrip gaven mii vleugels.

Tot slot, iedereen en allemaal, voor uw steun en inbreng, heel, heel hartelijk

dank. 